NBER WORKING PAPER SERIES

\title{
TRADING VOLUME: IMPLICATIONS OF AN INTERTEMPORAL CAPITAL ASSET PRICING MODEL
}

\author{
Andrew W. Lo \\ Jiang Wang \\ Working Paper 8565 \\ http://www.nber.org/papers/w8565
NATIONAL BUREAU OF ECONOMIC RESEARCH
1050 Massachusetts Avenue
Cambridge, MA 02138 \\ October 2001
}

We thank Joon Chae, Ilan Guedj, Jannette Papastaikoudi, Antti Petajisto, and Jean-Paul Sursock for excellent research assistance, and Jonathan Lewellen for providing his industry classification scheme. We are grateful to seminar and conference participants at the Chinese University of Hong Kong, Georgetown University, the Shenzhen Stock Exchange, UCLA, University of Pennsylvania, the 8th World Congress of the Econometric Society, and the 2001 Lectures in Financial Economics in Beijing and Taipei for helpful comments and suggestions. Financial support from the MIT Laboratory for Financial Engineering and the National Science Foundation (Grant No. SBR \{9709976) is gratefully acknowledged. The views expressed herein are those of the authors and not necessarily those of the National Bureau of Economic Research.

(C) 2001 by Andrew W. Lo and Jiang Wang. All rights reserved. Short sections of text, not to exceed two paragraphs, may be quoted without explicit permission provided that full credit, including $(\mathrm{C}$ notice, is given to the source. 
Trading Volume: Implications of An Intertemporal Capital Asset Pricing Model Andrew W. Lo and Jiang Wang

NBER Working Paper No. 8565

October 2001

JEL No. G12, G11, G14

\begin{abstract}
We derive an intertemporal capital asset pricing model with multiple assets and heterogeneous investors, and explore its implications for the behavior of trading volume and asset returns. Assets contain two types of risks: market risk and the risk of changing market conditions. We show that investors trade only in two portfolios: the market portfolio, and a hedging portfolio, which allows them to hedge the dynamic risk. This implies that trading volume of individual assets exhibit a two-factor structure, and their factor loadings depend on their weights in the hedging portfolio. This allows us to empirically identify the hedging portfolio using volume data. We then test the two properties of the hedging portfolio: its return provides the best predictor of future market returns and its return together with the return of the market portfolio are the two risk factors determining the cross-section of asset returns.
\end{abstract}

\author{
Andrew W. Lo \\ Sloan School of Management \\ MIT \\ 50 Memorial Drive \\ Cambridge, MA 02142-1347 \\ and NBER \\ alo@mit.edu
}

\author{
Jiang Wang \\ MIT \\ E52-435 \\ 50 Memorial Drive \\ Cambridge, MA 02142-1347 \\ and NBER \\ wangj@mit.edu
}




\section{Contents}

1 Introduction $\quad 1$

2 The Model $\quad 2$

2.1 The Economy . . . . . . . . . . . . . . . . . . . . 3

2.2 Discussion . . . . . . . . . . . . . . . . . . . 4

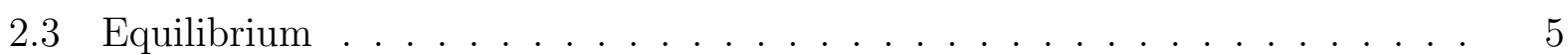

3 The Behavior of Returns and Volume $\quad 8$

3.1 The Cross Section of Volume . . . . . . . . . . . . . . . . . . . . 8

3.2 Time Series Implications for the Hedging Portfolio . . . . . . . . . . . . . . . 10

3.3 Cross-Sectional Implications for the Hedging Portfolio . . . . . . . . . . . . . 10

4 An Empirical Implementation $\quad 13$

4.1 The Data . . . . . . . . . . . . . . . . . . . . . 13

4.2 Construction of the Hedging Portfolio . . . . . . . . . . . . . . . 14

5 The Forecast Power of the Hedging Portfolio 19

5.1 Hedging-Portfolio Returns . . . . . . . . . . . . . . . . . . . . 19

5.2 Optimal Forecasting Portfolios (OFPs) . . . . . . . . . . . . . . 21

5.3 Hedging Portfolio Return as A Predictor of Market Returns . . . . . . . . . 23

6 The Hedging-Portfolio Return as a Risk Factor 24

$\begin{array}{lll}7 & \text { Conclusion } & 27\end{array}$

$\begin{array}{ll}\text { Appendix } & 29\end{array}$

A.1 Proof of Theorem $1 \ldots \ldots \ldots \ldots$

A.2 Proofs of Propositions $1-4 \ldots \ldots \ldots \ldots$

$\begin{array}{ll}\text { References } & 32\end{array}$ 


\section{Introduction}

Fundamental shocks to the economy drive both the supply and demand of financial assets and their prices. Thus, any asset-pricing model that attempts to establish a structural link between asset prices and underlying economic factors also establishes links between prices and quantities such as trading volume. In fact, asset-pricing models link the the joint behavior of prices and quantities with economic fundamentals such as the preferences of investors and the future payoffs of the assets. Therefore, the construction and empirical implementation of any asset-pricing model should involve both price and quantities as its key elements. Even from a purely empirical perspective, the joint behavior of price and quantities reveals more information about the relation between asset prices and economic factors than prices alone. Yet the asset-pricing literature has centered more on prices and much less on quantities. For example, empirical investigations of well-known asset-pricing models such as the Capital Asset Pricing Model (CAPM) and its intertemporal extensions (ICAPM) have focused exclusively on prices and returns, completely ignoring the information contained in quantities. In this paper, we hope to show that even if our main interest is in the behavior of prices, valuable information about price dynamics can be gleaned from trading volume.

We begin by developing an intertemporal capital asset pricing model of multiple assets in the spirit of Merton's ICAPM. We explicitly model investors' asset demands and derive equilibrium asset prices and asset holdings. In our model, assets are exposed to two sources of risks: market risk and the risk of changes in market conditions. ${ }^{1}$ As a result, investors wish to hold two distinct portfolios of risky assets: the market portfolio and a hedging portfolio. The market portfolio allows them to adjust their exposure to market risk, and the hedging portfolio allows them hedge the risk of changes in market conditions. In equilibrium, investors trade in only these two portfolios, and expected asset returns are determined by their exposure to these two risks, i.e., a two-factor linear pricing model holds, where the two factors are the returns on the market portfolio and the hedging portfolio, respectively.

We then explore the implications of this model on the joint behavior of volume and returns. Since investors hold only two portfolios - the market portfolio and the hedging

\footnotetext{
${ }^{1}$ One example of changes in market conditions is changes in the investment opportunity set considered by Merton (1973).
} 
portfolio - they trade in only these portfolios. This implies that trading volume also exhibits a two-factor structure: the first factor arises from their trades in the market portfolio and the second factor arises from their trades in the hedging portfolio. More importantly, we show that the factor loading of each asset's trading volume on the hedging-portfolio factor is identical to that asset's portfolio weight in the hedging portfolio. This remarkable property of the trading volume of individual assets suggests a way to identify the hedging portfolio from a rather unexpected source: volume data. Moreover, after arriving at such a portfolio, we have the means to verify that it is indeed the hedging portfolio: its returns should be the best predictor of future returns on the market portfolio. Collectively, these results provide concrete economic foundations for determining risk factors beyond the market portfolio for dynamic equilibrium asset-pricing models.

Using the weekly returns and volume data on NYSE and AMEX stocks from 1962 to 1996, we implement the model empirically. From the trading volume of individual stocks, we construct the hedging portfolio and its returns. We find that the hedging-portfolio returns consistently outperforms other factors in predicting future returns to the market portfolio. We then use the returns to the hedging and market portfolios as two risk factors in a crosssectional test along the lines of Fama and MacBeth (1973), and find that the hedging portfolio is comparable to other factors in explaining the cross-sectional variation of expected returns.

In Section 2, we present our intertemporal equilibrium model of asset-pricing and trading volume. In Section 3, we explore the model's implications for volume and returns. Section 4 describes the data used in our empirical implementation of the model, and outlines the construction of the hedging portfolio. In Section 5, we compare the forecast power of the hedging portfolio with other factors, and we perform cross-sectional tests of the hedging portfolio as a risk factor in Section 6. We conclude in Secton 7.

\section{The Model}

In this section, we develop an intertemporal equilibrium model of stock trading and pricing with multiple assets and heterogeneous investors. Since our purpose is to draw its qualitative implications on the joint behavior of return and volume, the model is kept as parsimonious as possible. Several generalizations of the model are discussed in Section 2.2. 


\subsection{The Economy}

We consider an economy defined on a set of discrete dates: $t=0,1,2, \ldots$ There are $J$ risky assets in the economy, which we call stocks. Each stock pays a stream of dividends over time. Let $D_{j t}$ denote the dividend of stock $j$ at date $t, j=1, \cdots, J$, and $D_{t} \equiv\left(D_{1 t} ; \cdots ; D_{J t}\right)$ denote the column vector of dividends. ${ }^{2}$ Without loss of generality, in this section we assume that the total number of shares outstanding is one for each stock.

A stock portfolio can be expressed in terms of its shares of each stock, denoted by $S \equiv\left(S_{1} ; \ldots ; S_{J}\right)$, where $S_{j}$ is the number of stock $j$ shares in the portfolio $(j=1, \ldots, J)$. A portfolio of particular importance is the market portfolio, denoted by $S_{M}$, which is given by

$$
S_{M}=\iota
$$

where $\iota$ is a vector of 1 's with rank $J . D_{M t} \equiv \iota^{\prime} D_{t}$ gives the dividend of the market portfolio, which is the aggregate dividend.

In addition to the stocks, there is also a risk-free bond that yields a constant, positive interest $r$ per time period.

There are $I$ investors in the economy. Each investor is endowed with equal shares of the stocks and no bond. Every period, investor $i, i=1, \ldots, I$, maximizes his expected utility of the following form:

$$
\mathrm{E}_{\mathrm{t}}\left[-e^{-W_{t+1}^{i}-\left(\lambda_{X} X_{t}+\lambda_{Y} Y_{t}^{i}\right) D_{M t+1}-\lambda_{Z}\left(1+Z_{t}^{i}\right) X_{t+1}}\right]
$$

where $W_{t+1}^{i}$ is investor $i$ 's wealth next period, $X_{t}, Y_{t}^{i}, Z_{t}^{i}$ are three one-dimensional state variables, and $\lambda_{X}, \lambda_{Y}, \lambda_{Z}$ are non-negative constants. Apparently, the utility function in (2) is state-dependent. We further assume

$$
\sum_{i=1}^{I} Y_{t}^{i}=\sum_{i=1}^{I} Z_{t}^{i}=0
$$

where $t=0,1, \ldots$

For simplicity, we assume that all the exogenous shocks, $D_{t}, X_{t},\left\{Y_{t}^{i}, Z_{t}^{i}, i=1, \ldots, I\right\}$, are IID over time with zero means. For tractability, we further assume that $D_{t}$ and $X_{t}$ are

\footnotetext{
${ }^{2}$ Throughout this paper, we follow the following convention: For a set of elements, $e_{1}, \ldots, e_{n},\left(e_{1} ; \ldots ; e_{n}\right)$ denotes the column vector and $\left(e_{1}, \ldots, e_{n}\right)$ denotes the row vector from these elements.
} 
jointly normally distributed:

$$
u_{t} \equiv\left(\begin{array}{c}
D_{t} \\
X_{t}
\end{array}\right) \stackrel{d}{\sim} N(\cdot, \sigma) \quad \text { where } \quad \sigma=\left(\begin{array}{cc}
\sigma_{D D} & \sigma_{D X} \\
\sigma_{X D} & \sigma_{X X}
\end{array}\right)
$$

Without loss of generality, $\sigma_{D D}$ is assumed to be positive definite.

\subsection{Discussion}

Our model has several features that might seem unusual. Most importantly, investors are assumed to have a myopic, but state-dependent utility function in (2). The purpose for using this utility function is to capture the dynamic nature of the investment problem without explicitly solving a dynamic optimization problem. This utility function should be interpreted as the equivalent of a value function from an appropriately specified dynamic optimization problem (see, for example, Wang, 1994 and Lo and Wang, 2000b). In an earlier draft of the paper, we did specify a canonical dynamic optimization problem for the investors, in which they have state-independent utility over their lifetime consumption. It was shown that the resulting value function, as a function of wealth and the state variables, has the form as the state-dependent utility function in (2). For simplicity in exposition, we directly start with $(2)$.

The state dependence of the utility function has the following properties. The marginal utility of wealth depends on the dividend of the market portfolio (the aggregate dividend), as reflected in the second term in the exponential of the utility function. When the aggregate dividend goes up, the marginal utility of wealth goes down. There are many ways to motivate this type of utility function. For example, the utility can be derived from wealth in reference to the market, not the level of wealth itself (see, for example, Abel, 1990, and Campbell and Cochrane, 1999). Alternatively, if in addition to their stock investments, investors are also exposed to other risks that are correlated to the market (see, for example, Wang, 1994). The marginal utility of wealth also depends on future state variables, in particular $X_{t+1}$, as reflected in the third term in the exponential of the utility function. The motivation for allowing such a dependence is as follows. Since the state variables determine the stock returns in equilibrium, the value function (indirect utility function) of an investor who optimizes dynamically would depend on these state variables. Without modelling the dynamic opti- 
mization problem explicitly, we explicitly impose such a dependence on the (myopic) utility function. This dependence introduces dynamic hedging motives in the investors' portfolio choices (see Merton, 1971, for a discussion on dynamic hedging).

Another simplification in the model is the IID assumption for the state variables. This might leave the impression that the model is effectively static. This impression, however, is false since the state-dependence of investors' utility function introduces important dynamics over time. We can allow richer dynamics for the state variables without changing the main properties of the model.

The particular form of the utility function and the normality of distribution for the state variables are assumed for tractability. These assumptions are restrictive. But we hope with some confidence that the qualitative predictions of the model that we explore in this paper are not sensitive to these assumptions.

In the model, we also assumed an exogenous interest rate for the bond without requiring the bond market to clear. This is a modelling choice we have made in order to simplify our analysis and to focus on the stock market. As will become clear later, changes in the interest rate is not important for the issues we examine in this paper. From an empirical point of view, at the frequency we are interested in (weekly), changes in interest rate are usually small.

\subsection{Equilibrium}

Let $P_{t} \equiv\left(P_{1 t} ; \ldots ; P_{J t}\right)$ and $S_{t}^{i} \equiv\left(S_{1 t}^{i} ; \ldots ; S_{J t}^{i}\right)$ be the (column) vectors of (ex-dividend) stock prices and investor $i$ 's stock holdings respectively. We now derive the equilibrium of the economy.

Definition 1 An equilibrium is given by a price process $\left\{P_{t}: t=0,1, \ldots\right\}$ and the investors stock positions $\left\{S_{t}^{i}: i=1, \ldots, I ; t=0,1, \ldots\right\}$ such that:

1. $S_{t}^{i}$ solves investor $i$ 's optimization problem:

$$
\begin{array}{rll}
S_{t}^{i}=\arg & \max & \mathrm{E}\left[-e^{-W_{t+1}^{i}-\left(\lambda_{X} X_{t}+\lambda_{Y} Y_{t}^{i}\right) D_{M t+1}-\lambda_{Z}\left(1+Z_{t}^{i}\right) X_{t+1}}\right] \\
& \text { s. t. } & W_{t+1}^{i}=W_{t}^{i}+S_{t}^{i \prime}\left[D_{t+1}+P_{t+1}-(1+r) P_{t}\right]
\end{array}
$$


2. stock market clears:

$$
\sum_{i=1}^{i} S_{t}^{i}=\iota .
$$

The above definition of equilibrium is standard, except that the bond market does not clear here. As discussed earlier, the interest rate is given exogenously and there is an elastic supply of bonds at that rate.

For $t=0,1, \ldots$, let $Q_{t+1}$ denote the vector of excess dollar returns on the stocks:

$$
Q_{t+1} \equiv D_{t+1}+P_{t+1}-(1+r) P_{t}
$$

Thus, $Q_{j t+1}=D_{j t+1}+P_{j t+1}-(1+r) P_{j t}$ gives the dollar return on one share of stock $j$ in excess of its financing cost for period $t+1$. For the remainder of the paper, we simply refer to $Q_{j t+1}$ as the dollar return of stock $j$, omitting the qualifier "excess". Dollar return $Q_{j t+1}$ differs from the conventional (excess) return measure $R_{j t+1}$ which is the dollar return normalized by the share price: $R_{j t+1} \equiv Q_{j t+1} / P_{j t}$. We refer to $R_{j t+1}$ simply as the return on stock $j$ in period $t+1$.

We can now state the solution to the equilibrium in the following theorem:

Theorem 1 The economy defined above has a unique linear equilibrium in which

$$
P_{t}=-a-b X_{t}
$$

and

$$
S_{t}^{i}=\left(I^{-1}-\lambda_{Y} Y_{t}^{i}\right) \iota-\left[\lambda_{Y}\left(b^{\prime} \iota\right) Y_{t}^{i}+\lambda_{Z} Z_{t}^{i}\right]\left(\sigma_{Q Q}\right)^{-1} \sigma_{Q X}
$$

where

$$
\begin{aligned}
\sigma_{Q Q} & =\sigma_{D D}-\left(b \sigma_{X D}+\sigma_{D X} b^{\prime}\right)+\sigma_{X}^{2} b b^{\prime} \\
\sigma_{Q X} & =\sigma_{D X}-\sigma_{X}^{2} b \\
a & =\frac{1}{r}\left(\bar{\alpha} \sigma_{Q Q} \iota+\lambda_{Z} \sigma_{Q X}\right) \\
b & \left.=\lambda_{X}\left[(1+r)+\lambda_{Z} \sigma_{X D} \iota\right)\right]^{-1} \sigma_{D D} \iota
\end{aligned}
$$

and $\bar{\alpha}=1 / I$. 
The nature of the equilibrium is intuitive. In our model, an investor's utility function depends not only on his wealth, but also on the stock payoffs directly. In other words, even he holds no stocks, his utility fluctuates with the payoff of the stocks. Such a "market spirit" affects his demand for the stocks, in addition to the usual factors such as the stocks' expected returns. The market spirit of investor $i$ is measured by $\left(\lambda_{X} X_{t}+\lambda_{Y} Y_{t}^{i}\right)$. When $\left(\lambda_{X} X_{t}+\lambda_{Z} Y_{t}^{i}\right)$ is positive, investor $i$ extracts positive utility when the aggregate stock payoff is high. Such a positive "attachment" to the market makes holding stocks less attractive to him. When $\left(\lambda_{X} X_{t}+\lambda_{Y} Y_{t}^{i}\right)$ is negative, he has a negative attachment to the market, which makes holding stocks more attractive. Such a market spirit at the aggregate level, which is captured by $X_{t}$, affects the aggregate stock demand, which in turn affects their equilibrium prices. Given the particular form of the utility function, $X_{t}$ affects the equilibrium stock prices linearly. The idiosyncratic differences among investors in their market spirit, which are captured by $Y_{t}^{i}$, offset each other at the aggregate level, thus do not affect the equilibrium stock prices. However, they do affect individual investors' stock holdings. As the first term of (9) shows, investors with positive $Y_{t}^{i}$ 's hold less stocks (they are already happy by just "watching" the stocks paying off).

Since the aggregate utility variable $X_{t}$ is driving the stock prices, it is also driving the stock returns. In fact, the expected returns on the stocks are changing with $X_{t}$ (see the discussion in the next section). The form of the utility function further states that the investors utility function directly depends on $X_{t}$, which fully characterizes the market conditions investors face, in particular, the investment opportunities. Such a dependence endogenously arises when investors optimize dynamically. In our setting, however, we assume that investors optimize myopically but insert such a dependence directly into the utility function. This dependence induces investors to care about future market conditions when choose their portfolios. In particular, they prefer those portfolios whose returns can help them to smooth fluctuations in their utility due to changes in market conditions. Such a preference gives rise to the hedging component in their asset demand, which is captured by the second term in (9). 


\section{The Behavior of Returns and Volume}

Given the intertemporal CAPM defined above, we can derive its implications on the behavior of return and volume. For the stocks, their dollar return vector can be re-expressed as follows:

$$
Q_{t+1}=r a+(1+r) b X_{t}+\tilde{Q}_{t+1}
$$

where $\tilde{Q}_{t+1} \equiv D_{t+1}-b Z_{t+1}$ denotes the vector of unexpected dollar returns on the stocks, which are IID over time with zero mean. Equation (10) shows that the expected returns on the stocks change over time. In particular, they are driven by a single state variable $X_{t}$.

The investors stock holdings can be expressed in the following form:

$$
S_{t}^{i}=h_{M t}^{i} \iota+h_{H t}^{i} S_{H} \quad \forall i=1,2, \ldots, I
$$

where $h_{M t}^{i} \equiv I^{-1}-\lambda_{Y} Y_{t}^{i}, h_{H t}^{i} \equiv \lambda_{Y}\left(b^{\prime} \iota\right) Y_{t}^{i}-\lambda_{z} Z_{t}^{i}$, and

$$
S_{H} \equiv\left(\sigma_{Q Q}\right)^{-1} \sigma_{Q X}
$$

Equation (11) simply states that two-fund separation holds for the investors' stock investments. That is, the stock investments of all investors can be viewed as investments in two common funds: the market portfolio $\iota$ and the hedging portfolio $S_{H} \cdot{ }^{3}$ In our current model, these two portfolios, expressed in terms of stock shares, are constant over time.

The particular structure of the returns and the investors' portfolios lead to several interesting predictions about the behavior of volume and returns. We present these predictions through a set of propositions.

\subsection{The Cross Section of Volume}

Given the heterogeneity in their preferences which change over time, investors trade among themselves to achieve their optimal stock holdings. The volume of trade can be measure by the turnover ratio. Since we have normalized the total number of shares outstanding to be

\footnotetext{
${ }^{3}$ The investors' total portfolios satisfy three-fund monetary separation: the risk-free bond and the two stock funds. For our discussion here, we restrict our attention to their stock investments and always focus on the two stock funds.
} 
one for all stocks, the turnover of a stock, say, stock $j$, is given by

$$
\tau_{j t} \equiv \frac{1}{2} \sum_{i=1}^{I}\left|\left(h_{M t}^{i}-h_{M t-1}^{i}\right)+\left(h_{H t}^{i}-h_{H t-1}^{i}\right) S_{H j}\right| \quad \forall j=1, \ldots, J .
$$

Let $\tau_{t}$ denote the vector of turnover for all stocks. We have the following proposition on the cross-section of volume:

Proposition 1 When investors' trading in the hedging portfolio is small relative to their trading in the market portfolio, the two-fund separation in their stock holdings leads to an approximate two-factor structure for stock turnover:

$$
\tau_{t} \approx \iota F_{M t}+S_{H} F_{H t}
$$

where

$$
F_{M t}=\frac{1}{2} \sum_{i=1}^{I}\left|h_{M t}^{i}-h_{M t-1}^{i}\right| \quad \text { and } \quad F_{H t}=\frac{1}{2} \sum_{i=1}^{I}\left(h_{H t}^{i}-h_{H t-1}^{i}\right) \operatorname{sgn}\left(h_{H t}^{i}-h_{H t-1}^{i}\right) .
$$

In the special case when one-fund separation holds for stock holdings (when $X_{t}=0 \quad \forall t$ ), turnover would have an exact one-factor structure, $\tau_{t}=\iota F_{M t}$. Moreover, the loading of individual turnover on the common factor is identical. In other words, the turnover is identical cross all stocks. This is not surprising. In the case of one-fund separation for stock investments, investors trade in one stock portfolio, which has to be the market portfolio. Thus, they trade all the stocks in same proportions (in shares). Consequently, the turnover must be the same for all stocks. ${ }^{4}$

In the general case when two-fund separation holds for stock investments, turnover has an approximate two-factor structure as given in (14). It is important to note that the loading of stock $j$ 's turnover on the second factor is proportional to its share weight in the hedging portfolio. Thus, empirically if we can identify the two common factors, $F_{M t}$ and $F_{H t}$, the stocks' loadings on the second factor allow us to identify the hedging portfolio. In our empirical analysis, we explore this information that the cross-section of volume conveys. As we discuss below, the hedging portfolio has important properties that allow us to better understand the behavior of returns. Merton (1971) has discussed the properties of hedging portfolios in a

\footnotetext{
${ }^{4}$ For a discussion on the implications of mutual fund separation on the cross-sectional behavior of volume, see Lo and Wang (2000a). See also Tkac (1996).
} 
continuous-time framework as a characterization of equilibrium. Our discussion here follows Merton in spirit, but is in a discrete-time, equilibrium environment.

\subsection{Time Series Implications for the Hedging Portfolio}

By the definition of the hedging portfolio in (12), it is easy to show that its current return gives the best forecast of future market return.

Let $Q_{M t+1}$ denote the dollar return on the market portfolio in period $t+1$ and $Q_{H t+1}$ denote the dollar return on the hedging portfolio. Then,

$$
Q_{M t+1}=\iota^{\prime} Q_{t+1} \quad \text { and } \quad Q_{H t+1}=S_{H}^{\prime} Q_{t+1}
$$

For an arbitrary portfolio $S$, its dollar return in period $t$, which is $Q_{t} \equiv S^{\prime} Q_{t}$, can serve as a predictor for the dollar of the market next period:

$$
Q_{M t+1}=\delta_{0}+\delta_{1} Q_{t}+\varepsilon_{M t+1}
$$

The predictive power of $S$ is measured by the $R^{2}$ of the above regression. We can solve for the portfolio that maximizes the $R^{2}$. The solution, up to a scaling constant, is the hedging portfolio. Thus, we have the following result:

Proposition 2 Among the returns of all portfolios, the dollar return of the hedging portfolio, $S_{H}$, provides the best forecast for the future dollar return of the market.

In other words, if we regress the market dollar return on the lagged dollar return of any portfolios, the hedging portfolio gives the highest $R^{2}$.

\subsection{Cross-Sectional Implications for the Hedging Portfolio}

We now turn to examine the predictions of our model on the cross-section of returns. For expositional simplicity, we introduce some additional notation. Let $Q_{p t+1}$ be the dollar return of a stock or a portfolio (of stocks). $\tilde{Q}_{p t+1} \equiv Q_{p t+1}-\mathrm{E}_{\mathrm{t}}\left[Q_{p t+1}\right]$ then denotes its unexpected dollar return and $\bar{Q}_{p}$ its unconditional mean. Thus, $\tilde{Q}_{M t+1}$ and $\tilde{Q}_{H t+1}$ denote, respectively, the unexpected dollar returns on the market portfolio and the hedging portfolio, and

$$
\sigma_{M}^{2} \equiv \operatorname{Var}\left[\tilde{Q}_{M t+1}\right], \quad \sigma_{H}^{2} \equiv \operatorname{Var}\left[\tilde{Q}_{H t+1}\right], \quad \sigma_{M H} \equiv \operatorname{Cov}\left[\tilde{Q}_{M t+1}, \tilde{Q}_{H t+1}\right]
$$


denote their conditional variances and covariances. It is easy to show that

$$
\sigma_{M}^{2}=\iota^{\prime} \sigma_{Q Q} \iota, \quad \sigma_{H}^{2}=\sigma_{X Q}\left(\sigma_{Q Q}\right)^{-1} \sigma_{Q X}, \quad \sigma_{M H}=\iota^{\prime} \sigma_{Q X}
$$

where $\sigma_{Q Q}$ and $\sigma_{Q X}$ are given in Theorem 1. From Theorem 1, we have

$$
\begin{gathered}
\bar{Q}=\bar{\alpha} \sigma_{Q Q} \iota+\lambda_{Z} \sigma_{Q X} \\
\bar{Q}_{M}=\bar{\alpha} \sigma_{M}^{2}+\lambda_{Z} \sigma_{M H} \\
\bar{Q}_{H}=\bar{\alpha} \sigma_{M H}+\lambda_{Z} \sigma_{H}^{2} .
\end{gathered}
$$

Equation (16) characterizes the cross-sectional variation in the stocks' expected dollar returns.

In order to develop more intuition about (16), we first consider the special case when $X_{t}=0 \forall t$. In this case, returns are IID over time. The risk of a stock is measured by its co-variability with the market portfolio. We have the following result:

Proposition 3 When $X_{t}=0 \quad \forall t$, we have

$$
\mathrm{E}\left[\tilde{Q}_{t+1} \mid \tilde{Q}_{M t+1}\right]=\beta_{M} \tilde{Q}_{M t+1}
$$

where

$$
\beta_{M} \equiv \operatorname{Cov}\left[\tilde{Q}_{t+1}, \tilde{Q}_{M t+1}\right] / \operatorname{Var}\left[\tilde{Q}_{M t+1}\right]=\sigma_{D D} \iota /\left(\iota^{\prime} \sigma_{D D} \iota\right)
$$

is the vector of the stocks' market betas. Moreover,

$$
\bar{Q}=\beta_{M} \bar{Q}_{M}
$$

where $\bar{Q}_{M}=\bar{\alpha} \sigma_{M}^{2} \geq 0$.

Obviously in this case, the CAPM holds for the dollar returns. It can be shown that it also holds for the returns.

In the general case when $X_{t}$ changes over time, there is an additional risk due to changing market conditions (dynamic risk). Moreover, this risk is represented by the dollar return of the hedging portfolio, which is denoted by $Q_{H t} \equiv S_{H}^{\prime} Q_{t}$. In this case, the risk of a stock is measured by its risk with respect to the market portfolio and its risk with respect to the 
hedging portfolio. In other words, there are two risk factors, the (contemporaneous) market risk and the (dynamic) risk of changing market conditions. The expected returns of the stocks are then determined by their exposures to these two risks and the associated risk premia. The result is summarized in the following proposition:

Proposition 4 When $X_{t}$ changes over time, we have

$$
\mathrm{E}\left[\tilde{Q}_{t+1} \mid \tilde{Q}_{M t+1}, \tilde{Q}_{H t+1}\right]=\beta_{M} \tilde{Q}_{M t+1}+\beta_{H} \tilde{Q}_{H t+1}
$$

where

$$
\begin{aligned}
\left(\beta_{M}, \beta_{H}\right) & =\operatorname{Cov}\left[\tilde{Q}_{t+1},\left(\tilde{Q}_{M t+1}, \tilde{Q}_{H t+1}\right)\right]\left\{\operatorname{Var}\left[\left(\tilde{Q}_{M t+1}, \tilde{Q}_{H t+1}\right)\right]\right\}^{-1} \\
& =\left(\sigma_{Q M}, \sigma_{Q H}\right)\left(\begin{array}{cc}
\sigma_{M}^{2} & \sigma_{M H} \\
\sigma_{M H} & \sigma_{H}^{2}
\end{array}\right)^{-1}
\end{aligned}
$$

is the vector of the stocks' market betas and hedging betas. Moreover, The stocks' expected dollar returns satisfy

$$
\bar{Q}=\beta_{M} \bar{Q}_{M}+\beta_{H} \bar{Q}_{H}
$$

where $\bar{Q}_{M}=\bar{\alpha} \sigma_{M}^{2}+\lambda_{Z} \sigma_{M H}$ and $\bar{Q}_{H}=\bar{\alpha} \sigma_{M H}+\lambda_{Z} \sigma_{H}^{2}$.

Thus, a stock's risk is measured by its beta with respect to the market portfolio and its beta with respect to the hedging portfolio. The expected dollar return on the market portfolio gives the premium of the market risk and the expected dollar return on the hedging portfolio gives the premium of the dynamic risk. (20) simply states that the premium on a stock is then given by the sum of the product of its exposure to each risk and the associated premium.

Under constant market conditions $\left(X_{t}=0, \forall t\right)$, the premium for the market risk, $\bar{Q}$, is always positive. However, under changing market conditions, the premium for the market risk need not always be positive. In particular, when $\sigma_{M H}$ is significantly negative ( $\lambda_{z}$ is assumed to be positive), $\bar{Q}$ can become negative. This is simply because that the premium is determined by the covariance between the market return and investors' marginal utility, which depends on both their wealth and the other state variables. The positive covariance between the market return and investors' wealth gives a positive premium to the market portfolio. But the negative covariance between the market return and the state 
variable $X_{t}$ that drives the utility function gives a negative premium. The total premium on the market portfolio is the sum of these two components, which can be negative when the second component dominates.

The pricing relation we obtain in Proposition 4 is in the spirit of Merton's Intertemporal CAPM in a continuous-time framework (Merton, 1971). However, it is important to note that Merton's result is a characterization of the pricing relation under a (class of) proposed price processes and no equilibrium is provided to support these price processes. In contrast, our pricing relation is derived from a dynamic equilibrium model. In this sense, we model provides an particular equilibrium model for which Merton's characterization holds.

If we can identify the hedging portfolio empirically, its return provides the second risk factor. Differences in the stocks' expected returns can then be fully explained by their exposures to the two risks (market risk and dynamic risk), as measured by their market betas and hedging betas.

\section{An Empirical Implementation}

Our empirical analysis of the implications of the model outlined in Sections 2 and 3 is comprised of three parts. In the first part, we exploit the model's cross-sectional implications to construct the hedging portfolio from volume data. In the second part, we examine the ability of the hedging portfolio to forecast future market-portfolio returns. And in the third part, we investigate the role of the hedging-portfolio return as a risk factor in explaining the cross-sectional variation of expected returns. We focus on the first part in this section, and consider the second and third parts in Sections 5 and 6 .

\subsection{The Data}

We use an extract of the CRSP Daily Master File called the "MiniCRSP Returns and Turnover" database described in Lo and Wang (2000a). This extract consists of weekly return and turnover series for individual stocks traded on NYSE and AMEX from July 1962 to December 1996 (1800 weeks). We choose weekly holding periods as a compromise between maximizing the sample size and minimizing the impact of high-frequency return and turnover fluctuations that are likely to be of less direct economic consequence. We also 
limit our focus to ordinary common shares (CRSP sharecodes 10 and 11 only).

As documented in Lo and Wang (2000a) and in many other studies, aggregate turnover seems to be nonstationary, exhibiting a significant time trend and time-varying volatilities. For example, the average weekly turnover in the period from 1962 to 1966 is $0.57 \%$, but grows to $1.31 \%$ in the period from 1992 to 1996 , and the volatilities during these two periods were $0.07 \%$ and to $0.23 \%$, respectively. Detrending has been advocated by several other authors (e.g., Andersen, 1996 and Gallant, Rossi, and Tauchen 1992), and there is no doubt that such procedures may help to induce more desirable time series properties for turnover. However, Lo and Wang (2000a) show that the different types of detrending methods, e.g., linear, logarithmic, or quadratic, yield detrended time series with markedly different statistical properties. Since we do not have any specific priors or theoretical justification for the kinds of nonstationarities in aggregate turnover, we use the raw data in our empirical analysis. To address the issue of nonstationarities, we conduct our empirical analysis on five-year subperiods only. ${ }^{5}$ For notational convenience, we shall sometimes refer to these subperiods by the following numbering scheme:

Subperiod 1: $\quad$ July 1962 to December 1966

Subperiod 2: January 1967 to December 1971

Subperiod 3: January 1972 to December 1976

Subperiod 4: $\quad$ January 1977 to December 1981

Subperiod 5: $\quad$ January 1982 to December 1986

Subperiod 6: January 1987 to December 1991

Subperiod 7: January 1992 to December 1996

\subsection{Construction of the Hedging Portfolio}

Our first step in empirically implementing the intertemporal model of Sections 2 and 3 is to construct the hedging portfolio from turnover data. From (14), we know that in the two-factor model for turnover in Proposition 1, stock $j$ 's loading on the second factor $F_{H t}$ yields the number of shares (as a fraction of its total number of shares outstanding) of stock $j$ in the hedging portfolio. In principle, this identifies the hedging portfolio. However, we face two challenges in practice. First, the exact two-factor specification (14) is, at best, an

\footnotetext{
${ }^{5}$ Obviously, from a purely statistical perspective, using shorter subperiods does not render a nonstationary time series stationary. However, if the sources of nonstationarity are institutional changes and shifts in general business conditions, confining our attention to shorter timespans does improve the quality of statistical inference. See Lo and Wang (2000a) for further discussion.
} 
approximation for the true data-generating process of turnover. Second, the two common factors are generally not observable. We address both of these problems in turn.

A more realistic starting point for modelling turnover is an approximate two-factor model:

$$
\tau_{j t}=F_{M t}+\theta_{H j} F_{H t}+\varepsilon_{j t}, \quad j=1, \ldots, J
$$

where $F_{M t}$ and $F_{H t}$ are the two factors that generate trading in the market portfolio and the hedging portfolio, respectively, $\theta_{H} j$ is the percentage of shares of stock $j$ in the hedging portfolio (as a percentage of its total number of shares outstanding), and $\varepsilon_{j t}$ is the error term, which is assumed to be independent across stocks.

Cross-sectional independence of the errors is a restrictive assumption. If, for example, there are other common factors in addition to $F_{M t}$ and $F_{H t}$, then $\varepsilon_{j t}$ is likely to be correlated across stocks. The appropriateness of the independence assumption is an empirical matter, and in Lo and Wang (2000a), we have found evidence supporting the two- factor structure. In particular, the covariance matrices of turnover for a collection of turnover-beta-sorted portfolios generally exhibit two large eigenvalues that dominate the rest. This provides limited justification for assuming that $\varepsilon_{j t}$ is independent across stocks.

Since we do not have any sufficient theoretical foundation to identify the two common factors $F_{M t}$ and $F_{H t}$, we use two turnover indexes as their proxies: the equally-weighted and share-weighted turnover of the market. Specifically. let $N_{j}$ denote the total number of shares outstanding for stock $j$ and $N \equiv \sum_{j} N_{j}$ the total number of shares outstanding of all stocks. The two turnover indexes are

$$
\begin{gathered}
\tau_{t}^{E W} \equiv \frac{1}{J} \sum_{j=1}^{J} \tau_{j t}=F_{M t}+n^{E W} F_{H t}+\varepsilon_{t}^{E W} \\
\tau_{t}^{S W} \equiv \sum_{j=1}^{J} \frac{N_{j}}{N} \tau_{j t}=F_{M t}+n^{S W} F_{H t}+\varepsilon_{t}^{S W}
\end{gathered}
$$

where

$$
n^{E W}=\frac{1}{J} \sum_{j=1}^{J} \theta_{H j} \text { and } n^{S W}=\sum_{j=1}^{J} \frac{N_{j}}{N} \theta_{H j}
$$

are the average percentage of shares of each stock in the hedging portfolio and the percentage of all shares (of all stocks) in the hedging portfolio, respectively, and $\varepsilon_{t}^{E W}$ and $\varepsilon_{t}^{S W}$ are the 
error terms for the two indexes. ${ }^{6}$ Since the error terms in (21) are assumed to be independent across stocks, the error terms of the two indexes, which are weighted averages of the error terms of individual stocks, become negligible when the number of stocks is large. For the remainder of our analysis, we shall ignore them.

Simple algebra then yields the following relation between individual turnover and the two indexes:

$$
\tau_{j t}=\beta_{\tau j}^{S W} \tau_{t}^{S W}+\beta_{\tau j}^{E W} \tau_{t}^{E W}+\varepsilon_{j t}
$$

where

$$
\beta_{\tau j}^{E W}=\frac{n^{E W}-\theta_{H j}}{n^{E W}-n^{S W}} \text { and } \beta_{\tau j}^{S W}=\frac{\theta_{H j}-n^{S W}}{n^{E W}-n^{S W}} .
$$

These expressions imply that the following relations for $\beta_{\tau j}^{E W}$ and $\beta_{\tau j}^{S W}$ must hold:

$$
\begin{aligned}
& \beta_{\tau j}^{E W}+\beta_{\tau j}^{S W}=1 \quad \forall j \\
& \frac{1}{J} \sum_{j=1}^{J} \beta_{\tau j}^{E W}=1 .
\end{aligned}
$$

These relations should come as no surprise since the two-factor specification for turnover, (21), has only $J$ parameters $\left\{\theta_{H j}\right\}$, whereas the transformed two-factor model (23) has two sets of parameters, $\left\{\beta_{\tau j}^{E W}\right\}$ and $\left\{\beta_{\tau j}^{S W}\right\}$. The first relation, (24a), exactly reflects the dependence between the parameters and the second relation, (24b), comes from the fact that the coefficients in (23) are independent of the scale of $\left\{\theta_{H j}\right\}$.

Using the MiniCRSP volume database, we can empirically estimate $\left\{\beta_{\tau j}^{E W}\right\}$ and $\left\{\beta_{\tau j}^{S W}\right\}$ by estimating the following constrained regression:

$$
\begin{aligned}
\tau_{j t}= & \beta_{\tau j}^{S W} \tau_{t}^{S W}+\beta_{\tau j}^{E W} \tau_{t}^{E W}+\varepsilon_{j t}, \quad j=1, \ldots, J \\
\text { s.t. } & \beta_{\tau j}^{E W}+\beta_{\tau j}^{S W}=1 \\
& \sum_{j=1}^{J} \beta_{\tau j}^{E W}=J .
\end{aligned}
$$

From the estimates $\left\{\widehat{\beta}_{\tau j}^{E W}\right\}$, we can construct estimates of the portfolio weights of the hedging

\footnotetext{
${ }^{6}$ To avoid degeneracy, we need $N_{j} \neq N_{k}$ for some $j \neq k$, which is surely valid empirically.
} 
portfolio in the following manner

$$
\widehat{\theta}_{H j}=\left(n^{E W}-n^{S W}\right) \widehat{\beta}_{\tau j}^{E W}+n^{S W} .
$$

However, there are two remaining parameters, $n^{E W}$ and $n^{S W}$, that need to be estimated. It should be emphasized that these two remaining degrees of freedom are inherent in the model (21). When the two common factors are not observed, the parameters $\left\{\theta_{H} j\right\}$ are only identified up to a scaling constant and a rotation. Clearly, (21) is invariant when $F_{H t}$ is rescaled as long as $\left\{\theta_{H j}\right\}$ is also rescaled appropriately. In addition, when the two factors are replaced by their linear combinations, (21) remains formally the same as long as $\left\{\theta_{H j}\right\}$ is also adjusted with an additive constant. ${ }^{7}$ Since the hedging portfolio $\left\{\theta_{H j}\right\}$ is defined only up to a scaling constant, we let

$$
\begin{array}{r}
n^{S W}=1 \\
n^{E W}-n^{S W}=\phi
\end{array}
$$

where $\phi$ is a parameter that we calibrate to the data (see Section 5). This yields the final expression for the $J$ components of the hedging portfolio:

$$
\widehat{\theta}_{H j}=\phi \widehat{\beta}_{\tau j}^{E W}+1
$$

The normalization $n^{S W}=1$ sets the total number of shares in the portfolio to a positive value. If $\phi=0$, the portfolio has equal percentage of all the shares of each company, implying that it is the market portfolio. Nonzero values of $\phi$ represent deviations from the market portfolio.

To estimate $\left\{\beta_{\tau j}^{E W}\right\}$ and $\left\{\beta_{\tau j}^{S W}\right\}$, we first construct the two turnover indexes. Figure 1 plots their time series over the entire sample period from 1962 to 1996 . We estimate (25a)-(25b) for each of the seven five-year subperiods, ignoring the global constraint (25c). ${ }^{8}$ Therefore, we estimate constrained linear regressions of the weekly turnover for each stock on equal-

\footnotetext{
${ }^{7}$ For example, for any $a$, we have $\forall j$ :

$$
\tau_{j t}=F_{M t}+\theta_{H j} F_{H t}+\varepsilon_{j t}=\left(F_{M t}+a F_{H t}\right)+\left(\theta_{H j}-a\right) F_{H t}+\varepsilon_{j t}=\tilde{F}_{M t}+\tilde{\theta}_{H j} F_{H t}+\varepsilon_{j t}
$$

where $\tilde{F}_{M t}=F_{M t}+a F_{H t}$ and $\tilde{\theta}_{H j}=\theta_{H j}-a$.

${ }^{8}$ We ignore this constraint for two reasons. First, given the large number of stocks in our sample, imposing a global constraint like (25c) requires a large amount of computer memory, which was unavailable to us. Second, because of the large number of individual regressions involved, neglecting the reduction of one dimension should not significantly affect any of the final results.
} 
and share-weighted turnover indexes in each of the seven five-year subperiods of our sample.

Figure 2 plots the histogram of $\left\{\widehat{\beta}_{\tau j}^{E W}\right\}$ for each of the subperiods. There is clearly a wide distribution of estimated coefficients, ranging from -2 to 10 in the first four subperiods and -10 to 10 in the last three. Outliers in the raw turnover data are often the source of these large estimates (see Lo and Wang, 2000a, for a more detailed discussion of outliers).

Table 1 reports summary statistics for these constrained regressions. To provide a clearer sense of the dispersion of these regressions, we first sort them into deciles based on $\left\{\widehat{\beta}_{\tau j}^{E W}\right\}$, and then compute the means and standard deviations of the estimated coefficients $\left\{\widehat{\beta}_{\tau j}^{E W}\right\}$ and $\left\{\widehat{\beta}_{\tau j}^{S W}\right\}$, their $t$-statistics, and the $\bar{R}^{2}$ s within each decile. The $t$-statistics indicate that the estimated coefficients are generally significant - even in the fifth and sixth deciles, the average $t$-statistic for $\left\{\widehat{\beta}_{\tau j}^{E W}\right\}$ is 4.585 and 6.749 , respectively (we would, of course, expect significant $t$-statistics in the extreme deciles even if the true coefficients were zero, purely from sampling variation). The $\bar{R}^{2}$ s also look impressive, however, they must be interpreted with some caution because of the imposition of the constraint (25b), which can yield $\bar{R}^{2}$ greater than unity and less than zero. ${ }^{9}$ Table 1 shows that negative $\bar{R}^{2}$ s appear mainly in the two extreme deciles, except in the last subperiod when they are negative for all the deciles, presumably an indication that the constraint is not consistent with the data in this last subperiod.

For comparison, we estimate the unconstrained version of (25a) and compute the same summary statistics, reported in Table 2. Table 2 also reports the mean and standard deviation within each decile of $p$-values corresponding to the statistic that (25b) holds. Except for the last subperiod, the constraint seems to be reasonably consistent with the data, with average $p$-values well above $5 \%$ for all but the extreme deciles in most subperiod. For example, in the first subperiod, the average $p$-values range from a minimum of $4.0 \%$ in decile 1 to a maximum of $32.4 \%$ in decile 6 , and with a value of $19.4 \%$ in decile 10 . However, in the last subperiod, the average $p$-value is less than $5 \%$ deciles $2-6$, and close to significance for most of the other deciles, which explains the negative $\bar{R}^{2}$ s in Table 1.

Without the constraint, the $\bar{R}^{2}$ s in Table 2 are well behaved, and of similar magnitude to those in Table1 that are between $0 \%$ and 100\%, ranging from $40 \%$ to $60 \%$, even in the

\footnotetext{
${ }^{9}$ For example, a negative $\bar{R}^{2}$ arises when the variance of $\widehat{\beta}_{\tau j}^{E W} \tau_{t}^{E W}+\widehat{\beta}_{\tau j}^{S W} \tau_{t}^{S W}$ exceeds the variance of the dependent variable $\tau_{j t}$, which can happen when the constraint (25b) is imposed.
} 
last subperiod. Clearly the two-factor model of turnover accounts for a significant amount of variation in the weekly turnover of individual stocks.

\section{The Forecast Power of the Hedging Portfolio}

Having constructed the hedging portfolio up to a parameter $\phi$ to be determined, we can examine its time-series properties as predicted by the model of Sections 2 and 3. In particular, in this section we focus on the degree to which the the hedging portfolio can predict future stock returns, especially the return on the market portfolio. We first construct the returns of the hedging portfolio in Section 5.1 by calibrating $\phi$, and then compare its forecast power with other factors in Sections 5.2 and 5.3.

\subsection{Hedging-Portfolio Returns}

To construct the return on the hedging portfolio, we begin by calculating its dollar value and dollar returns. Let $k$ denote subperiod $k, k=2, \ldots, 7, V_{j t}(k)$ denote the total market capitalization of stock $j$ at time period $t$ (the end of week $t$ ) in subperiod $k, Q_{j t}(k)$ denote its dividend-adjusted excess dollar return for the same period, and $R_{j t}(k)$ denote the dividend-adjusted excess return, and $\theta_{j}(k)$ the estimated share (as fraction of its total shares outstanding) in the hedging portfolio in subperiod $k$.

For stock $j$ to be included in the hedging portfolio in subperiod $k$, which we shall refer to as the "testing period", we require it to have volume data for at least one third of the sample in the previous subperiod $(k-1)$, which we call the "estimation period". Among the stocks satisfying this criteria, we eliminate those ranked in the top and bottom $0.5 \%$ according to their volume betas (or their share weights in the hedging portfolio) to limit the potential impact of outliers. ${ }^{10}$ We let $J_{t}(k)$ denote the set of stocks that survive these two filters and that have price and return data for week $t$ of subperiod $k$. The hedging portfolio in week $t$ of sub-period $k$ is then given by:

$$
\theta_{H j t}(k)= \begin{cases}\widehat{\theta}_{H j}, & j \in J_{t}(k) \\ 0, & j \notin J_{t}(k)\end{cases}
$$

\footnotetext{
${ }^{10}$ See Lo and Wang (2000a) for the importance of outliers in volume data.
} 
The dollar return of the hedging portfolio for week $t$ follows naturally:

$$
Q_{H t}(k) \equiv \sum_{j} \theta_{H j t}(k) V_{j t} R_{j t}
$$

and the (rate of) return of the hedging portfolio is given by

$$
R_{H t}(k) \equiv \frac{Q_{H j t}(k)}{V_{H t}(k)}
$$

where

$$
V_{H t}(k) \equiv \sum_{j} \theta_{H j t}(k) V_{j t-1}
$$

is the value of the hedging portfolio at the beginning of the week.

The procedure outlined above yields the return and the dollar return of the hedging portfolio up to the parameter $\phi$, which must be calibrated. To do so, we exploit a key property of the hedging portfolio: its return is the best forecaster of future market returns (see Section 3). Therefore, for a given value of $\phi$, we can estimate the following regression

$$
R_{M t+1}=\delta_{0}+\delta_{1}\left\{R_{H t} \text { or } Q_{H t}\right\}+\varepsilon_{M t+1}
$$

where the single regressor is either the return of the hedging portfolio $R_{H t}$ or its dollar return for a given choice of $\phi$, and then vary $\phi$ to maximize the $\bar{R}^{2}{ }^{11}$

Figures 3 and 4 show how the $\bar{R}^{2}$ from the regression of $R_{M t}$ on the lagged return and dollar-return, respectively, of the hedging portfolio varies with the value of $\phi$ in each of the subperiods. In all cases, there is a unique global maximum, from which we obtain $\phi$. However, for some values of $\phi$, the value of the hedging portfolio changes sign, and in these cases, defining the return on the portfolio becomes problematic. Therefore, we eliminate these values from consideration, and for all subperiods except subperiod 4 and 7 (i.e., subperiods $2,3,5,6$ ), the omitted values of $\phi$ do not seem to affect the choice of $\phi$ for the maximum $R^{2}$.

For subperiods 2 to 7 , the values for $\phi$ that give the maximum $R^{2}$ are $1.25,4.75,1.75$, 47,38 , and 0.25 , respectively, using $R_{H t}$ as the predictor. Using $Q_{H t}$, the values of $\phi$ are 1.5 ,

\footnotetext{
${ }^{11}$ This approach ignores the impact of statistical variation on the "optimal" $\phi$, which is beyond the scope of this paper but is explored further in related contexts by Foster, Smith, and Whaley (1997) and Lo and MacKinlay (1997).
} 
$4.25,2,20,27$, and 0.75 , respectively. With these values of $\phi$ in hand, we have fully specified the hedging portfolio, its return and dollar return. Table 3 reports the summary statistics for the return and dollar return on the hedging portfolio.

\subsection{Optimal Forecasting Portfolios (OFPs)}

Having constructed the return of the hedging portfolio in Section 5.1, we wish to compare its forecast power to those of other factors. According to Proposition 2, the returns of the hedging portfolio should outperform the returns of any other portfolios in predicting future market returns. Specifically, if we regress $R_{M t}$ on the lagged return of any arbitrary portfolio $p$, the $\bar{R}^{2}$ should be less than that of (33).

It is impractical to compare (33) to all possible portfolios, and uninformative to compare it to random portfolios. Instead, we need only make comparisons to "optimal forecast portfolios", portfolios that are optimal forecasters of $R_{M t}$, since by construction, no other portfolios can have higher levels of predictability than these. The following proposition shows how to construct optimal forecasting portfolios (OFPs) (see Lo and Wang, 2001 for details):

Proposition 5 Let $\Gamma_{0}$ and $\Gamma_{1}$ denote the contemporaneous and first-order autocovariance matrix of the vector of all returns. For any arbitrary target portfolio $q$ with weights $w_{q}=$ $\left(w_{q 1} ; \ldots ; w_{q N}\right)$, define $A \equiv \Gamma_{0}{ }^{-1} \Gamma_{1} w_{q} w_{q}{ }^{\prime} \Gamma_{1}{ }^{\prime}$. The optimal forecast portfolio of $w_{q}$ is given by the normalized eigenvector of $A$ corresponding to its largest eigenvalue.

Since $\Gamma_{0}$ and $\Gamma_{1}$ are unobservable, they must be estimated using historical data. Given the large number of stocks in our sample (over 2,000 in each subperiod) and the relatively short time series in each subperiod (261 weekly observations), the standard estimators for $\Gamma_{0}$ and $\Gamma_{1}$ are not viable. However, it is possible to construct OFPs from a much smaller number of "basis portfolios", and then compare the predictive power of these OFPs to the hedging portfolio. As long as the basis portfolios are not too specialized, the $\bar{R}^{2}$ s are likely to be similar to those obtained from the entire universe of all stocks.

We form several sets of basis portfolios by sorting all the $J$ stocks into $K$ groups of equal numbers $(K \leq J)$ according to: market capitalization, market beta, and SIC codes, and then construct value-weighted portfolios within each group. ${ }^{12}$ This procedure yields $K$

\footnotetext{
${ }^{12}$ It is important that we use value-weighted portfolios here so that the market portfolio, whose return
} 
basis portfolios for which the corresponding $\Gamma_{0}$ and $\Gamma_{1}$ can be estimated using the portfolios' weekly returns within each subperiod. Based on the estimated autocovariance matrices, the OFP can be computed easily according to Proposition 5.

In selecting the number of basis portfolios $K$, we face the following trade-off: fewer portfolios yields better sampling properties for the covariance matrix estimators, but less desirable properties for the OFP since the predictive power of the OFP is obviously maximized when when $K=J$. As a compromise, for the OFPs based market capitalization and market betas, we choose $K$ to be 10, 15, 20, and 25. For the OFP based on SIC codes, we choose 13 industry groupings, described in more detail below.

Specifically, for each five-year subperiod in which we wish to evaluate the forecast power of the hedging portfolio (the testing period), we use the previous five-year subperiod (the estimation period) to estimate the OFPs. For the OFP based on 10 market-capitalizationsorted portfolios, which we call "CAP10", we construct 10 value-weighted portfolios each week, one for each market-capitalization decile. Market-capitalization deciles are recomputed each week, and the time series of decile returns form the 10 basis portfolio returns of CAP10, with which we can estimate $\Gamma_{0}$ and $\Gamma_{1}$. To compute the OFP, we also require the weights $\omega_{q}$ of the target portfolio, in this case the market portfolio. Since the testing period follows the estimation period, we use the market capitalization of each group in the last week of the estimation period to map the weights of the market portfolio into a $10 \times 1$-vector of weights for the 10 basis portfolios. The weights of the OFP for the basis portfolios CAP10 follow immediately from Proposition 5. The same procedure is used to form OFPs for CAP15, CAP20, and CAP25 basis portfolios.

The OFPs of market-beta-sorted basis portfolios are constructed in a similar manner. We first estimate the market betas of individual stocks in the estimation period, sort them according to their estimated betas and then form small groups of basis portfolios, calculating value-weighted returns for each group. We consider 10, 15, 20 and 25 groups, denoted by "Beta10", "Beta15", and so on. The same procedure is then followed to construct the OFPs for each of these sets of basis portfolios.

we wish to predict, is a portfolio of these basic portfolios (recall that the target portfolio $\omega_{q}$ that we wish to forecast is a linear combination of the vector of returns for which $\Gamma_{k}$ is the $k$-th order autocovariance matrix). 
Finally, the industry portfolios are based on SIC-code groupings. The first two digits of the SIC code yield sixty to eighty industry categories, depending on the sample period, and some of categories contain only one or two stocks. On the other, the first digit yields only eight broad industry categories. As a compromise, we use a slightly more disaggregated grouping of 13 industries, given by the following correspondence: ${ }^{13}$

$\begin{array}{rll}\# & \text { SIC Codes } & \text { Description } \\ 1 & 1-14 & \text { Agriculture, forest, fishing, mining } \\ 2 & 15-19,30,32-34 & \text { Construction, basic materials (steel, glass, concrete, etc.) } \\ 3 & 20-21 & \text { Food and tobacco } \\ 4 & 22,23,25,31,39 & \text { Textiles, clothing, consumer products } \\ 5 & 24,26-27 & \text { Logging, paper, printing, publishing } \\ 6 & 28 & \text { Chemicals } \\ 7 & 29 & \text { Petroleum } \\ 8 & 35-36,38 & \text { Machinery and equipment supply, including computers } \\ 9 & 37,40-47 & \text { Transportation-related } \\ 10 & 48-49 & \text { Utilities and telecommunications } \\ 11 & 50-59 & \text { Wholesale distributors, retail } \\ 12 & 60-69 & \text { Financial } \\ 13 & 70-89,98-99 & \text { Recreation, entertainment, services, conglomerates, etc. }\end{array}$

Each week, stocks are sorted according to their SIC codes into the 13 categories defined above, and value-weighted returns are computed for each group, yielding the 13 basis portfolios which we denote by "SIC13". The autocovariance matrices are then estimated and the OFP constructed according to Proposition 5.

\subsection{Hedging Portfolio Return as A Predictor of Market Returns}

Table 4 reports the results of the regressions of $R_{M t}$ on various lagged OFP returns and on the hedging portfolios $R_{H t}$ and $Q_{H t}$. For completeness, we have also included four additional regressions, with lagged value- and equal-weighted CRSP index returns, the logarithm of the reciprocal of lagged market-capitalization, and the lagged three-month constant-maturity Treasury bill return as predictors. ${ }^{14}$ Table 4 shows that the hedging portfolios outperforms

\footnotetext{
${ }^{13}$ We are grateful to Jonathan Lewellen for sharing his industry classification scheme.

${ }^{14} \mathrm{We}$ also considered nine other interest-rate predictors (six-month and one-year Treasury bill rates, three-month, six-month, and one-year off-the-run Treasury bill rates, one-month and three-month CD and Eurodollar rates, and the Fed Funds rate (all obtained from the Federal Reserve Bank of St. Louis, http://www.stls.frb.org/fred/data/wkly.html). Each of these variables produced results similar to those for the three-month constant-maturity Treasury bill return, hence we omit those regressions from Table 4.
} 
all of the other competing portfolios in forecasting future market returns in three of the six subperiods (subperiods 2, 4, and 6). In subperiod 3, only one OFP (Beta20) outperforms the hedging portfolio, and in subperiod 5, Beta20 and SIC13's OFPs outperform the hedging portfolio, but only marginally. And in subperiod 7, the equal-weighted CRSP index return outperforms the hedging portfolio.

However, several caveats should be kept in mind with regard to the three subperiods in which the hedging portfolios were surpassed by one or two competing portfolios. First, in these three subperiods, the hedging portfolio still outperforms most of the other competing portfolios. Second, there is no consistent winner in these subperiods. Third, the performance of the hedging portfolios are often close to the best performer. Moreover, the best performers in these subperiods performed poorly in the other subperiods, raising the possibility that their performance might be due to sampling variation. In contrast, the hedging portfolios forecasted $R_{M t}$ consistently in every subperiod. Indeed, among all of the regressors, the hedging portfolios were the most consistent across all six subperiods, a remarkable confirmation of the properties of the model of Sections 2 and $3 .^{15}$

\section{The Hedging-Portfolio Return as a Risk Factor}

To evaluate the success of the hedging-portfolio return as a risk factor in the cross section of expected returns, we implement a slightly modified version of the well-known regression tests outlined in Fama and MacBeth (1973). The basic approach is the same: form portfolios sorted by an estimated parameter such as market beta coefficients in one time period (the "portfolio-formation period"), estimate betas for those same portfolios in a second nonoverlapping time period (the "estimation period"), and perform a cross-sectional regression test for the explanatory power of those betas using the returns of a third non-overlapping time period (the "testing period"). However, in contrast to Fama and MacBeth (1973), we use weekly instead of monthly returns, and our portfolio-formation, estimation, and testing

\footnotetext{
${ }^{15}$ On the other hand, the results in Table 4 must be tempered by the fact that the OFPs are only as good as the basis portfolios from which they are constructed. Increasing the number of basis portfolios should, in principle, increase the predictive power of the OFP. However, as the number of basis portfolios increases, the estimation errors in the autocovariance estimators $\widehat{\gamma}_{0}$ and $\widehat{\gamma}_{1}$ also increase for a fixed set of time series observations, hence the impact on the predictive power of the OFP is not clear.
} 
periods are five years each. ${ }^{16}$

Specifically, we run the following bivariate regression for each security in the portfolioformation period, using only those securities that exist in all three periods: ${ }^{17}$

$$
R_{j t}=\alpha_{j}+\beta_{j}^{M} R_{M t}+\beta_{j}^{H} R_{H t}+\varepsilon_{i t}
$$

where $R_{M t}$ is the return on the CRSP value-weighted index and $R_{H t}$ is the return on the hedging portfolio. Using the estimated coefficients $\left\{\widehat{\beta}_{i}^{M}\right\}$ and $\left\{\widehat{\beta}_{i}^{H}\right\}$, we perform a double sort among the individual securities in the estimation period, creating 100 portfolios corresponding to the deciles of the estimated market and hedging-portfolio betas. We re-estimate the two betas for each of these 100 portfolios in the estimation period, and use these estimated betas as regressors in the testing period, for which we estimate the following cross-sectional regression:

$$
R_{p t}=\gamma_{0 t}+\gamma_{1 t} \widehat{\beta}_{p}^{M}+\gamma_{2 t} \widehat{\beta}_{p}^{H}+\eta_{p t}
$$

where $R_{p t}$ is the equal-weighted portfolio return for securities in portfolio $p, p=1, \ldots, 100$, constructed from the double-sorted rankings of the portfolio-estimation period, and $\widehat{\beta}_{p t}^{M}$ and $\widehat{\beta}_{p t}^{H}$ are the market and hedging-portfolio returns, respectively, of portfolio $p$ obtained from the estimation period. This cross-sectional regression is estimated for each of the 261 weeks in the five-year testing period, yielding a time series of coefficients $\left\{\widehat{\gamma}_{0 t}\right\},\left\{\widehat{\gamma}_{1 t}\right\}$, and $\left\{\widehat{\gamma}_{2 t}\right\}$. Summary statistics for these coefficients and their diagnostics are then reported, and this entire procedure is repeated by incrementing the portfolio-formation, estimation, and testing periods by five years. We then perform the same analysis for the hedge-portfolio dollar-return series $\left\{Q_{H t}\right\}$.

Because we use weekly instead of monthly data, it may be difficult to compare our results to other cross-sectional tests in the extant literature, e.g., Fama and French (1992). Therefore, we apply our procedure to three other benchmark models: the standard CAPM in

\footnotetext{
${ }^{16}$ Our first portfolio-formation period, from 1962 to 1966, is only four and a half years because the CRSP Daily Master file begins in July 1962. Fama and MacBeth's (1973) original procedure used a seven-year portfolio-formation period, a five-year estimation period, and a four-year testing period.

${ }^{17}$ This induces a certain degree of survivorship bias, but the effects may not be as severe given that we apply the selection criterion three periods at a time. Moreover, while survivorship bias has a clear impact on expected returns and on the size effect, its implications for the cross-sectional explanatory power of the hedging portfolio is less obvious, hence we proceed cautiously with this selection criterion.
} 
which $R_{M t}$ is the only regressor in (34) and 100 market-beta-sorted portfolios constructed, a two-factor model in which the hedging-portfolio return factor is replaced by a "small-minusbig capitalization" or "SMB" portfolio return factor as in Fama and French (1993), and a two-factor model in which the hedging-portfolio return factor is replaced by the OFP return factor described in Section 5.2. ${ }^{18}$

Table 5 reports the the correlations between the different portfolio return factors, returns on CRSP value- and equal-weighted portfolios, return and dollar return on the hedging portfolio, returns on the SMB portfolio and, OFP, Beta20, and the two turnover indices. Table 6 reports the summary statistics for the return betas from the five risk models on returns: the single-factor market model and the four two-factors models.

Table 7 summarizes the results of all of these cross-sectional regression tests for each of the five testing periods from 1972 to 1996. In the first subpanel, corresponding to the first testing period from 1972 to 1976, there is little evidence in support of the CAPM or any of the two-factor models estimated. ${ }^{19}$ For example, the first three rows show that the timeseries average of the market-beta coefficients, $\left\{\widehat{\gamma}_{1 t}\right\}$, is 0.000 , with a $t$-statistic of 0.348 and an average $\bar{R}^{2}$ of $10.0 \% .{ }^{20}$ When the hedging-portfolio beta $\widehat{\beta}_{t}^{H}$ is added to the regression, the $\bar{R}^{2}$ does increase to $14.3 \%$ but the average of the coefficients $\left\{\hat{\gamma}_{2 t}\right\}$ is -0.002 with a $t$-statistic of -0.820 . The average market-beta coefficient is still insignificant, but it has now switched sign. The results for the two-factor model with the hedging-portfolio dollar-return factor and the two-factor model with the SMB factor are similar.

In the second testing period, both specifications with the hedging-portfolio factor exhibit statistically significant means for the hedging-portfolio betas, with average coefficients and $t$-statistics of -0.012 and -3.712 for the hedging-portfolio return factor and -1.564 and -4.140 for the hedging-portfolio dollar-return factor, respectively. In contrast, the market-

\footnotetext{
${ }^{18}$ Specifically, the SMB portfolio return is constructed by taking the difference of the value-weighted returns of securities with market capitalization below and above the median market capitalization at the start of the five-year subperiod.

${ }^{19}$ The two-factor model with OFP as the second factor is not estimated until the second testing period because we use the 1962-1966 period to estimate the covariances from which the OFP returns in the 19671971 period are constructed. Therefore, the OFP returns are not available in the first portfolio-formation period.

${ }^{20}$ The $t$-statistic is computed under the assumption of independently and identically distributed coefficients $\left\{\gamma_{1 t}\right\}$, which may not be appropriate. However, since this has become the standard method for reporting the results of these cross-sectional regression tests, we follow this convention to make our results comparable to those in the literature.
} 
beta coefficients are not significant in either of these specifications, and are also of the wrong sign. The only other specification with a significant mean coefficient is the two-factor model with SMB as the second factor, with an average coefficient of 0.299 for the SMB factor and a $t$-statistic of 4.433 .

For the three remaining test periods, the only specifications with any statistically significant factors are the SMB and MPP two-factor models in the 1992-1996 testing period. However, the $\bar{R}^{2}$ s in the last two testing periods are substantially lower than in the earlier periods, perhaps reflecting the greater volatility of equity returns in recent years.

Overall, the results do not provide overwhelming support for any factor in explaining the cross-sectional variation of expected returns. There is, of course, the ubiquitous problem of lack of power in these cross-sectional regression tests, hence we should not be surprised that no single factor stands out. ${ }^{21}$ However, the point estimates of the cross-sectional regressions show that the hedging-portfolio factor is comparable in magnitude and in performance to other commonly proposed factors.

\section{Conclusion}

By deriving an explicit link between economic fundamentals and the dynamic properties of asset returns and volume, we have shown that interactions between prices and quantities in equilibrium yield a rich set of implications for any asset-pricing model. Indeed, by exploiting the relation between prices and volume in our dynamic equilibrium model, we are able to identify and construct the hedging portfolio that all investors use to hedge against changes in market conditions. Moreover, our empirical analysis shows that this hedging portfolio has considerable forecast power in predicting future returns of the market portfolio - a property of the true hedging portfolio - and its abilities to explain cross-sectional variation in expected returns is comparable to other popular risk factors such as market betas, the Fama and French (1993) SMB factor, and optimal forecast portfolios.

Although our model is purposefully parsimonious so as to focus attention on the essential features of risk-sharing and trading activity, it underscores the general point that quantities, together with prices, should be an integral part of any analysis of asset markets, both the-

\footnotetext{
${ }^{21}$ See, for example, MacKinlay $(1987,1994)$.
} 
oretically and empirically. Our results provide compelling motivation for determining risk factors from economic fundamentals rather than through statistical means. Although this is an old theme that has its origins in Black (1972), Mayers (1973), and Merton (1973), it has become less fashionable as competing approaches such as the statistical approach of Roll and Ross (1980) and Chamberlain and Rothschild (1983) and the empirical approach of Fama and French (1992) have become more popular. We hope to revive interest in the lofty goal of identifying risk factors through the logic of equilibrium analysis in general, and by exploiting the information contained in trading volume in particular. 


\section{Appendix}

\section{A.1 Proof of Theorem 1}

We prove Theorem 1 by first deriving the investors' asset demand under the price function (8) and then solves the coefficient vector $a$ and $b$ to clear the stock market.

For simplicity in notation, let $u_{t} \equiv\left(D_{t} ; X_{t}\right)$, where $(\cdot ; \cdot)$ denotes a column vector and $(\cdot, \cdot)$ denotes a row vector. From $(8)$, we have

$$
Q_{t+1}=\bar{Q}_{t}+\tilde{Q}_{t+1}
$$

where

$$
\bar{Q}_{t}=r a+(1+r) b X_{t} \quad \text { and } \quad \tilde{Q}_{t+1}=(1,-b) u_{t+1}
$$

where 1 is an $(n \times n)$ identity matrix. We also let $\lambda_{1 t} \equiv \lambda_{X} X_{t}+\lambda_{Y} Y_{t}^{i}$ and $\lambda_{2 t} \equiv \lambda_{z}\left(1+Z_{t}^{i}\right)$.

We now consider investor $i$ 's optimal portfolio choice. Let $S_{t}$ be the vector of his stock holding in period $t$. His wealth next period is $W_{t+1}=W_{t}+S_{t}{ }^{\prime} \bar{Q}_{t+1}+S_{t}{ }^{\prime}(1,-b) u_{t+1}$, where we have omitted superscript $i$ for brevity. Then,

$$
\begin{aligned}
\mathrm{E}\left[e^{-W_{t+1}-\lambda_{1 t} D_{M t+1}-\lambda_{2 t} X_{t+1}}\right] & =\mathrm{E}\left[e^{-W_{t}-S_{t}{ }^{\prime} \bar{Q}_{t}+\left(S_{t}+\lambda_{1 t} \iota ;-b^{\prime} S_{t}+\lambda_{2 t}\right)^{\prime} u_{t+1}}\right] \\
& =\mathrm{E}\left[e^{-W_{t}-S_{t}{ }^{\prime} \bar{Q}_{t}+\frac{1}{2}\left(S_{t}+\lambda_{1 t} \iota ;-b^{\prime} S_{t}+\lambda_{2 t}\right)^{\prime} \sigma\left(S_{t}+\lambda_{1 t} t ;-b^{\prime} S_{t}+\lambda_{2 t}\right)}\right] .
\end{aligned}
$$

where $\sigma$ is the covariance matrix for $u_{t}$. Thus, the investor's optimization problem is reduced to

$$
\max _{S_{t}} S_{t}^{\prime} \bar{Q}_{t}-\frac{1}{2}\left(S_{t}+\lambda_{1 t} \iota ;-b^{\prime} S_{t}+\lambda_{2 t}\right)^{\prime} \sigma\left(S_{t}+\lambda_{1 t} \iota ;-b^{\prime} S_{t}+\lambda_{2 t}\right)
$$

The first order condition is

$$
0=\bar{Q}_{t}-\left(\sigma_{D D}-b \sigma_{D X}{ }^{\prime}-\sigma_{D X} b^{\prime}+\sigma_{X X} b b^{\prime}\right) S_{t}-\lambda_{1 t}\left(\sigma_{D D}-b \sigma_{D Z}\right) \iota-\lambda_{2 t}\left(\sigma_{D X}-b \sigma_{X X}\right) .
$$

The solution gives the investor's stock demand

$$
S_{t}=\left(\sigma_{D D}-b \sigma_{D X}{ }^{\prime}-\sigma_{D X} b^{\prime}+\sigma_{X X} b b^{\prime}\right)^{-1}\left[\bar{Q}_{t}-\lambda_{1 t}\left(\sigma_{D D}-b \sigma_{D Z}\right) \iota-\lambda_{2 t}\left(\sigma_{D X}-b \sigma_{X X}\right)\right] .
$$

Summing (A.2) over all investors and imposing the market clearing condition, $\sum_{i} S_{t}^{i}=\iota$, 
we have

$$
0=I\left[r a+(1+r) b X_{t}\right]-\sigma_{Q Q} \iota-\lambda^{X} I \sigma_{Q D} \iota X_{t}-\lambda_{Z} I \sigma_{Q X} .
$$

It follows that

$$
\begin{aligned}
r a & =(1 / I) \sigma_{Q Q} \iota+\lambda_{Z} \sigma_{Q X} \\
(1+r) b & =\lambda_{X} \sigma_{Q D} \iota
\end{aligned}
$$

which uniquely determine the equilibrium $a$ and $b$. Substitute (A.4) into (A.3), we obtain investor $i$ 's equilibrium stock holding:

$$
S_{t}^{i}=\left(I^{-1}-\lambda_{Y} Y_{t}^{i}\right) \iota-\left[\lambda_{Y}\left(b^{\prime} \iota\right) Y_{t}^{i}+\lambda_{Z} Z_{t}^{i}\right]\left(\sigma_{Q Q}\right)^{-1} \sigma_{Q Z}
$$

where is (9). Q.E.D.

\section{A.2 Proofs of Propositions 1-4}

\section{Proof of Proposition 1}

A proof of a more general version of Proposition 1 with multiple funds is given in Lo and Wang (2000a). Q.E.D.

\section{Proof of Proposition 2}

Suppose we use the (dollar) return of portfolio $S$ to predict future market return. The resulting $R^{2}$ is

$$
R^{2}=\left(\operatorname{Cov}\left[\left(S^{\prime} Q_{t}\right) Q_{M t+1}\right]\right)^{2} /\left(\operatorname{Var}\left[S^{\prime} Q_{t}\right] \operatorname{Var}\left[Q_{M t+1}\right]\right)
$$

To choose the $S$ to maximize $R^{2}$, we solve the following problem

$$
\begin{array}{ll}
\max _{S} & S^{\prime} \sigma_{Q X}\left(b^{\prime} \iota\right) \\
\text { s.t. } & S^{\prime} \sigma_{Q Q} S=v .
\end{array}
$$

Up to a scaling constant, the solution is $S_{H}=\left(\sigma_{Q Q}\right)^{-1} \sigma_{Q X}$. Q.E.D. 


\section{Proof of Proposition 3}

When $X_{t}=0 \forall t, Q_{t}=r a+\tilde{Q}_{t}=(1,-b) u_{t}$. Then, $\operatorname{Cov}\left[\tilde{Q}_{t}, \tilde{Q}_{M t}\right]=\operatorname{Cov}\left[\tilde{Q}_{t}, \iota^{\prime} \tilde{Q}_{t}\right]=\sigma_{D D} \iota$, $\operatorname{Var}\left[\tilde{Q}_{M t}\right]=\iota^{\prime} \sigma_{D D} \iota$ and (17) follows. Since $\sigma_{Q X}=0$ in this case, $\sigma_{M H}=0$ and $\bar{Q}_{M}=(1 / I) \sigma_{M}^{2}$. Thus, $\bar{Q}=\beta_{M} \bar{Q}_{M}$ which is (18). Q.E.D.

\section{Proof of Proposition 4}

Equation (19) simply follows from the joint normality of $\tilde{Q}_{t+1}, \tilde{Q}_{M t+1}$, and $\tilde{Q}_{H t+1}$. (20) can be verified by substituting in the expressions for $\beta_{M}, \beta_{M}, \bar{Q}_{M}$ and $\bar{Q}_{H}$, which gives (16c). Q.E.D. 


\section{References}

Abel, A., 1990, "Asset Prices under Habit Formation and Catching Up with the Joneses", American Economic Review 80, 38-42.

Andersen, T., 1996, "Return Volatility and Trading Volume: An Information Flow Interpretation", Journal of Finance 51, 169-204.

Antoniewicz, R.L., 1993, Relative Volume and Subsequent Stock Price Movements, working paper, Board of Governors of the Federal Reserve System.

Atkins, A. and E. Dyl, 1997, "Market Structure and Reported Trading Volume: NASDAQ versus the NYSE", Journal of Financial Research 20, 291-304.

Banz, R., 1981, "The Relation between Return and Market Value of Common Stocks", Journal of Financial Economics 9, 3-18.

Black, F., 1972, "Capital Market Equilibrium with Restricted Borrowing", Journal of Business 45, 444-454.

Black, F., 1976, "Studies of Stock Price Volatility Changes", in Proceedings of the 1976 Meetings of the Business and Economic Statistics Section, American Statistical Association, 177-181.

Black, F., M. Jensen, and M. Scholes, 1972, "The Capital Asset Pricing Model: Some Empirical Tests", Studies in the Theory of Capital Markets (M. Jensen ed.), Praeger Publishers.

Brown, K., Van Harlow, W. and S. Tinic, 1993, "The Risk and Required Return of Common Stock Following Major Price Innovations", Journal of Financial and Quantitative Analysis 28, 101-116.

Campbell, J. and J. Cochrane, 1999, "By Force of Habit: A Consumption-Based Explanation of Aggregate Stock Market Behavior", Journal of Political Economy 107, 205-251.

Campbell, J., Grossman S. and J. Wang, 1993, "Trading Volume and Serial Correlation in Stock Returns", Quarterly Journal of Economics 108, 905-939.

Campbell, J., A. Lo and C. MacKinlay, 1996, The Econometrics of Financial Markets, Princeton University Press.

Chamberlain, G. and M. Rothschild, 1983, "Arbitrage and Mean-Variance Analysis on Large Asset Markets", Econometrica 51, 1281-1301.

Chan, L. and J. Lakonishok, 1995, "The Behavior of Stock Prices Around Institutional Trades", Journal of Finance 50, 1147-74.

Conrad, J., Hameed, A. and C. Niden, 1994, "Volume and Autocovariances in Short-Horizon Individual Security Returns", Journal of Finance 49, 1305-1329. 
Epps, T. and M. Epps, 1976, "The Stochastic Dependence of Security Price Changes and Transaction Volumes: Implications for the Mixture of Distribution Hypothesis", Econometrica 44, 305-321.

Fama, E. and K. French, 1992, "The Cross-Section of Expected Stock Returns", Journal of Finance 47, 427-465.

Fama, E. and J. MacBeth, 1973, "Risk, Return, and Equilibrium: Empirical Tests", Journal of Political Economy 81, 607-636.

Foster, D., Smith, T. and R. Whaley, 1997, "Assessing Goodness-of-Fit of Asset Pricing Models: The Distribution of the Maximal R-Squared", Journal of Finance 52, 591-607.

Gallant, R., Rossi, P. and G. Tauchen, 1992, "Stock Prices and Volume", Review of Financial Studies 5, 199-242.

Hiemstra, C. and J. Jones, 1994, "Testing for Linear and Nonlinear Granger Causality in the Stock Price-Volume Relation", Journal of Finance 49, 1639-1664.

He, H., and J. Wang, 1995, "Differential Information and Dynamic Behavior of Stock Trading Volume", Review of Financial Studies 8, 919-972.

Hu, S., 1997, "Trading Turnover and Expected Stock Returns: Does It Matter and Why?", working paper, National Taiwan University.

Jain, P. and G. Joh, 1988, "The Dependence between Hourly Prices and Trading Volume", Journal of Financial and Quantitative Analysis 23, 269-282.

James, C., and R. Edmister, 1983, "The Relation between Common Stock Returns, Trading Activity and Market Value", Journal of Finance 38, 1075-1086.

Jegadeesh, N. and S. Titman, 1993, "Returns to Buying Winners and Selling Losers: Implications for Stock Market Efficiency", Journal of Finance 48, 65-91.

Karpoff, J., 1987, "The Relation between Price Changes and Trading Volume: A Survey", Journal of Financial and Quantitative Analysis 22, 109-126.

Lakonishok, J. and S. Smidt, 1986, "Volume for Winners and Losers: Taxation and Other Motives for Stock Trading", Journal of Finance 41, 951-974.

Lakonishok, J. and T. Vermaelen, 1986, "Tax-Induced Trading Around Ex-Dividend Days", Journal of Financial Economics 16, 287-319.

Lamoureux, C. and W. Lastrapes, 1990, "Heteroskedasticity in Stock Return Data: Volume vs. GARCH Effects", Journal of Finance 45, 487-498.

Lamoureux, C. and W. Lastrapes, 1994 "Endogenous Trading Volume and Momentum in Stock-Return Volatility", Journal of Business and Economic Statistics 12, 253-160.

Lamoureux, C. and J. Wansley, 1987, "Market Effects of Changes in the Standard \& Poor's 500 Index", Financial Review 22, 53-69. 
LeBaron, B., 1992, "Persistence of the Dow Jones Index on Rising Volume", working paper, University of Wisconsin.

Lim, T., Lo, A., Wang, J. and P. Adamek, 1998, "Trading Volume and the MiniCRSP Database: An Introduction and User's Guide", MIT Laboratory for Financial Engineering Working Paper No. LFE-1038-98.

Llorente, G., R. Michaely, G. Saar and J. Wang, 2000, "Dynamic Volume-Return Relations for Individual Stocks", Review of Financial Studies, forthcoming.

Lo, A. and C. MacKinlay, 1997, "Maximizing Predictability in the Stock and Bond Markets", Macroeconomic Dynamics 1(1997), 102-134.

Lo, A., H. Mamaysky and J. Wang, 2000, "Asset Prices and Trading Volume under Fixed Transaction Costs", working paper, MIT.

Lo, A. and J. Wang, 2000a, Trading Volume: Definitions, Data Analysis, and Implications of Portfolio Theory, Review of Financial Studies 13, 257-300.

Lo, A. and J. Wang, 2000b, "Trading Volume", to appear in Advances in Economic Theory: Eight World Congress, Econometric Society Monograph.

Lo, A. and J. Wang, 2001, "Optimal Forecast Portfolios", work in progress, MIT.

MacKinlay, C., 1994, "Multi-Factor Models Do Not Explain Deviations From the CAPM", Journal of Financial Economics 38, 3-28.

MacKinlay, C., 1987, "On Multivariate Tests of the CAPM", Journal of Financial Economics 18, 341-371.

Mayers, D., 1972, "Nonmarketable Assets and Capital Market Equilibrium Under Uncertainty", in M. Jensen, ed., Studies in the Theory of Capital Markets. New York: Praeger Publishers.

Merton, R., 1971, "Optimal Consumption and Portfolio Rules in a Continuous-Time Model", Journal of Economic Theory 3, 373-413.

Merton, R., 1973, "An Intertemporal Capital Asset Pricing Model”, Econometrica 41, 867887.

Michaely, R., 1991, "Ex-Dividend Day Stock Price Behavior: The Case of the 1986 Tax Reform Act", Journal of Finance 46, 845-860.

Michaely, R. and J. Vila, 1995, "Investors' Heterogeneity, Prices and Volume Around the Ex-Dividend Day", Journal of Financial and Quantitative Analysis 30, 171-198.

Michaely, R. and J. Vila, 1996, "Trading Volume with Private Valuation: Evidence from the Ex-Dividend Day", Review of Financial Studies 9, 471-509. 
Michaely, R., J.-L. Vila and J. Wang, "A Model of Trading Volume with Tax-Induced Heterogeneous Valuation and Transaction Costs" Journal of Financial Intermediation 5, 340-371, 1996.

Morse, D., 1980, "Asymmetric Information in Securities Markets and Trading Volume", Journal of Financial and Quantitative Analysis 15, 1129-1148.

Smidt, S., 1990, "Long-Run Trends in Equity Turnover", Journal of Portfolio Management , Fall, 66-73.

Shleifer, A., 1986, "Do Demand Curves for Stocks Slope Down?", Journal of Finance 41, $579-590$.

Stickel, S., 1991, "The Ex-Dividend Day Behavior of Nonconvertible Preferred Stock Returns and Trading Volume", Journal of Financial and Quantitative Analysis 26, 45-61.

Stickel, S. and R. Verrecchia, 1994, "Evidence that Volume Sustains Price Changes", Financial Analysts Journal (November-December), 57-67.

Tauchen, G., and M. Pitts, "The Price Variability-Volume Relationship On Speculative Markets", Econometrica 51, 485-506.

Tkac, P., 1996, "A Trading Volume Benchmark: Theory and Evidence", working paper, Department of Finance and Business Economics, University of Notre Dame.

Wang, J., 1994, "A Model of Competitive Stock Trading Volume", Journal of Political Economy 102, 127-168.

Ying, C., 1966, "Stock Market Prices and Volume of Sales", Econometrica 34, 676-686. 
Equal-Weighted Turnover

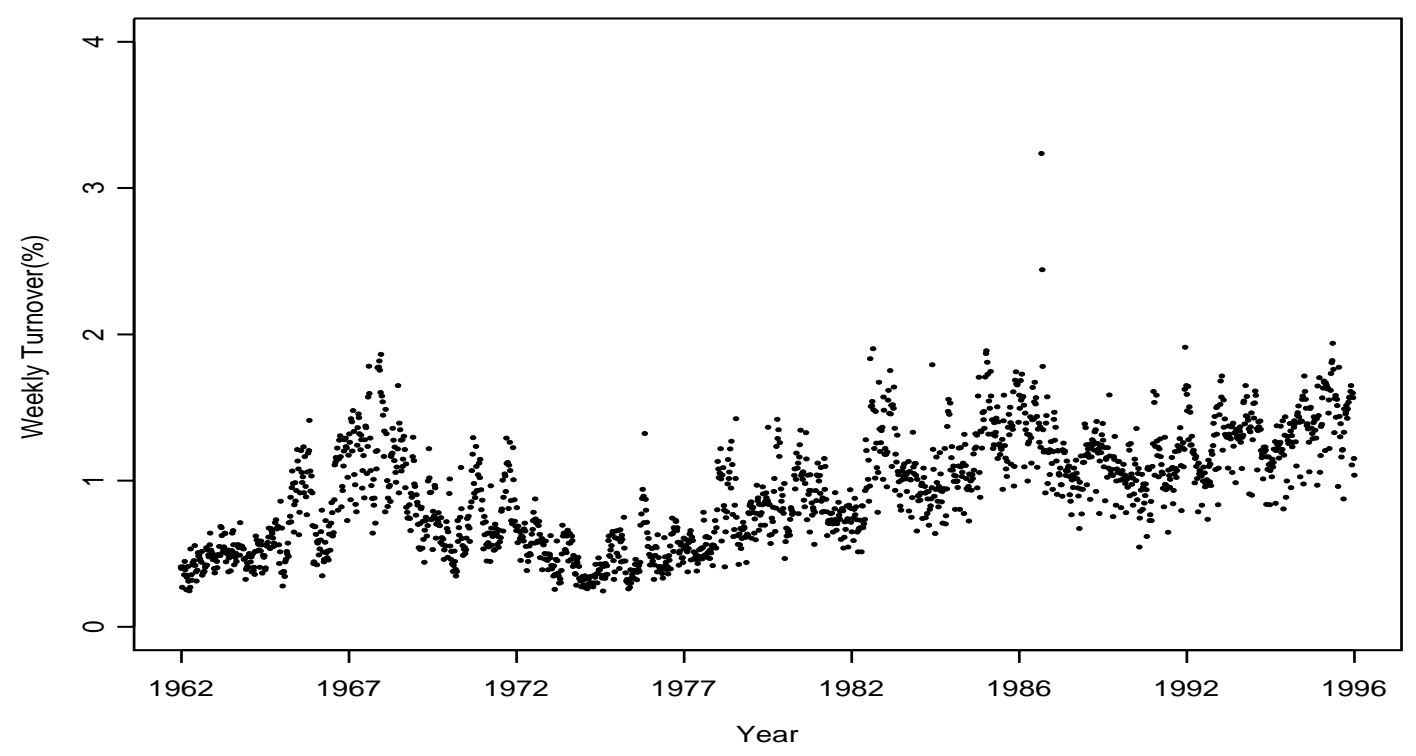

(a)

Share-Weighted Turnover

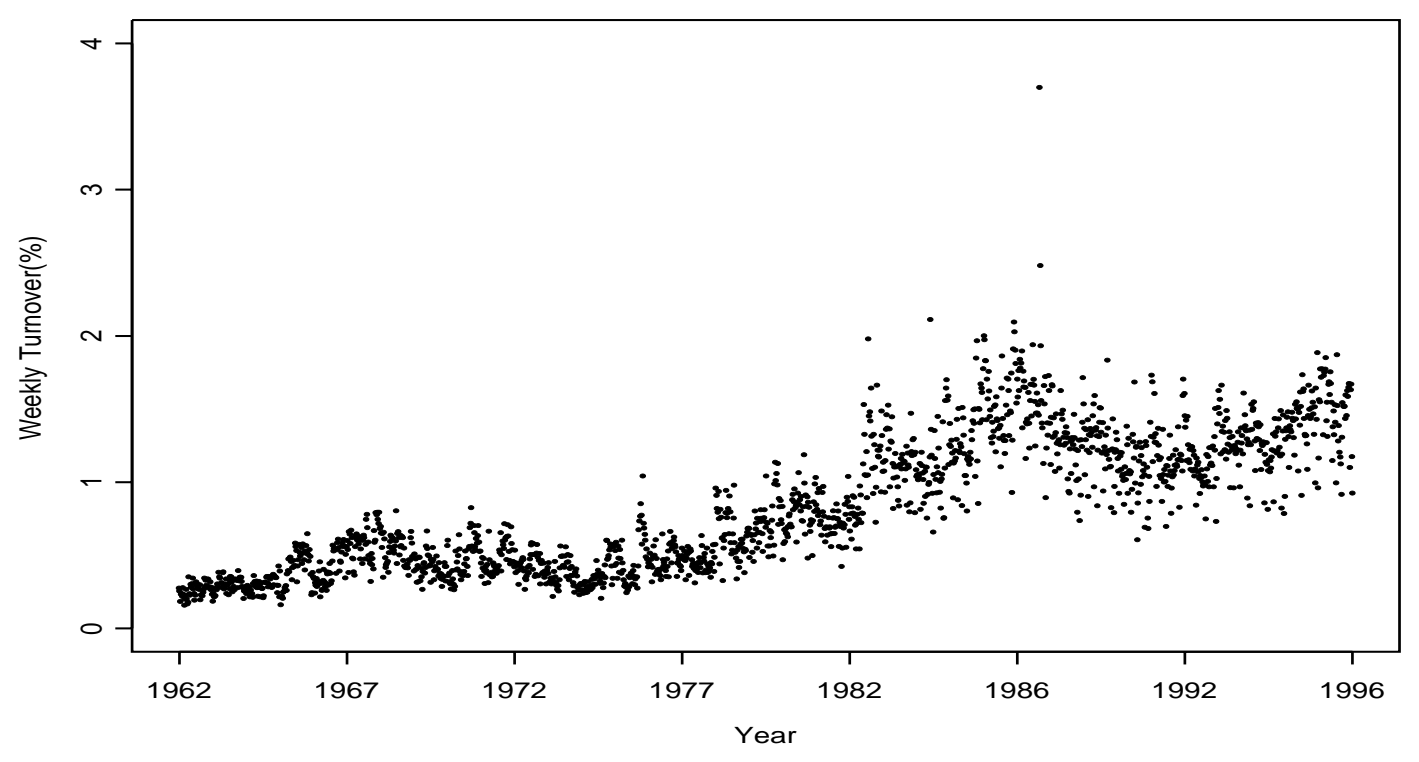

(b)

Figure 1: Time series of equally- and share-weighted turnover indices from 1962 to 1997. 

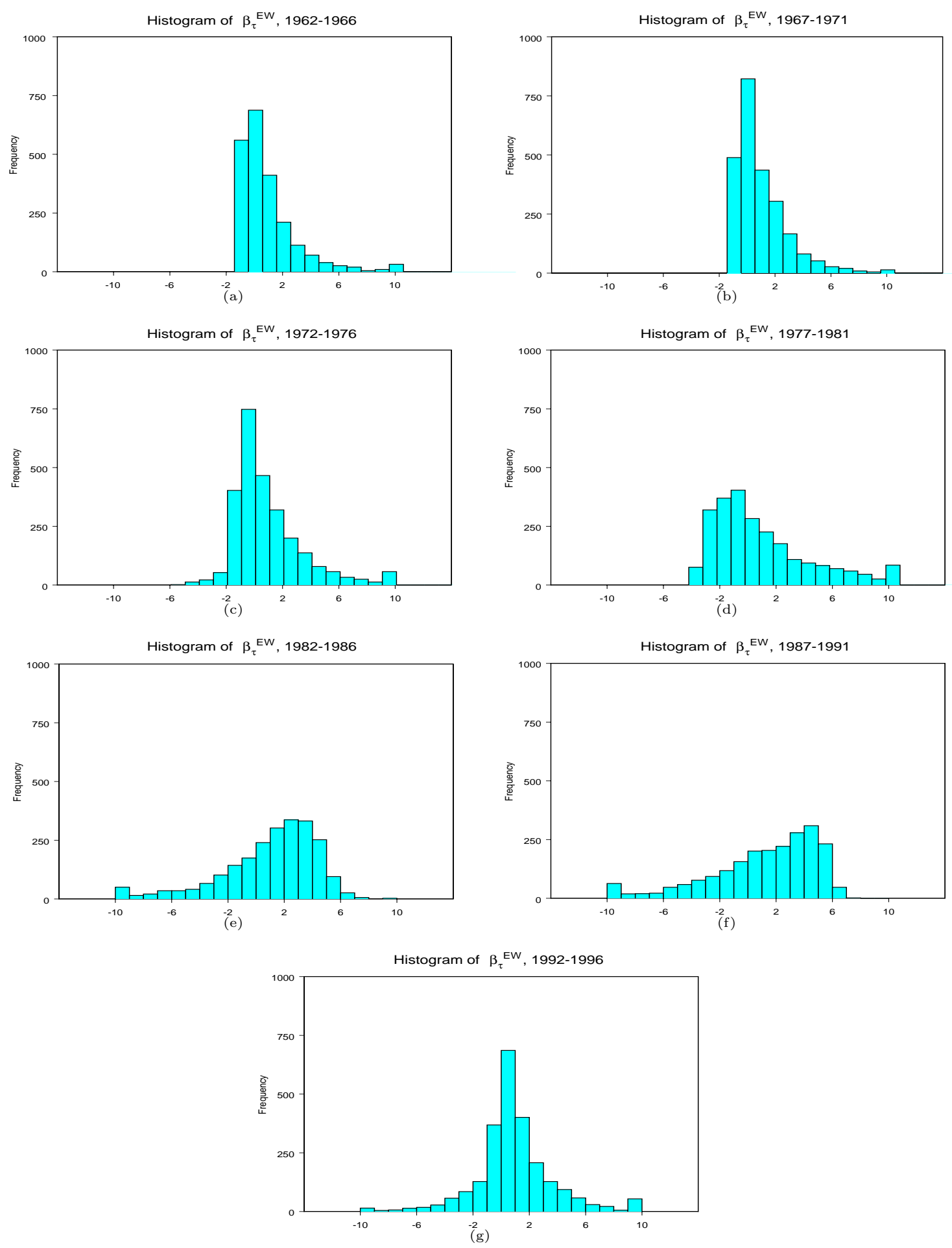

Figure 2: Histogram of turnover betas on the equally-weighted turnover index for each of the 5-year subperiod from 1962 to 1997. 

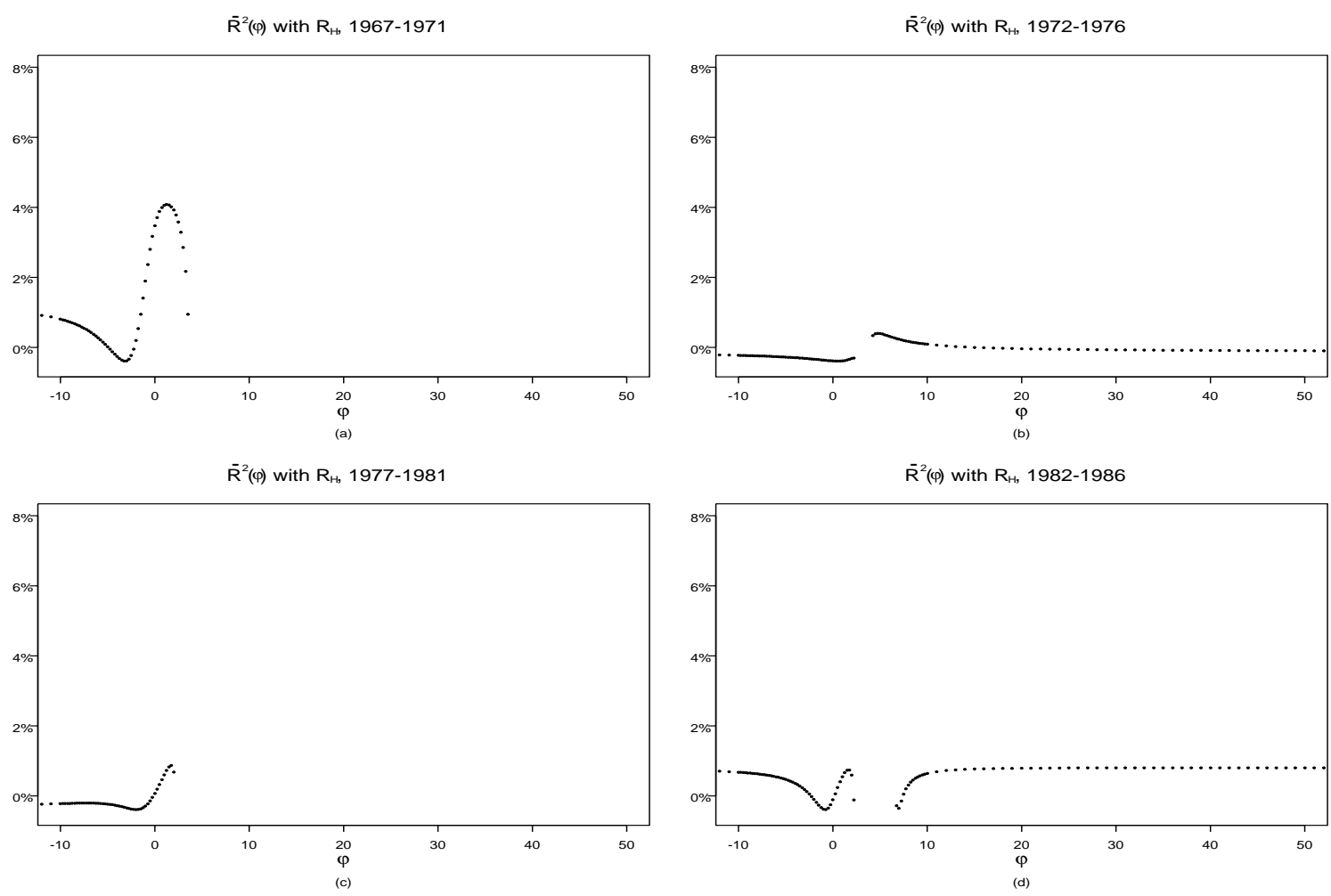

$\overline{\mathrm{R}}^{2}(\varphi)$ with $\mathrm{R}_{\mathrm{H}}, 1987-1991$
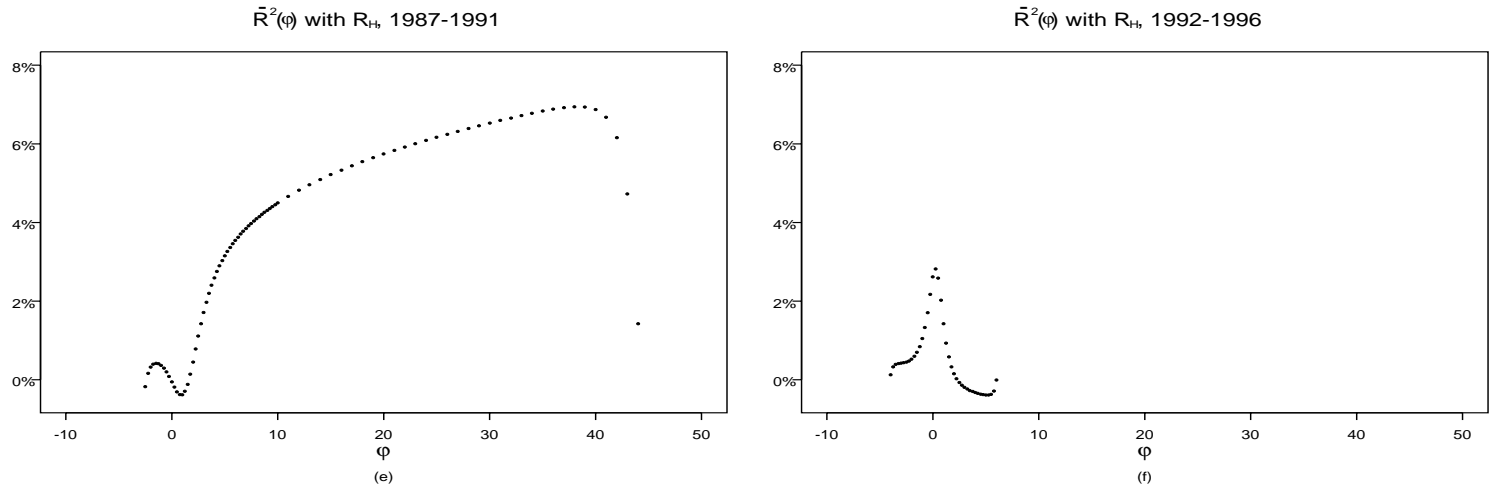

Figure 3: $R^{2}$ of the return of the candidate hedging portfolio in predicting future market returns as a function $\phi$ for the second to the seventh 5-year subperiods from 1962 to 1996. 

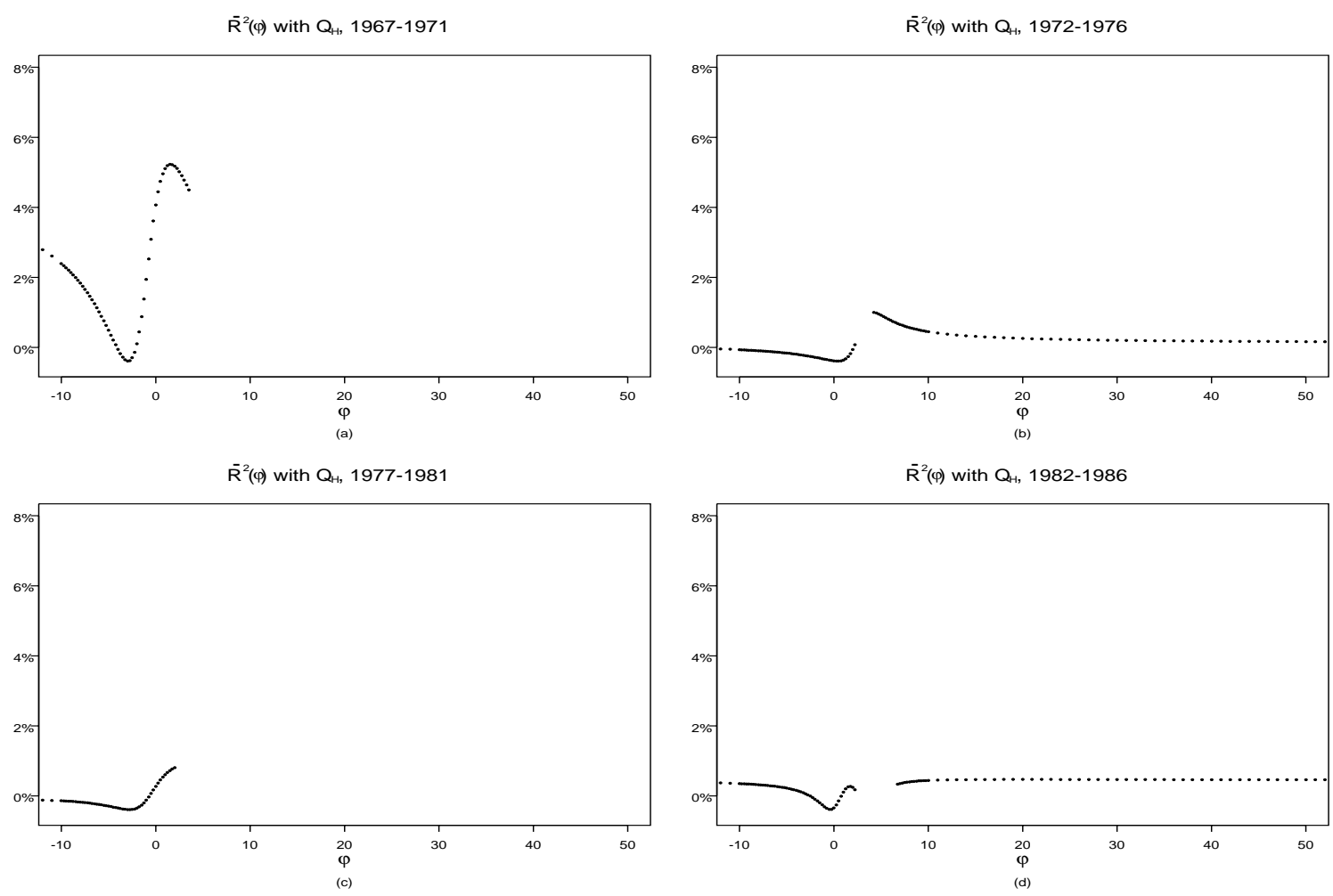

$\overline{\mathrm{R}}^{2}(\varphi)$ with $\mathrm{Q}_{\mathrm{H}}, 1987-1991$
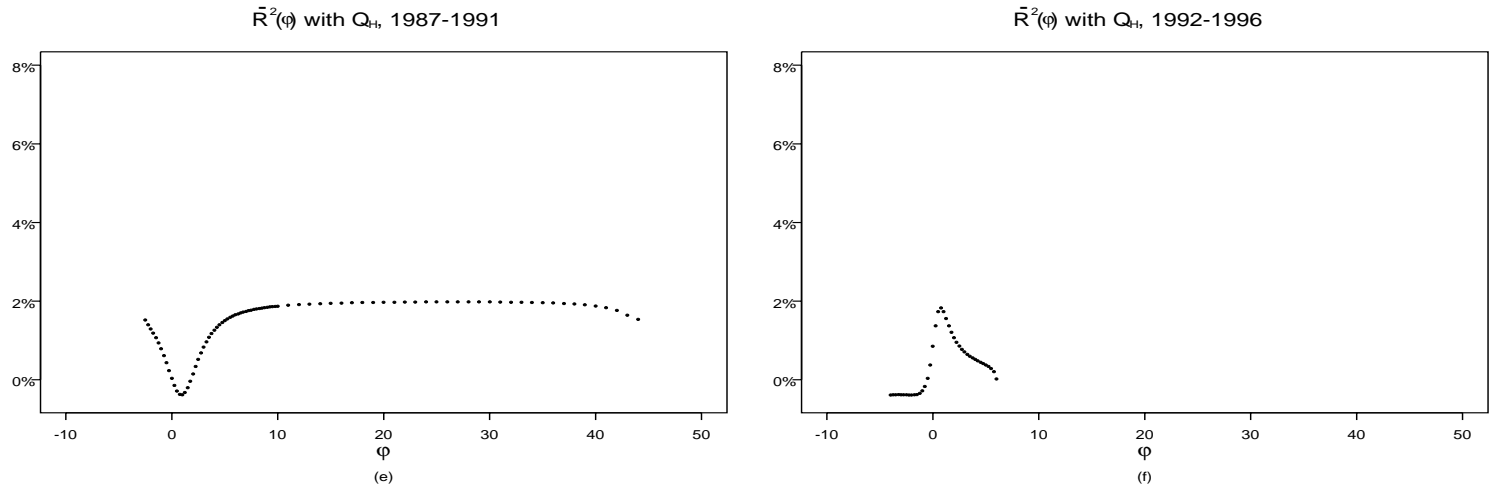

Figure 4: $R^{2}$ of the dollar return of the candidate hedging portfolio in predicting future market returns as a function $\phi$ for the second to the seventh 5-year subperiods from 1962 to 1996. 


\section{Table 1}

Summary statistics for the restricted volume betas using weekly returns and volume data for NYSE and AMEX stocks from 1962 to 1996. Turnover over individual stocks is regressed on the equallyweighted and share- weighted turnover indices, subject to the restriction that the two regression coefficients, $\widehat{\beta}_{\tau}^{E W}$ and $\widehat{\beta}_{\tau}^{S W}$, must add up to one. The stocks are then sorted into ten deciles by $\widehat{\beta}_{\tau}^{E W}$. The summary statistics are then reported for each decile.

\begin{tabular}{|c|c|c|c|c|c|c|c|c|c|c|c|}
\hline \multirow{2}{*}{ Decile } & \multirow{2}{*}{$\begin{array}{c}\text { Sample } \\
\text { Size }\end{array}$} & \multicolumn{2}{|c|}{$\widehat{\beta}_{\tau}^{E W}$} & \multicolumn{2}{|c|}{$t\left(\widehat{\beta}_{\tau}^{E W}\right)$} & \multicolumn{2}{|c|}{$\widehat{\beta}_{\tau}^{S W}$} & \multicolumn{2}{|c|}{$t\left(\widehat{\beta}_{\tau}^{S W}\right)$} & \multicolumn{2}{|c|}{$\bar{R}^{2}(\%)$} \\
\hline & & Mean & S.D. & Mean & S.D. & Mean & S.D. & Mean & S.D. & Mean & S.D. \\
\hline \multicolumn{12}{|c|}{ July 1962 to December 1966 (234 Weeks) } \\
\hline 1 & 218 & -0.906 & 0.119 & -49.394 & 19.023 & 1.906 & 0.119 & 103.944 & $38.755-$ & -2520.4 & 27817.4 \\
\hline 2 & 219 & -0.657 & 0.069 & -26.187 & 12.805 & 1.657 & 0.069 & 65.488 & 30.083 & 56.5 & 19.5 \\
\hline 3 & 219 & -0.432 & 0.064 & -10.917 & 5.956 & 1.432 & 0.064 & 35.879 & 17.907 & 55.0 & 20.4 \\
\hline 4 & 218 & -0.188 & 0.082 & -3.812 & 2.732 & 1.188 & 0.082 & 22.907 & 10.555 & 57.1 & 17.8 \\
\hline 5 & 219 & 0.107 & 0.097 & 1.273 & 1.243 & 0.893 & 0.097 & 11.365 & 4.570 & 51.5 & 16.0 \\
\hline 6 & 219 & 0.494 & 0.119 & 4.585 & 1.943 & 0.506 & 0.119 & 4.847 & 2.401 & 50.6 & 16.5 \\
\hline 7 & 218 & 0.927 & 0.145 & 6.749 & 2.258 & 0.073 & 0.145 & 0.639 & 1.190 & 50.7 & 15.5 \\
\hline 8 & 219 & 1.520 & 0.229 & 8.229 & 2.893 & -0.520 & 0.229 & -2.714 & 1.348 & 49.2 & 15.4 \\
\hline 9 & 219 & 2.568 & 0.434 & 10.410 & 3.491 & -1.568 & 0.434 & -6.292 & 2.401 & 49.4 & 15.2 \\
\hline 10 & 218 & 6.563 & 4.100 & 11.682 & 3.880 & -5.563 & 4.100 & -9.500 & 3.332 & 47.1 & 15.3 \\
\hline \multicolumn{12}{|c|}{ January 1967 to December 1971 (261 Weeks) } \\
\hline 1 & 242 & -0.783 & 0.134 & -36.725 & 17.343 & 1.783 & 0.134 & 84.302 & 38.946 & -175.3 & 976.2 \\
\hline 2 & 243 & -0.529 & 0.056 & -18.772 & 8.459 & 1.529 & 0.056 & 53.969 & 22.871 & 58.2 & 16.1 \\
\hline 3 & 242 & -0.315 & 0.068 & -7.905 & 4.099 & 1.315 & 0.068 & 32.431 & 13.771 & 56.4 & 16.3 \\
\hline 4 & 243 & -0.054 & 0.089 & -1.139 & 1.845 & 1.054 & 0.089 & 18.479 & 7.855 & 55.2 & 14.3 \\
\hline 5 & 242 & 0.264 & 0.087 & 3.269 & 1.482 & 0.736 & 0.087 & 9.228 & 3.260 & 54.1 & 13.2 \\
\hline 6 & 243 & 0.623 & 0.126 & 6.035 & 2.217 & 0.377 & 0.126 & 3.723 & 1.871 & 53.5 & 13.4 \\
\hline 7 & 243 & 1.110 & 0.154 & 8.367 & 2.719 & -0.110 & 0.154 & -0.735 & 1.178 & 54.4 & 13.0 \\
\hline 8 & 242 & 1.782 & 0.205 & 10.314 & 3.151 & -0.782 & 0.205 & -4.477 & 1.630 & 53.2 & 13.2 \\
\hline 9 & 243 & 2.661 & 0.330 & 12.249 & 3.120 & -1.661 & 0.330 & -7.609 & 2.149 & 54.6 & 11.0 \\
\hline 10 & 242 & 5.410 & 2.540 & 13.019 & 4.172 & -4.410 & 2.540 & -10.260 & 3.383 & 52.6 & 14.2 \\
\hline \multicolumn{12}{|c|}{ January 1972 to December 1977 (261 Weeks) } \\
\hline 1 & 262 & -2.013 & 0.845 & -13.276 & 4.901 & 3.013 & 0.845 & 20.755 & 8.319 & -1147.6 & 5034.9 \\
\hline 2 & 263 & -1.069 & 0.129 & -10.986 & 3.890 & 2.069 & 0.129 & 21.239 & 7.045 & 25.4 & 44.6 \\
\hline 3 & 263 & -0.697 & 0.096 & -6.014 & 2.466 & 1.697 & 0.096 & 14.600 & 5.619 & 44.3 & 27.1 \\
\hline 4 & 263 & -0.359 & 0.105 & -2.825 & 1.444 & 1.359 & 0.105 & 10.608 & 4.044 & 50.3 & 22.8 \\
\hline 5 & 263 & 0.015 & 0.114 & 0.062 & 0.765 & 0.985 & 0.114 & 6.620 & 2.466 & 53.0 & 19.2 \\
\hline 6 & 263 & 0.485 & 0.156 & 2.577 & 1.159 & 0.515 & 0.156 & 2.792 & 1.354 & 52.8 & 15.4 \\
\hline 7 & 263 & 1.084 & 0.187 & 4.684 & 1.801 & -0.084 & 0.187 & -0.322 & 0.870 & 51.4 & 14.5 \\
\hline 8 & 263 & 1.888 & 0.289 & 6.827 & 2.426 & -0.888 & 0.289 & -3.180 & 1.421 & 52.8 & 14.2 \\
\hline 9 & 263 & 3.161 & 0.501 & 8.894 & 3.311 & -2.161 & 0.501 & -6.060 & 2.431 & 52.5 & 14.0 \\
\hline 10 & 262 & 7.770 & 4.940 & 11.202 & 4.447 & -6.770 & 4.940 & -9.480 & 3.965 & 52.3 & 13.8 \\
\hline \multicolumn{12}{|c|}{ January 1977 to December 1981 (261 Weeks) } \\
\hline 1 & 242 & -3.096 & 0.347 & -22.164 & 4.591 & 4.096 & 0.347 & 29.341 & 5.815 & -872.7 & 6958.8 \\
\hline 2 & 243 & -2.284 & 0.192 & -15.799 & 4.883 & 3.284 & 0.192 & 22.701 & 6.846 & 32.7 & 23.6 \\
\hline 3 & 243 & -1.654 & 0.208 & -10.524 & 4.628 & 2.654 & 0.208 & 16.861 & 7.167 & 48.9 & 20.8 \\
\hline 4 & 243 & -1.021 & 0.156 & -5.505 & 2.335 & 2.021 & 0.156 & 10.884 & 4.304 & 54.1 & 18.4 \\
\hline 5 & 243 & -0.394 & 0.189 & -1.833 & 1.180 & 1.394 & 0.189 & 6.387 & 2.655 & 55.6 & 17.1 \\
\hline 6 & 243 & 0.355 & 0.250 & 1.277 & 1.045 & 0.645 & 0.250 & 2.472 & 1.438 & 55.5 & 16.5 \\
\hline 7 & 243 & 1.330 & 0.308 & 3.864 & 1.519 & -0.330 & 0.308 & -0.894 & 0.971 & 53.6 & 15.7 \\
\hline 8 & 243 & 2.599 & 0.457 & 6.198 & 2.242 & -1.599 & 0.457 & -3.782 & 1.560 & 54.5 & 15.7 \\
\hline 9 & 243 & 4.913 & 0.809 & 8.860 & 2.983 & -3.913 & 0.809 & -7.038 & 2.487 & 55.3 & 14.5 \\
\hline 10 & 242 & 10.090 & 4.231 & 11.202 & 3.618 & -9.090 & 4.231 & -9.980 & 3.311 & 55.2 & 13.4 \\
\hline
\end{tabular}


Table 1 (continued)

\begin{tabular}{|c|c|c|c|c|c|c|c|c|c|c|c|}
\hline \multirow{2}{*}{ Decile } & \multirow{2}{*}{$\begin{array}{c}\text { Sample } \\
\text { Size }\end{array}$} & \multicolumn{2}{|c|}{$\widehat{\beta}_{\tau}^{E W}$} & \multicolumn{2}{|c|}{$t\left(\widehat{\beta}_{\tau}^{E W}\right)$} & \multicolumn{2}{|c|}{$\widehat{\beta}_{\tau}^{S W}$} & \multicolumn{2}{|c|}{$t\left(\widehat{\beta}_{\tau}^{S W}\right)$} & \multicolumn{2}{|c|}{$\bar{R}^{2}(\%)$} \\
\hline & & Mean & S.D. & Mean & S.D. & Mean & S.D. & Mean & S.D. & Mean & S.D. \\
\hline \multicolumn{12}{|c|}{ January 1982 to December 1986 (261 Weeks) } \\
\hline 1 & 227 & -6.968 & 3.038 & -5.636 & 2.328 & 7.968 & 3.038 & 6.525 & 2.577 & 46.6 & 15.9 \\
\hline 2 & 228 & -2.257 & 0.624 & -3.249 & 1.604 & 3.257 & 0.624 & 4.724 & 2.199 & 52.7 & 20.2 \\
\hline 3 & 228 & -0.640 & 0.380 & -1.223 & 0.967 & 1.640 & 0.380 & 3.180 & 1.667 & 45.5 & 136.9 \\
\hline 4 & 227 & 0.501 & 0.283 & 1.166 & 0.841 & 0.499 & 0.283 & 1.177 & 0.903 & 55.4 & 22.4 \\
\hline 5 & 228 & 1.357 & 0.231 & 3.540 & 1.655 & -0.357 & 0.231 & -0.954 & 0.786 & 41.3 & 90.7 \\
\hline 6 & 228 & 2.077 & 0.201 & 5.319 & 2.159 & -1.077 & 0.201 & -2.758 & 1.216 & -19.5 & 686.3 \\
\hline 7 & 227 & 2.754 & 0.196 & 7.402 & 2.342 & -1.754 & 0.196 & -4.710 & 1.531 & 28.3 & 52.8 \\
\hline 8 & 228 & 3.431 & 0.201 & 9.244 & 2.667 & -2.431 & 0.201 & -6.548 & 1.922 & 3.2 & 101.8 \\
\hline 9 & 228 & 4.168 & 0.237 & 11.354 & 2.905 & -3.168 & 0.237 & -8.630 & 2.248 & -163.1 & 1678.6 \\
\hline 10 & 227 & 5.399 & 1.170 & 14.045 & 5.229 & -4.399 & 1.170 & -11.392 & 4.405 & -348.1 & 1027.1 \\
\hline \multicolumn{12}{|c|}{ January 1987 to December 1991 (261 Weeks) } \\
\hline 1 & 216 & -8.487 & 7.040 & -7.093 & 3.763 & 9.487 & 7.040 & 8.082 & 4.137 & 50.2 & 16.8 \\
\hline 2 & 217 & -2.866 & 0.725 & -4.616 & 2.439 & 3.866 & 0.725 & 6.263 & 3.224 & 54.8 & 18.8 \\
\hline 3 & 217 & -0.843 & 0.494 & -1.832 & 1.512 & 1.843 & 0.494 & 4.097 & 2.537 & 56.8 & 21.0 \\
\hline 4 & 217 & 0.441 & 0.330 & 1.196 & 1.277 & 0.559 & 0.330 & 1.423 & 1.268 & 57.0 & 19.9 \\
\hline 5 & 217 & 1.502 & 0.317 & 4.887 & 3.062 & -0.502 & 0.317 & -1.693 & 1.583 & 57.8 & 18.8 \\
\hline 6 & 217 & 2.510 & 0.280 & 8.434 & 4.070 & -1.510 & 0.280 & -5.074 & 2.582 & 51.2 & 18.7 \\
\hline 7 & 217 & 3.389 & 0.234 & 12.139 & 4.615 & -2.389 & 0.234 & -8.567 & 3.325 & 42.2 & 15.6 \\
\hline 8 & 217 & 4.157 & 0.196 & 15.329 & 4.607 & -3.157 & 0.196 & -11.637 & 3.513 & 23.8 & 19.8 \\
\hline 9 & 217 & 4.836 & 0.212 & 18.370 & 4.580 & -3.836 & 0.212 & -14.572 & 3.673 & -27.0 & 66.1 \\
\hline 10 & 217 & 5.743 & 0.402 & 21.430 & 5.101 & -4.743 & 0.402 & -17.682 & 4.229 & -921.9 & 4682.1 \\
\hline \multicolumn{12}{|c|}{ January 1992 to December 1996 (261 Weeks) } \\
\hline 1 & 241 & -4.275 & 2.858 & -2.409 & 1.092 & 5.275 & 2.858 & 3.097 & 1.342 & -423.6 & 3336.7 \\
\hline 2 & 241 & -1.074 & 0.384 & -1.277 & 0.741 & 2.074 & 0.384 & 2.538 & 1.369 & -147.7 & 2631.2 \\
\hline 3 & 242 & -0.245 & 0.155 & -0.371 & 0.301 & 1.245 & 0.155 & 1.944 & 0.899 & -14.7 & 508.2 \\
\hline 4 & 241 & 0.189 & 0.100 & 0.298 & 0.203 & 0.811 & 0.100 & 1.296 & 0.534 & -135.1 & 899.3 \\
\hline 5 & 241 & 0.520 & 0.098 & 0.779 & 0.313 & 0.480 & 0.098 & 0.729 & $0.330-$ & -1353.9 & 5755.2 \\
\hline 6 & 242 & 0.865 & 0.106 & 1.226 & 0.414 & 0.135 & 0.106 & 0.196 & 0.177 & -197.6 & 669.1 \\
\hline 7 & 241 & 1.303 & 0.159 & 1.725 & 0.641 & -0.303 & 0.159 & -0.400 & 0.260 & -130.3 & 931.7 \\
\hline 8 & 242 & 2.022 & 0.254 & 2.391 & 0.824 & -1.022 & 0.254 & -1.202 & 0.480 & -58.9 & 684.5 \\
\hline 9 & 241 & 3.271 & 0.498 & 3.061 & 1.027 & -2.271 & 0.498 & -2.117 & 0.769 & -24.9 & 225.8 \\
\hline 10 & 241 & 8.234 & 9.836 & 3.844 & 1.360 & -7.234 & 9.836 & -3.237 & 1.190 & -219.9 & 1145.7 \\
\hline
\end{tabular}




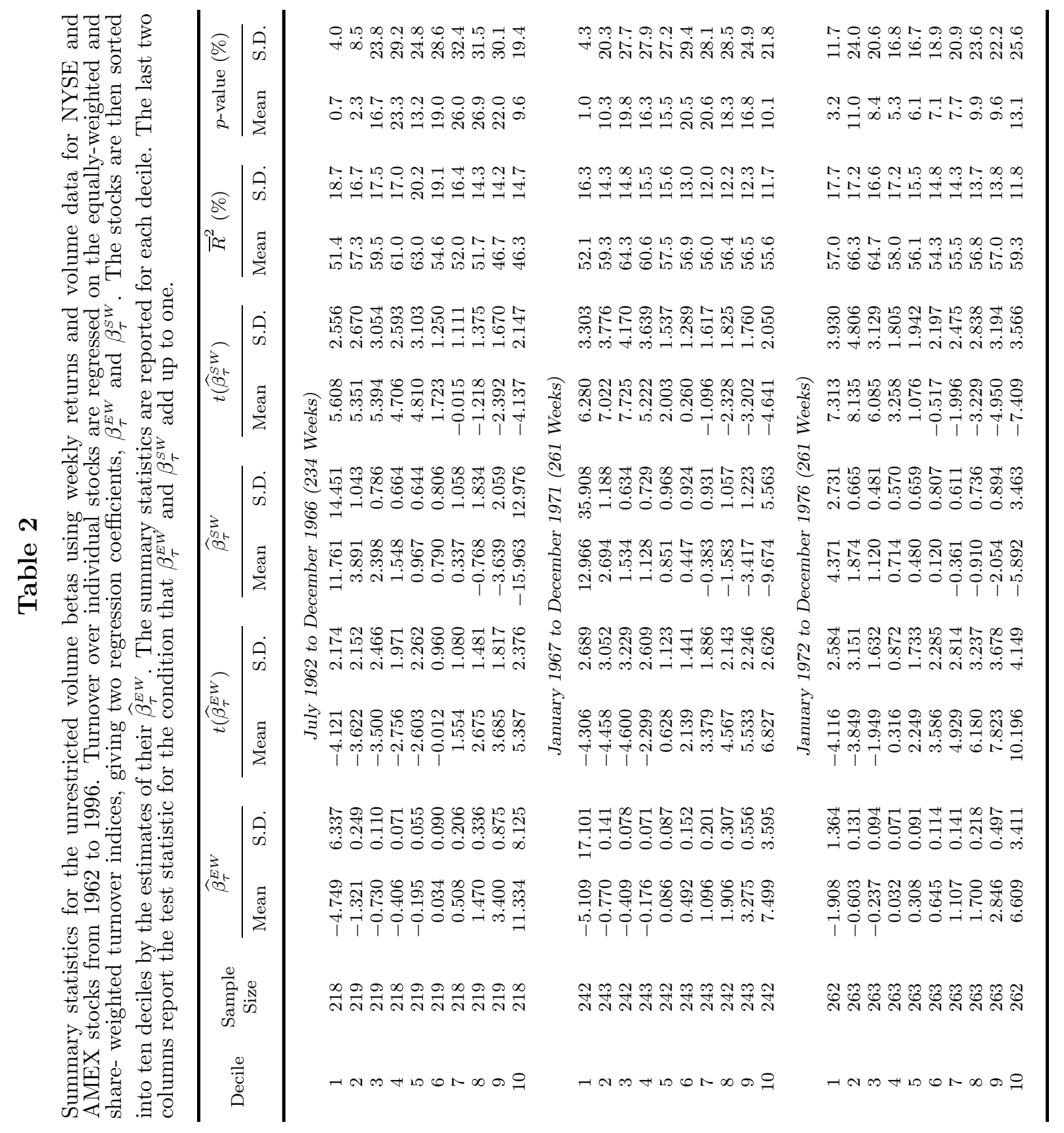




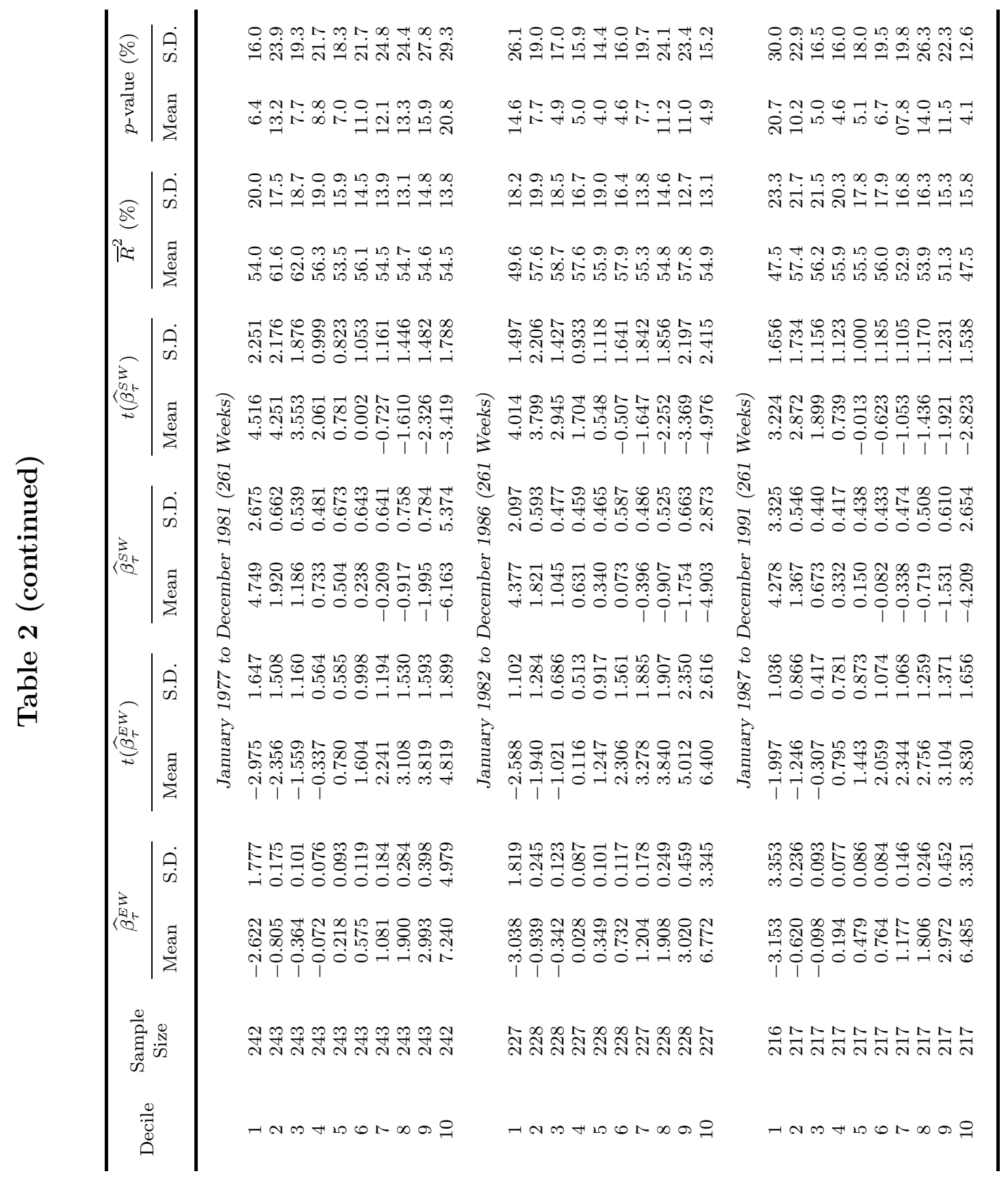

Vol2.10.04.01

Tables

Page 4 of 23 


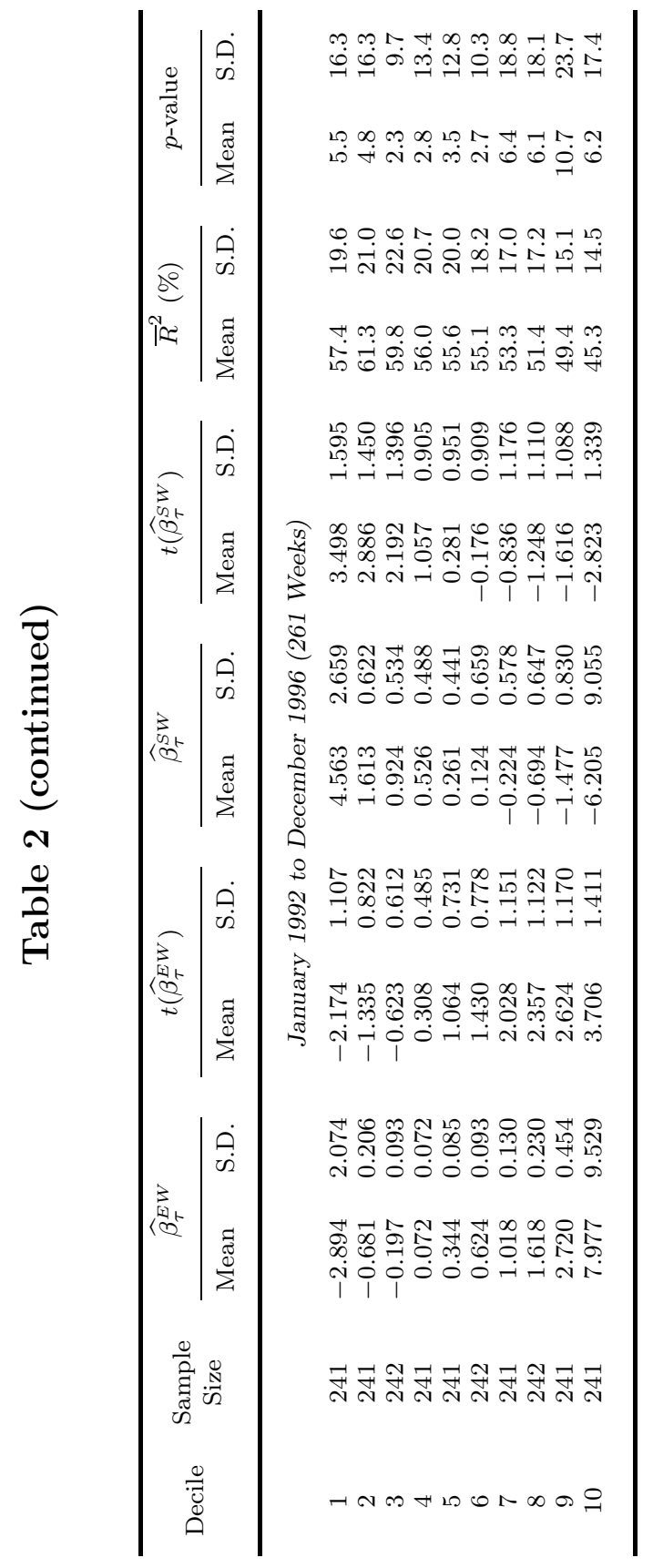

Vol2.10.04.01

Tables

Page 5 of 23 


\section{Table 3}

Summary statistics for the returns and dollar returns of the hedging portfolio constructed from individual stocks' volume data using weekly returns and volume data for NYSE and AMEX stocks from 1962 to 1996.

\begin{tabular}{|c|c|c|c|c|c|c|c|}
\hline \multirow{2}{*}{ Statistic } & \multicolumn{7}{|c|}{ Sample Period } \\
\hline & Entire & $67-71$ & $72-76$ & $77-81$ & $82-86$ & $87-91$ & $92-96$ \\
\hline \multicolumn{8}{|c|}{ Hedging Portfolio Return $R_{H t}$} \\
\hline Mean & 0.013 & 0.001 & 0.005 & 0.007 & 0.011 & 0.052 & 0.003 \\
\hline S.D. & 0.198 & 0.029 & 0.039 & 0.045 & 0.046 & 0.477 & 0.013 \\
\hline Skewness & 24.092 & 0.557 & 0.542 & -0.330 & 0.270 & 10.200 & -0.214 \\
\hline Kurtosis & 747.809 & 1.479 & 7.597 & 0.727 & 1.347 & 130.476 & 0.945 \\
\hline$\rho_{1}$ & 0.017 & 0.199 & 0.141 & 0.196 & 0.125 & 0.004 & -0.165 \\
\hline$\rho_{2}$ & -0.058 & 0.018 & 0.006 & 0.071 & 0.036 & -0.070 & -0.028 \\
\hline$\rho_{3}$ & 0.104 & -0.028 & -0.036 & -0.010 & 0.073 & 0.099 & -0.003 \\
\hline$\rho_{4}$ & 0.184 & 0.070 & 0.043 & 0.045 & -0.113 & 0.182 & -0.010 \\
\hline$\rho_{5}$ & -0.086 & 0.114 & 0.144 & -0.026 & -0.103 & -0.099 & -0.025 \\
\hline$\rho_{6}$ & 0.079 & -0.003 & 0.258 & -0.089 & -0.093 & 0.072 & 0.020 \\
\hline$\rho_{7}$ & 0.217 & 0.037 & 0.083 & -0.031 & -0.173 & 0.218 & 0.098 \\
\hline$\rho_{8}$ & -0.098 & 0.002 & -0.124 & -0.008 & 0.006 & -0.111 & -0.130 \\
\hline$\rho_{9}$ & 0.048 & -0.002 & -0.008 & -0.060 & 0.011 & 0.041 & 0.006 \\
\hline$\rho_{10}$ & -0.044 & -0.017 & 0.174 & -0.037 & -0.117 & -0.055 & 0.035 \\
\hline \multicolumn{8}{|c|}{ Hedging Portfolio Dollar Return $Q_{H t}$} \\
\hline Mean & 2.113 & 0.072 & 1.236 & 2.258 & 5.589 & 3.244 & 0.281 \\
\hline S.D. & 16.836 & 3.639 & 11.059 & 21.495 & 25.423 & 20.906 & 1.845 \\
\hline Skewness & 0.717 & 0.210 & -0.144 & -0.495 & -0.080 & 2.086 & 0.215 \\
\hline Kurtosis & 14.082 & -0.085 & 0.500 & 2.286 & 6.537 & 13.286 & 2.048 \\
\hline$\rho_{1}$ & 0.164 & 0.219 & 0.251 & 0.200 & 0.098 & 0.157 & -0.122 \\
\hline$\rho_{2}$ & 0.082 & 0.014 & 0.148 & 0.052 & 0.125 & -0.015 & -0.095 \\
\hline$\rho_{3}$ & 0.039 & 0.003 & 0.077 & 0.010 & 0.071 & -0.041 & 0.037 \\
\hline$\rho_{4}$ & 0.021 & 0.061 & 0.084 & 0.127 & -0.037 & -0.066 & 0.014 \\
\hline$\rho_{5}$ & 0.036 & 0.116 & 0.102 & -0.002 & 0.051 & -0.016 & -0.027 \\
\hline$\rho_{6}$ & -0.010 & -0.044 & 0.127 & -0.094 & -0.053 & 0.057 & -0.014 \\
\hline$\rho_{7}$ & -0.006 & 0.034 & 0.013 & -0.060 & -0.014 & 0.010 & 0.107 \\
\hline$\rho_{8}$ & -0.046 & 0.005 & -0.055 & -0.028 & -0.127 & 0.016 & -0.075 \\
\hline$\rho_{9}$ & 0.027 & -0.016 & 0.045 & -0.006 & 0.047 & 0.005 & -0.006 \\
\hline$\rho_{10}$ & -0.001 & -0.030 & 0.042 & 0.026 & 0.014 & -0.082 & 0.031 \\
\hline
\end{tabular}




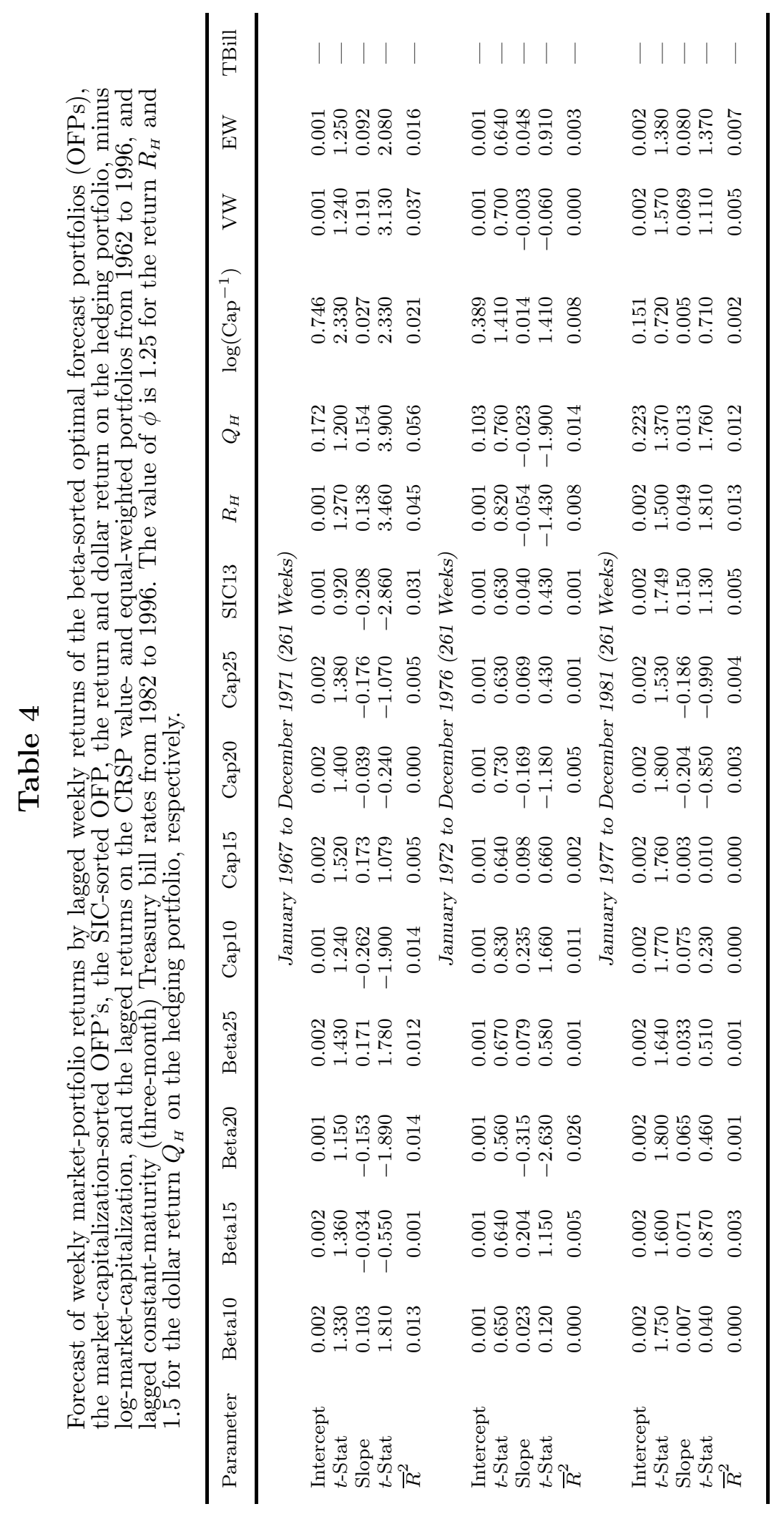

Vol2.10.04.01

Tables

Page 7 of 23 


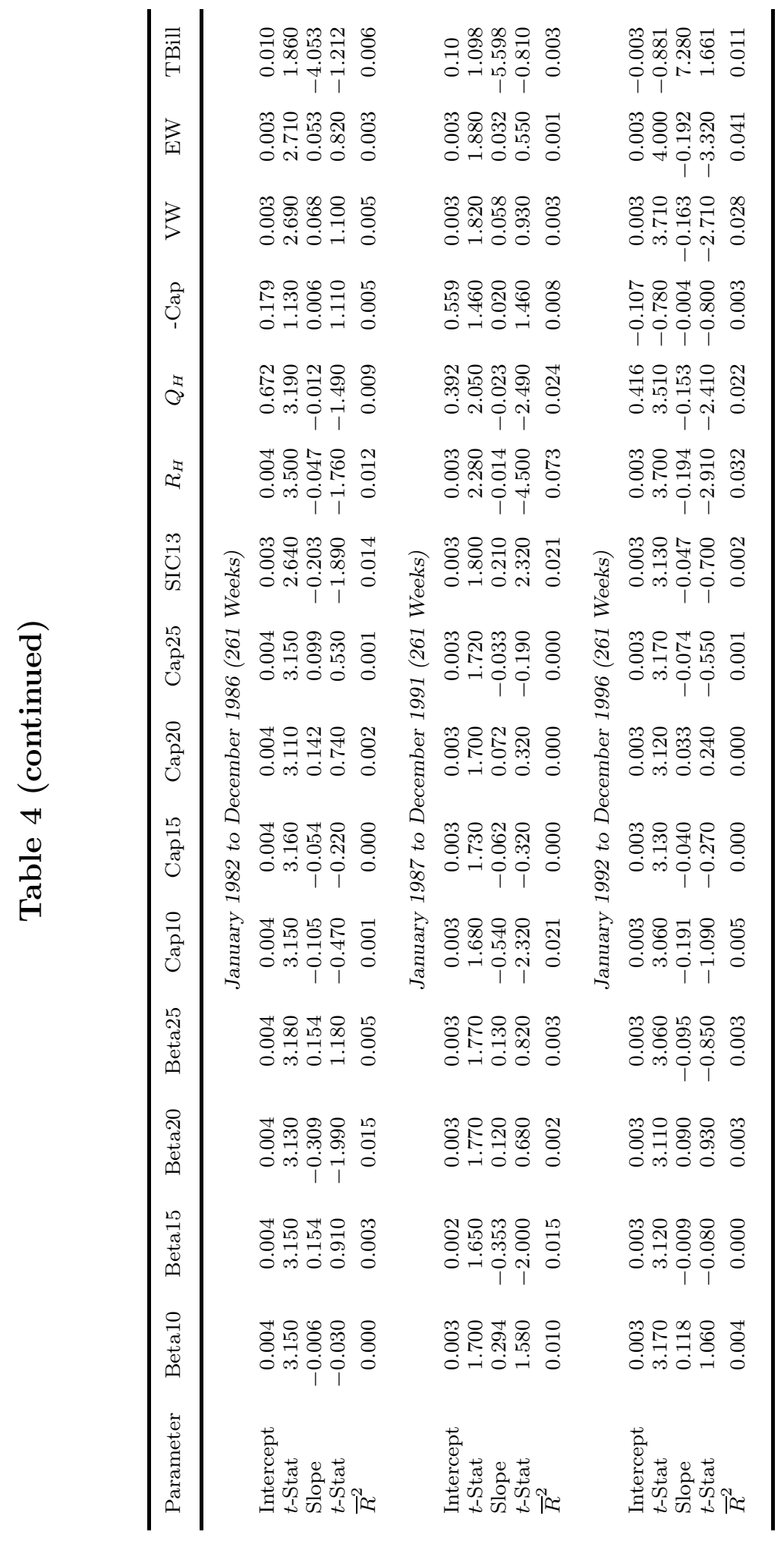

Vol2.10.04.01

Tables

Page 8 of 23 


\section{Table 5}

Correlation matrix for weekly returns on the CRSP value-weighted index $\left(R_{V W t}\right)$, the CRSP equal-weighted index $\left(R_{E W t}\right)$, the hedging-portfolio return $\left(R_{H t}\right)$, the hedging-portfolio dollarreturn $\left(Q_{H t}\right)$, the return of the small-minus-big capitalization stocks portfolio $\left(R_{S M B t}\right)$, the return return $R_{O F P t}$ of the optimal-forecast portfolio (OFP) for the set of 25 market-beta-sorted basis portfolios, and the equal-weighted and share-weighted turnover indices $\left(\tau_{t}^{E W}\right.$ and $\tau_{t}^{S W}$ ), using CRSP weekly returns and volume data for NYSE and AMEX stocks from 1962 to 1996 and in five-year subperiods.

\begin{tabular}{|c|c|c|c|c|c|c|c|c|}
\hline & $R_{V W t}$ & $R_{E W t}$ & $R_{H t}$ & $Q_{H t}$ & $R_{S M B t}$ & $R_{O F P t}$ & $\tau_{t}^{E W}$ & $\tau_{t}^{S W}$ \\
\hline \multicolumn{9}{|c|}{ July 1962 to December 1996 (1,800 Weeks) } \\
\hline$R_{V W t}$ & 100.0 & 88.7 & -13.2 & 15.6 & 14.0 & -26.9 & 10.6 & 8.1 \\
\hline$R_{E W t}$ & 88.7 & 100.0 & -15.8 & 4.6 & 53.5 & -25.3 & 12.6 & 5.5 \\
\hline$R_{H t}$ & -13.2 & -15.8 & 100.0 & 40.3 & -10.7 & -11.0 & 14.9 & 16.8 \\
\hline$Q_{H t}$ & 15.6 & 4.6 & 40.3 & 100.0 & -13.3 & -6.7 & 7.5 & 9.9 \\
\hline$R_{S M B t}$ & 14.0 & 53.5 & -10.7 & -13.3 & 100.0 & -4.8 & 4.6 & -5.8 \\
\hline$R_{O F P t}$ & -26.9 & -25.3 & -11.0 & -6.7 & -4.8 & 100.0 & -4.9 & -2.4 \\
\hline$\tau_{t}^{E W}$ & 10.6 & 12.6 & 14.9 & 7.5 & 4.6 & -4.9 & 100.0 & 86.2 \\
\hline$\tau_{t}^{S W}$ & 8.1 & 5.5 & 16.8 & 9.9 & -5.8 & -2.4 & 86.2 & 100.0 \\
\hline \multicolumn{9}{|c|}{ January 1967 to December 1971 (261 Weeks) } \\
\hline$R_{V W t}$ & 100.0 & 92.6 & 95.6 & 91.5 & 62.7 & -76.2 & 19.1 & 26.3 \\
\hline$R_{E W t}$ & 92.6 & 100.0 & 92.3 & 88.4 & 84.5 & -71.9 & 32.8 & 36.9 \\
\hline$R_{H t}$ & 95.6 & 92.3 & 100.0 & 97.4 & 70.7 & -65.0 & 22.0 & 29.6 \\
\hline$Q_{H t}$ & 91.5 & 88.4 & 97.4 & 100.0 & 69.8 & -60.1 & 22.9 & 29.8 \\
\hline$R_{S M B t}$ & 62.7 & 84.5 & 70.7 & 69.8 & 100.0 & -46.6 & 39.7 & 38.2 \\
\hline$R_{O F P t}$ & -76.2 & -71.9 & -65.0 & -60.1 & -46.6 & 100.0 & -7.5 & -10.4 \\
\hline$\tau_{t}^{E W}$ & 19.1 & 32.8 & 22.0 & 22.9 & 39.7 & -7.5 & 100.0 & 93.1 \\
\hline$\tau_{t}^{S W}$ & 26.3 & 36.9 & 29.6 & 29.8 & 38.2 & -10.4 & 93.1 & 100.0 \\
\hline \multicolumn{9}{|c|}{ January 1972 to December 1977 (261 Weeks) } \\
\hline$R_{V W t}$ & 100.0 & 84.5 & 13.3 & 14.2 & -6.9 & -59.5 & 19.0 & 27.6 \\
\hline$R_{E W t}$ & 84.5 & 100.0 & -11.5 & -18.2 & 44.1 & -45.4 & 24.3 & 35.4 \\
\hline$R_{H t}$ & 13.3 & -11.5 & 100.0 & 86.6 & -55.2 & -8.3 & -2.8 & -1.9 \\
\hline$Q_{H t}$ & 14.2 & -18.2 & 86.6 & 100.0 & -70.4 & -11.6 & -4.1 & -4.2 \\
\hline$R_{S M B t}$ & -6.9 & 44.1 & -55.2 & -70.4 & 100.0 & 15.0 & 11.3 & 16.3 \\
\hline$R_{O F P t}$ & -59.5 & -45.4 & -8.3 & -11.6 & 15.0 & 100.0 & -6.7 & -12.4 \\
\hline$\tau_{t}^{E W}$ & 19.0 & 24.3 & -2.8 & -4.1 & 11.3 & -6.7 & 100.0 & 87.3 \\
\hline$\tau_{t}^{S W}$ & 27.6 & 35.4 & -1.9 & -4.2 & 16.3 & -12.4 & 87.3 & 100.0 \\
\hline \multicolumn{9}{|c|}{ January 1977 to December 1981 (261 Weeks) } \\
\hline$R_{V W t}$ & 100.0 & 90.2 & 85.4 & 82.3 & 23.8 & 22.6 & 12.6 & 15.7 \\
\hline$R_{E W t}$ & 90.2 & 100.0 & 88.5 & 82.0 & 59.3 & 12.7 & 7.6 & 8.1 \\
\hline$R_{H t}$ & 85.4 & 88.5 & 100.0 & 87.1 & 51.2 & 9.3 & 7.6 & 8.6 \\
\hline$Q_{H t}$ & 82.3 & 82.0 & 87.1 & 100.0 & 49.0 & 10.4 & 11.0 & 12.3 \\
\hline$R_{S M B t}$ & 23.8 & 59.3 & 51.2 & 49.0 & 100.0 & -16.7 & -8.3 & -12.7 \\
\hline$R_{O F P t}$ & 22.6 & 12.7 & 9.3 & 10.4 & -16.7 & 100.0 & 10.7 & 10.4 \\
\hline$\tau_{t}^{E W}$ & 12.6 & 7.6 & 7.6 & 11.0 & -8.3 & 10.7 & 100.0 & 94.9 \\
\hline$\tau_{t}^{S W W}$ & 15.7 & 8.1 & 8.6 & 12.3 & -12.7 & 10.4 & 94.9 & 100.0 \\
\hline
\end{tabular}


Table 5 (continued)

\begin{tabular}{|c|c|c|c|c|c|c|c|c|}
\hline & $R_{V W t}$ & $R_{E W t}$ & $R_{H t}$ & $Q_{H t}$ & $R_{S M B t}$ & $R_{O F P t}$ & $\tau_{t}^{E W}$ & $\tau_{t}^{S W}$ \\
\hline \multicolumn{9}{|c|}{ January 1982 to December 1986 (261 Weeks) } \\
\hline$R_{V W t}$ & 100.0 & 92.1 & -17.0 & 6.1 & -2.8 & -23.5 & 27.1 & 28.6 \\
\hline$R_{E W t}$ & 92.1 & 100.0 & -34.1 & -10.2 & 30.6 & -30.6 & 36.0 & 31.6 \\
\hline$R_{H t}$ & -17.0 & -34.1 & 100.0 & 73.3 & -54.5 & 13.5 & -12.2 & -7.8 \\
\hline$Q_{H t}$ & 6.1 & -10.2 & 73.3 & 100.0 & -41.1 & 8.0 & 1.3 & 4.2 \\
\hline$R_{S M B t}$ & -2.8 & 30.6 & -54.5 & -41.1 & 100.0 & -15.9 & 19.9 & 6.5 \\
\hline$R_{O F P t}$ & -23.5 & -30.6 & 13.5 & 8.0 & -15.9 & 100.0 & -20.7 & -17.9 \\
\hline$\tau_{t}^{E W}$ & 27.1 & 36.0 & -12.2 & 1.3 & 19.9 & -20.7 & 100.0 & 93.2 \\
\hline$\tau_{t}^{S W}$ & 28.6 & 31.6 & -7.8 & 4.2 & 6.5 & -17.9 & 93.2 & 100.0 \\
\hline \multicolumn{9}{|c|}{ January 1987 to December 1991 (261 Weeks) } \\
\hline$R_{V W t}$ & 100.0 & 91.2 & -40.4 & -36.0 & 8.1 & 18.9 & -15.0 & -17.0 \\
\hline$R_{E W t}$ & 91.2 & 100.0 & -44.3 & -46.5 & 44.6 & 36.3 & -16.7 & -20.9 \\
\hline$R_{H t}$ & -40.4 & -44.3 & 100.0 & 58.1 & -23.8 & -26.2 & 43.2 & 43.7 \\
\hline$Q_{H t}$ & -36.0 & -46.5 & 58.1 & 100.0 & -37.1 & -32.8 & 25.3 & 24.0 \\
\hline$R_{S M B t}$ & 8.1 & 44.6 & -23.8 & -37.1 & 100.0 & 45.1 & -11.4 & -16.9 \\
\hline$R_{O F P t}$ & 18.9 & 36.3 & -26.2 & -32.8 & 45.1 & 100.0 & -18.5 & -19.7 \\
\hline$\tau_{t}^{E W}$ & -15.0 & -16.7 & 43.2 & 25.3 & -11.4 & -18.5 & 100.0 & 94.7 \\
\hline$\tau_{t}^{S W}$ & -17.0 & -20.9 & 43.7 & 24.0 & -16.9 & -19.7 & 94.7 & 100.0 \\
\hline \multicolumn{9}{|c|}{ January 1992 to December 1996 (261 Weeks) } \\
\hline$R_{V W t}$ & 100.0 & 84.3 & 95.5 & 66.5 & -1.2 & -13.1 & 15.5 & 10.4 \\
\hline$R_{E W t}$ & 84.3 & 100.0 & 73.2 & 40.5 & 46.1 & -5.2 & 18.2 & 5.4 \\
\hline$R_{H t}$ & 95.5 & 73.2 & 100.0 & 84.8 & -19.7 & -8.7 & 15.3 & 11.2 \\
\hline$Q_{H t}$ & 66.5 & 40.5 & 84.8 & 100.0 & -41.6 & 0.2 & 12.0 & 9.2 \\
\hline$R_{S M B t}$ & -1.2 & 46.1 & -19.7 & -41.6 & 100.0 & 11.3 & 3.0 & -10.1 \\
\hline$R_{O F P t}$ & -13.1 & -5.2 & -8.7 & 0.2 & 11.3 & 100.0 & -3.0 & -3.3 \\
\hline$\tau_{t}^{E W}$ & 15.5 & 18.2 & 15.3 & 12.0 & 3.0 & -3.0 & 100.0 & 92.7 \\
\hline$\tau_{t}^{S W}$ & 10.4 & 5.4 & 11.2 & 9.2 & -10.1 & -3.3 & 92.7 & 100.0 \\
\hline
\end{tabular}




\section{Table 6a}

Summary statistics for market betas estimated with weekly returns data for NYSE and AMEX stocks from July 1962 to December 1996 in five-year subperiods. Returns of individual stocks are regressed on the returns of the CRSP value-weighted returns index, yielding the beta coefficient $\widehat{\beta}_{j}^{M}$. The betas are sorted into deciles and means and standard deviations of the estimated coefficients are reported for each decile.

\begin{tabular}{|c|c|c|c|c|c|c|c|}
\hline \multirow{2}{*}{ Decile } & \multirow{2}{*}{$\begin{array}{c}\text { Sample } \\
\text { Size }\end{array}$} & \multicolumn{2}{|c|}{$\widehat{\beta}_{\tau}^{M}$} & \multicolumn{2}{|c|}{$t\left(\widehat{\beta}_{\tau}^{M}\right)$} & \multicolumn{2}{|c|}{$\bar{R}^{2}(\%)$} \\
\hline & & Mean & S.D. & Mean & S.D. & Mean & S.D. \\
\hline \multicolumn{8}{|c|}{ January 1967 to December 1971 (261 Weeks) } \\
\hline 1 & 242 & 0.432 & 0.136 & 4.103 & 1.990 & 7.2 & 5.2 \\
\hline 2 & 243 & 0.710 & 0.058 & 5.532 & 1.881 & 11.9 & 6.2 \\
\hline 3 & 242 & 0.880 & 0.041 & 6.343 & 2.233 & 14.9 & 7.7 \\
\hline 4 & 243 & 1.020 & 0.044 & 6.811 & 2.476 & 17.3 & 8.6 \\
\hline 5 & 242 & 1.168 & 0.040 & 7.122 & 2.345 & 18.1 & 8.1 \\
\hline 6 & 243 & 1.307 & 0.038 & 7.166 & 2.293 & 18.4 & 8.6 \\
\hline 7 & 243 & 1.463 & 0.050 & 7.682 & 2.180 & 20.7 & 7.9 \\
\hline 8 & 242 & 1.648 & 0.061 & 7.554 & 2.165 & 19.9 & 8.2 \\
\hline 9 & 243 & 1.881 & 0.077 & 8.290 & 2.158 & 23.4 & 7.7 \\
\hline 10 & 242 & 2.282 & 0.239 & 8.814 & 2.190 & 26.7 & 8.2 \\
\hline \multicolumn{8}{|c|}{ January 1972 to December 1977 (261 Weeks) } \\
\hline 1 & 262 & 0.300 & 0.146 & 2.774 & 1.853 & 3.7 & 4.3 \\
\hline 2 & 263 & 0.537 & 0.047 & 4.493 & 2.051 & 8.1 & 6.4 \\
\hline 3 & 263 & 0.680 & 0.038 & 5.161 & 2.067 & 10.3 & 6.7 \\
\hline 4 & 263 & 0.792 & 0.030 & 5.671 & 2.331 & 12.0 & 7.9 \\
\hline 5 & 263 & 0.896 & 0.030 & 6.334 & 2.422 & 14.3 & 8.5 \\
\hline 6 & 263 & 1.004 & 0.031 & 7.011 & 2.793 & 16.9 & 9.7 \\
\hline 7 & 263 & 1.113 & 0.032 & 7.365 & 3.120 & 18.2 & 11.2 \\
\hline 8 & 263 & 1.242 & 0.046 & 7.550 & 2.788 & 18.9 & 10.1 \\
\hline 9 & 263 & 1.428 & 0.065 & 8.337 & 2.957 & 21.9 & 10.6 \\
\hline 10 & 262 & 1.818 & 0.240 & 9.085 & 2.949 & 25.4 & 10.4 \\
\hline \multicolumn{8}{|c|}{ January 1977 to December 1981 (261 Weeks) } \\
\hline 1 & 242 & 0.262 & 0.111 & 2.324 & 1.549 & 2.5 & 3.1 \\
\hline 2 & 243 & 0.490 & 0.048 & 4.046 & 1.885 & 6.8 & 5.2 \\
\hline 3 & 243 & 0.643 & 0.038 & 4.689 & 1.806 & 8.6 & 5.5 \\
\hline 4 & 243 & 0.761 & 0.032 & 5.475 & 2.047 & 11.2 & 6.5 \\
\hline 5 & 243 & 0.870 & 0.033 & 6.103 & 2.485 & 13.6 & 8.7 \\
\hline 6 & 243 & 0.977 & 0.026 & 6.479 & 2.609 & 15.1 & 9.1 \\
\hline 7 & 243 & 1.091 & 0.037 & 7.162 & 2.709 & 17.6 & 9.8 \\
\hline 8 & 243 & 1.223 & 0.040 & 7.631 & 2.793 & 19.2 & 10.1 \\
\hline 9 & 243 & 1.397 & 0.066 & 8.050 & 2.609 & 21.1 & 9.3 \\
\hline 10 & 242 & 1.756 & 0.220 & 9.013 & 2.762 & 26.6 & 9.7 \\
\hline \multicolumn{8}{|c|}{ January 1982 to December 1986 (261 Weeks) } \\
\hline 1 & 227 & 0.208 & 0.157 & 1.645 & 1.354 & 1.3 & 2.3 \\
\hline 2 & 228 & 0.456 & 0.046 & 3.744 & 1.681 & 5.8 & 4.5 \\
\hline 3 & 228 & 0.590 & 0.040 & 4.327 & 1.973 & 7.9 & 6.0 \\
\hline 4 & 227 & 0.718 & 0.032 & 4.931 & 1.833 & 9.8 & 6.1 \\
\hline 5 & 228 & 0.823 & 0.033 & 5.617 & 2.084 & 12.1 & 7.2 \\
\hline 6 & 228 & 0.928 & 0.027 & 6.269 & 2.493 & 14.4 & 8.4 \\
\hline 7 & 227 & 1.032 & 0.034 & 7.189 & 2.524 & 17.6 & 9.0 \\
\hline 8 & 228 & 1.141 & 0.035 & 7.576 & 2.795 & 19.5 & 10.0 \\
\hline 9 & 228 & 1.302 & 0.060 & 8.050 & 2.810 & 21.7 & 9.9 \\
\hline 10 & 227 & 1.667 & 0.231 & 8.231 & 3.201 & 22.7 & 11.3 \\
\hline
\end{tabular}

Vol2.10.04.01

Tables

Page 11 of 23 
Table 6a (continued)

\begin{tabular}{|c|c|c|c|c|c|c|c|}
\hline \multirow{2}{*}{ Decile } & \multirow{2}{*}{$\begin{array}{c}\text { Sample } \\
\text { Size }\end{array}$} & \multicolumn{2}{|c|}{$\widehat{\beta}_{\tau}^{M}$} & \multicolumn{2}{|c|}{$t\left(\widehat{\beta}_{\tau}^{M}\right)$} & \multicolumn{2}{|c|}{$\bar{R}^{2}(\%)$} \\
\hline & & Mean & S.D. & Mean & S.D. & Mean & S.D. \\
\hline \multicolumn{8}{|c|}{ January 1987 to December 1991 (261 Weeks) } \\
\hline 1 & 216 & 0.268 & 0.219 & 3.368 & 2.845 & 6.2 & 7.5 \\
\hline 2 & 217 & 0.540 & 0.061 & 4.659 & 2.807 & 9.6 & 8.8 \\
\hline 3 & 217 & 0.701 & 0.036 & 5.479 & 2.726 & 12.3 & 9.4 \\
\hline 4 & 217 & 0.839 & 0.040 & 6.750 & 3.427 & 16.7 & 11.8 \\
\hline 5 & 217 & 0.956 & 0.032 & 7.920 & 3.860 & 21.5 & 13.6 \\
\hline 6 & 217 & 1.056 & 0.025 & 8.350 & 4.121 & 23.1 & 14.3 \\
\hline 7 & 217 & 1.151 & 0.031 & 8.979 & 4.061 & 25.0 & 14.5 \\
\hline 8 & 217 & 1.264 & 0.033 & 9.001 & 4.202 & 25.6 & 15.0 \\
\hline 9 & 217 & 1.418 & 0.054 & 9.490 & 4.345 & 27.7 & 15.0 \\
\hline 10 & 217 & 1.737 & 0.217 & 8.926 & 4.058 & 27.7 & 14.5 \\
\hline \multicolumn{8}{|c|}{ January 1992 to December 1996 (261 Weeks) } \\
\hline 1 & 241 & -0.001 & 0.448 & 0.394 & 0.788 & -0.2 & 0.6 \\
\hline 2 & 241 & 0.368 & 0.050 & 2.301 & 1.312 & 2.3 & 2.6 \\
\hline 3 & 242 & 0.515 & 0.033 & 2.990 & 1.614 & 3.9 & 3.9 \\
\hline 4 & 241 & 0.636 & 0.037 & 3.337 & 1.652 & 4.8 & 4.2 \\
\hline 5 & 241 & 0.763 & 0.040 & 3.972 & 1.837 & 6.7 & 5.4 \\
\hline 6 & 242 & 0.881 & 0.030 & 4.676 & 2.134 & 8.9 & 6.3 \\
\hline 7 & 241 & 1.000 & 0.035 & 4.959 & 2.187 & 9.9 & 6.8 \\
\hline 8 & 242 & 1.139 & 0.045 & 5.651 & 2.620 & 12.5 & 9.0 \\
\hline 9 & 241 & 1.336 & 0.076 & 5.591 & 2.484 & 12.3 & 8.5 \\
\hline 10 & 241 & 1.820 & 0.340 & 5.760 & 2.794 & 13.8 & 9.3 \\
\hline
\end{tabular}




\section{Table $6 \mathrm{~b}$}

Summary statistics for market and hedging-portfolio return betas estimated with weekly returns data for NYSE and AMEX stocks from July 1962 to December 1996 in five-year subperiods. Returns of individual stocks are regressed on the returns of the CRSP value-weighted returns index and the hedging-portfolio return index $R_{H t}$, yielding two beta coefficients $\widehat{\beta}_{j}^{M}$ and $\widehat{\beta}_{j}^{H R}$. The pairs are sorted into deciles according to their market betas and means and standard deviations of the estimated coefficients are reported for each decile.

\begin{tabular}{|c|c|c|c|c|c|c|c|c|c|c|c|}
\hline \multirow{2}{*}{ Decile } & \multirow{2}{*}{$\begin{array}{c}\text { Sample } \\
\text { Size }\end{array}$} & \multicolumn{2}{|c|}{$\widehat{\beta}_{\tau}^{M}$} & \multicolumn{2}{|c|}{$t\left(\widehat{\beta}_{\tau}^{M}\right)$} & \multicolumn{2}{|c|}{$\widehat{\beta}_{\tau}^{H R}$} & \multicolumn{2}{|c|}{$t\left(\widehat{\beta}_{\tau}^{H R}\right)$} & \multicolumn{2}{|c|}{$\bar{R}^{2}(\%)$} \\
\hline & & Mean & S.D. & Mean & S.D. & Mean & S.D. & Mean & S.D. & Mean & S.D. \\
\hline \multicolumn{12}{|c|}{ January 1967 to December 1971 (261 Weeks) } \\
\hline 1 & 242 & -1.250 & 0.605 & -1.451 & 0.755 & 2.027 & 0.640 & 3.571 & 1.514 & 22.4 & 12.9 \\
\hline 2 & 243 & -0.297 & 0.155 & -0.405 & 0.248 & 1.196 & 0.436 & 2.347 & 0.939 & 17.9 & 11.0 \\
\hline 3 & 242 & 0.147 & 0.101 & 0.233 & 0.207 & 0.806 & 0.419 & 1.611 & 0.796 & 15.9 & 9.6 \\
\hline 4 & 243 & 0.420 & 0.070 & 0.744 & 0.350 & 0.553 & 0.358 & 1.224 & 0.758 & 16.8 & 9.5 \\
\hline 5 & 242 & 0.648 & 0.060 & 1.192 & 0.578 & 0.391 & 0.359 & 0.777 & 0.834 & 16.7 & 8.7 \\
\hline 6 & 243 & 0.852 & 0.057 & 1.639 & 0.711 & 0.213 & 0.373 & 0.339 & 0.913 & 17.1 & 9.1 \\
\hline 7 & 243 & 1.053 & 0.061 & 2.234 & 0.908 & 0.056 & 0.336 & -0.128 & 1.064 & 18.8 & 8.4 \\
\hline 8 & 242 & 1.263 & 0.063 & 2.493 & 1.092 & -0.049 & 0.345 & -0.450 & 1.177 & 18.7 & 8.3 \\
\hline 9 & 243 & 1.527 & 0.091 & 3.113 & 1.368 & -0.227 & 0.331 & -0.953 & 1.273 & 20.8 & 8.8 \\
\hline 10 & 242 & 2.080 & 0.341 & 3.541 & 1.540 & -0.496 & 0.367 & -1.438 & 1.357 & 22.1 & 9.9 \\
\hline \multicolumn{12}{|c|}{ January 1972 to December 1977 (261 Weeks) } \\
\hline 1 & 262 & 0.316 & 0.157 & 3.025 & 1.924 & -0.099 & 0.134 & -0.811 & 1.230 & 4.7 & 4.6 \\
\hline 2 & 263 & 0.565 & 0.048 & 4.706 & 2.104 & -0.110 & 0.151 & -0.853 & 1.404 & 9.4 & 6.8 \\
\hline 3 & 263 & 0.714 & 0.040 & 5.427 & 2.168 & -0.129 & 0.159 & -1.055 & 1.361 & 11.5 & 7.4 \\
\hline 4 & 263 & 0.839 & 0.032 & 6.023 & 2.371 & -0.166 & 0.154 & -1.378 & 1.271 & 13.6 & 8.5 \\
\hline 5 & 263 & 0.947 & 0.029 & 6.673 & 2.567 & -0.171 & 0.171 & -1.327 & 1.365 & 16.0 & 9.1 \\
\hline 6 & 263 & 1.054 & 0.033 & 7.197 & 2.820 & -0.187 & 0.188 & -1.454 & 1.397 & 18.0 & 10.1 \\
\hline 7 & 263 & 1.180 & 0.038 & 7.296 & 3.077 & -0.247 & 0.212 & -1.697 & 1.444 & 18.6 & 11.2 \\
\hline 8 & 263 & 1.315 & 0.046 & 7.866 & 2.768 & -0.265 & 0.213 & -1.931 & 1.402 & 20.5 & 10.3 \\
\hline 9 & 263 & 1.511 & 0.068 & 8.120 & 2.948 & -0.312 & 0.211 & -2.135 & 1.294 & 21.7 & 10.4 \\
\hline 10 & 262 & 1.930 & 0.238 & 9.378 & 3.010 & -0.439 & 0.297 & -2.717 & 1.329 & 27.3 & 10.4 \\
\hline \multicolumn{12}{|c|}{ January 1977 to December 1981 (261 Weeks) } \\
\hline 1 & 242 & -0.244 & 0.295 & -0.523 & 0.519 & 0.350 & 0.202 & 2.335 & 1.052 & 5.7 & 5.7 \\
\hline 2 & 243 & 0.137 & 0.059 & 0.493 & 0.341 & 0.250 & 0.162 & 1.997 & 1.151 & 8.0 & 6.9 \\
\hline 3 & 243 & 0.308 & 0.040 & 1.246 & 0.600 & 0.186 & 0.149 & 1.634 & 1.232 & 9.3 & 6.2 \\
\hline 4 & 243 & 0.428 & 0.034 & 1.858 & 0.850 & 0.162 & 0.155 & 1.459 & 1.393 & 11.8 & 7.8 \\
\hline 5 & 243 & 0.528 & 0.027 & 2.380 & 1.019 & 0.151 & 0.164 & 1.324 & 1.454 & 14.3 & 8.1 \\
\hline 6 & 243 & 0.629 & 0.032 & 2.666 & 1.139 & 0.151 & 0.156 & 1.325 & 1.415 & 16.4 & 8.5 \\
\hline 7 & 243 & 0.742 & 0.035 & 3.124 & 1.163 & 0.131 & 0.143 & 1.233 & 1.385 & 18.4 & 9.1 \\
\hline 8 & 243 & 0.867 & 0.037 & 3.464 & 1.357 & 0.122 & 0.142 & 1.122 & 1.303 & 20.1 & 10.4 \\
\hline 9 & 243 & 1.035 & 0.068 & 4.205 & 1.742 & 0.093 & 0.143 & 0.795 & 1.259 & 23.2 & 10.7 \\
\hline 10 & 242 & 1.414 & 0.249 & 4.829 & 2.215 & 0.033 & 0.172 & 0.226 & 1.405 & 25.6 & 12.9 \\
\hline \multicolumn{12}{|c|}{ January 1982 to December 1986 (261 Weeks) } \\
\hline 1 & 227 & 0.202 & 0.164 & 1.573 & 1.343 & -0.079 & 0.164 & -0.465 & 1.360 & 1.7 & 2.7 \\
\hline 2 & 228 & 0.457 & 0.044 & 3.672 & 1.724 & -0.049 & 0.160 & -0.023 & 1.877 & 6.5 & 5.2 \\
\hline 3 & 228 & 0.590 & 0.040 & 4.440 & 2.107 & -0.049 & 0.182 & 0.040 & 2.123 & 9.4 & 7.6 \\
\hline 4 & 227 & 0.714 & 0.032 & 4.864 & 1.793 & -0.086 & 0.147 & -0.671 & 1.578 & 10.4 & 6.3 \\
\hline 5 & 228 & 0.818 & 0.031 & 5.598 & 2.078 & -0.093 & 0.150 & -0.821 & 1.510 & 12.8 & 7.4 \\
\hline 6 & 228 & 0.923 & 0.028 & 6.362 & 2.448 & -0.121 & 0.180 & -1.006 & 1.772 & 15.9 & 8.3 \\
\hline 7 & 227 & 1.028 & 0.033 & 7.141 & 2.651 & -0.107 & 0.161 & -1.017 & 1.570 & 18.8 & 9.5 \\
\hline 8 & 228 & 1.136 & 0.036 & 7.454 & 2.830 & -0.127 & 0.161 & -1.218 & 1.470 & 19.9 & 10.1 \\
\hline 9 & 228 & 1.299 & 0.059 & 8.007 & 2.886 & -0.178 & 0.204 & -1.765 & 1.910 & 23.3 & 10.5 \\
\hline 10 & 227 & 1.660 & 0.235 & 8.147 & 3.360 & -0.229 & 0.237 & -1.913 & 2.052 & 24.4 & 12.5 \\
\hline
\end{tabular}


Table $6 \mathrm{~b}$ (continued)

\begin{tabular}{|c|c|c|c|c|c|c|c|c|c|c|c|}
\hline \multirow{2}{*}{ Decile } & \multirow{2}{*}{$\begin{array}{c}\text { Sample } \\
\text { Size }\end{array}$} & \multicolumn{2}{|c|}{$\widehat{\beta}_{\tau}^{M}$} & \multicolumn{2}{|c|}{$t\left(\widehat{\beta}_{\tau}^{M}\right)$} & \multicolumn{2}{|c|}{$\widehat{\beta}_{\tau}^{H R}$} & \multicolumn{2}{|c|}{$t\left(\widehat{\beta}_{\tau}^{H R}\right)$} & \multicolumn{2}{|c|}{$\bar{R}^{2}(\%)$} \\
\hline & & Mean & S.D. & Mean & S.D. & Mean & S.D. & Mean & S.D. & Mean & S.D. \\
\hline \multicolumn{12}{|c|}{ January 1987 to December 1991 (261 Weeks) } \\
\hline 1 & 216 & 0.205 & 0.257 & 2.267 & 2.359 & -0.082 & 0.174 & -0.724 & 1.657 & 5.1 & 6.1 \\
\hline 2 & 217 & 0.484 & 0.048 & 4.365 & 2.830 & -0.048 & 0.116 & -0.351 & 2.057 & 10.7 & 9.2 \\
\hline 3 & 217 & 0.637 & 0.041 & 4.923 & 2.456 & -0.063 & 0.092 & -1.080 & 1.579 & 13.6 & 9.3 \\
\hline 4 & 217 & 0.775 & 0.039 & 5.373 & 2.931 & -0.075 & 0.098 & -1.012 & 1.644 & 15.1 & 11.4 \\
\hline 5 & 217 & 0.898 & 0.035 & 6.868 & 3.184 & -0.064 & 0.106 & -0.957 & 1.623 & 20.8 & 11.9 \\
\hline 6 & 217 & 1.005 & 0.028 & 7.740 & 3.675 & -0.063 & 0.112 & -0.756 & 1.587 & 23.9 & 13.6 \\
\hline 7 & 217 & 1.098 & 0.028 & 8.356 & 4.074 & -0.059 & 0.086 & -0.864 & 1.389 & 26.4 & 15.1 \\
\hline 8 & 217 & 1.215 & 0.038 & 8.771 & 4.157 & -0.068 & 0.103 & -0.927 & 1.461 & 27.8 & 15.7 \\
\hline 9 & 217 & 1.362 & 0.050 & 8.651 & 4.134 & -0.064 & 0.108 & -0.849 & 1.342 & 27.6 & 15.8 \\
\hline 10 & 217 & 1.699 & 0.239 & 8.413 & 3.661 & -0.119 & 0.207 & -0.893 & 1.280 & 28.4 & 14.6 \\
\hline \multicolumn{12}{|c|}{ January 1992 to December 1996 (261 Weeks) } \\
\hline 1 & 241 & -1.526 & 1.776 & -1.784 & 1.521 & 2.269 & 1.841 & 2.727 & 2.043 & 9.9 & 10.1 \\
\hline 2 & 241 & -0.031 & 0.209 & -0.058 & 0.347 & 0.660 & 0.456 & 0.921 & 0.764 & 6.2 & 8.1 \\
\hline 3 & 242 & 0.582 & 0.153 & 0.790 & 0.406 & 0.027 & 0.450 & 0.059 & 0.554 & 6.4 & 8.6 \\
\hline 4 & 241 & 1.086 & 0.138 & 1.370 & 0.602 & -0.469 & 0.440 & -0.521 & 0.488 & 6.4 & 7.3 \\
\hline 5 & 241 & 1.506 & 0.118 & 1.833 & 0.738 & -0.799 & 0.413 & -0.881 & 0.497 & 8.0 & 8.0 \\
\hline 6 & 242 & 1.965 & 0.132 & 2.156 & 0.935 & -1.279 & 0.507 & -1.260 & 0.603 & 7.7 & 7.4 \\
\hline 7 & 241 & 2.487 & 0.177 & 2.776 & 1.078 & -1.737 & 0.452 & -1.750 & 0.709 & 10.0 & 8.4 \\
\hline 8 & 242 & 3.166 & 0.213 & 3.067 & 1.182 & -2.344 & 0.521 & -2.064 & 0.805 & 10.3 & 8.6 \\
\hline 9 & 241 & 4.062 & 0.327 & 3.380 & 1.432 & -3.300 & 0.673 & -2.464 & 0.997 & 10.4 & 8.8 \\
\hline 10 & 241 & 6.789 & 2.540 & 4.211 & 2.113 & -6.058 & 2.827 & -3.342 & 1.684 & 12.4 & 9.9 \\
\hline
\end{tabular}




\section{Table 6c}

Summary statistics for market and hedging-portfolio dollar-return betas estimated with weekly returns data for NYSE and AMEX stocks from July 1962 to December 1996 in five-year subperiods. Returns of individual stocks are regressed on the returns of the CRSP value-weighted returns index and the hedging-portfolio dollar-return index $Q_{H t}$, yielding two beta coefficients $\widehat{\beta}_{j}^{M}$ and $\widehat{\beta}_{j}^{H Q}$. The pairs are sorted into deciles according to their market betas and means and standard deviations of the estimated coefficients are reported for each decile.

\begin{tabular}{|c|c|c|c|c|c|c|c|c|c|c|c|}
\hline \multirow{2}{*}{ Decile } & \multirow{2}{*}{$\begin{array}{c}\text { Sample } \\
\text { Size }\end{array}$} & \multicolumn{2}{|c|}{$\widehat{\beta}_{\tau}^{M}$} & \multicolumn{2}{|c|}{$t\left(\widehat{\beta}_{\tau}^{M}\right)$} & \multicolumn{2}{|c|}{$\widehat{\beta}_{\tau}^{H Q}$} & \multicolumn{2}{|c|}{$t\left(\widehat{\beta}_{\tau}^{H Q}\right)$} & \multicolumn{2}{|c|}{$\bar{R}^{2}(\%)$} \\
\hline & & Mean & S.D. & Mean & S.D. & Mean & S.D. & Mean & S.D. & Mean & S.D. \\
\hline \multicolumn{12}{|c|}{ January 1967 to December 1971 (261 Weeks) } \\
\hline 1 & 242 & -0.535 & 0.460 & -0.707 & 0.541 & 0.011 & 0.004 & 2.699 & 1.171 & 15.7 & 11.0 \\
\hline 2 & 243 & 0.142 & 0.101 & 0.270 & 0.237 & 0.006 & 0.003 & 1.838 & 0.984 & 14.7 & 9.9 \\
\hline 3 & 242 & 0.440 & 0.073 & 0.916 & 0.409 & 0.005 & 0.003 & 1.406 & 0.982 & 16.2 & 9.8 \\
\hline 4 & 243 & 0.652 & 0.054 & 1.580 & 0.761 & 0.003 & 0.003 & 0.799 & 1.106 & 16.7 & 8.6 \\
\hline 5 & 242 & 0.831 & 0.049 & 2.049 & 0.913 & 0.002 & 0.003 & 0.352 & 1.105 & 16.9 & 8.8 \\
\hline 6 & 243 & 1.007 & 0.051 & 2.331 & 0.959 & 0.001 & 0.003 & 0.133 & 1.091 & 18.1 & 8.2 \\
\hline 7 & 243 & 1.187 & 0.053 & 2.835 & 1.204 & 0.000 & 0.003 & -0.236 & 1.334 & 19.9 & 8.1 \\
\hline 8 & 242 & 1.393 & 0.062 & 3.195 & 1.510 & -0.001 & 0.003 & -0.550 & 1.333 & 21.3 & 8.9 \\
\hline 9 & 243 & 1.651 & 0.085 & 3.343 & 1.373 & -0.001 & 0.003 & -0.673 & 1.252 & 22.0 & 9.0 \\
\hline 10 & 242 & 2.280 & 0.472 & 3.555 & 1.261 & -0.003 & 0.003 & -0.982 & 1.032 & 23.1 & 9.6 \\
\hline \multicolumn{12}{|c|}{ January 1972 to December 1977 (261 Weeks) } \\
\hline 1 & 262 & 0.341 & 0.155 & 3.248 & 1.949 & -0.001 & 0.001 & -0.932 & 1.226 & 5.4 & 5.0 \\
\hline 2 & 263 & 0.595 & 0.052 & 4.836 & 2.049 & -0.001 & 0.001 & -1.111 & 1.512 & 10.1 & 7.1 \\
\hline 3 & 263 & 0.754 & 0.041 & 5.620 & 2.246 & -0.001 & 0.001 & -1.461 & 1.461 & 12.5 & 8.2 \\
\hline 4 & 263 & 0.885 & 0.032 & 6.182 & 2.451 & -0.001 & 0.001 & -1.522 & 1.370 & 14.4 & 9.3 \\
\hline 5 & 263 & 0.995 & 0.035 & 6.844 & 2.524 & -0.001 & 0.001 & -1.786 & 1.524 & 16.9 & 9.4 \\
\hline 6 & 263 & 1.108 & 0.032 & 7.368 & 2.953 & -0.001 & 0.001 & -1.856 & 1.686 & 18.9 & 11.3 \\
\hline 7 & 263 & 1.241 & 0.041 & 7.399 & 2.780 & -0.002 & 0.001 & -2.173 & 1.476 & 19.1 & 10.6 \\
\hline 8 & 263 & 1.387 & 0.046 & 7.777 & 2.589 & -0.002 & 0.001 & -2.507 & 1.341 & 20.1 & 9.6 \\
\hline 9 & 263 & 1.591 & 0.075 & 8.113 & 2.846 & -0.002 & 0.001 & -2.765 & 1.308 & 21.5 & 10.1 \\
\hline 10 & 262 & 2.023 & 0.241 & 9.674 & 3.046 & -0.003 & 0.001 & -3.359 & 1.458 & 28.1 & 10.6 \\
\hline \multicolumn{12}{|c|}{ January 1977 to December 1981 (261 Weeks) } \\
\hline 1 & 242 & -0.289 & 0.362 & -0.550 & 0.562 & 0.001 & 0.001 & 2.288 & 0.986 & 5.8 & 5.5 \\
\hline 2 & 243 & 0.179 & 0.075 & 0.613 & 0.410 & 0.001 & 0.000 & 1.679 & 1.150 & 7.5 & 6.5 \\
\hline 3 & 243 & 0.388 & 0.047 & 1.446 & 0.700 & 0.000 & 0.000 & 1.287 & 1.305 & 9.8 & 8.2 \\
\hline 4 & 243 & 0.532 & 0.033 & 2.148 & 0.937 & 0.000 & 0.000 & 1.009 & 1.416 & 12.2 & 7.4 \\
\hline 5 & 243 & 0.641 & 0.034 & 2.671 & 1.173 & 0.000 & 0.000 & 0.679 & 1.558 & 13.7 & 8.0 \\
\hline 6 & 243 & 0.748 & 0.033 & 3.050 & 1.397 & 0.000 & 0.000 & 0.522 & 1.634 & 15.4 & 9.2 \\
\hline 7 & 243 & 0.869 & 0.034 & 3.509 & 1.410 & 0.000 & 0.000 & 0.445 & 1.648 & 18.2 & 9.4 \\
\hline 8 & 243 & 1.008 & 0.045 & 3.885 & 1.477 & 0.000 & 0.000 & 0.263 & 1.380 & 19.5 & 9.7 \\
\hline 9 & 243 & 1.180 & 0.060 & 4.509 & 1.745 & 0.000 & 0.000 & 0.125 & 1.507 & 23.3 & 10.8 \\
\hline 10 & 242 & 1.552 & 0.261 & 5.386 & 2.286 & 0.000 & 0.001 & -0.747 & 1.582 & 25.6 & 11.9 \\
\hline \multicolumn{12}{|c|}{ January 1982 to December 1986 (261 Weeks) } \\
\hline 1 & 227 & 0.215 & 0.159 & 1.734 & 1.437 & 0.000 & 0.001 & -0.094 & 1.384 & 2.1 & 3.4 \\
\hline 2 & 228 & 0.460 & 0.042 & 3.784 & 1.757 & 0.000 & 0.001 & 0.362 & 1.793 & 7.2 & 6.5 \\
\hline 3 & 228 & 0.600 & 0.045 & 4.331 & 1.756 & 0.000 & 0.001 & 0.010 & 1.792 & 9.1 & 7.7 \\
\hline 4 & 227 & 0.738 & 0.035 & 4.989 & 1.786 & 0.000 & 0.001 & -0.401 & 1.350 & 10.5 & 6.5 \\
\hline 5 & 228 & 0.844 & 0.033 & 5.618 & 2.363 & 0.000 & 0.001 & -0.556 & 1.542 & 12.8 & 8.4 \\
\hline 6 & 228 & 0.957 & 0.030 & 6.491 & 2.431 & 0.000 & 0.001 & -0.801 & 1.466 & 15.8 & 8.9 \\
\hline 7 & 227 & 1.063 & 0.033 & 6.964 & 2.727 & 0.000 & 0.000 & -1.065 & 1.332 & 17.4 & 9.6 \\
\hline 8 & 228 & 1.181 & 0.039 & 7.554 & 2.724 & 0.000 & 0.000 & -1.309 & 1.255 & 19.6 & 9.9 \\
\hline 9 & 228 & 1.359 & 0.067 & 8.092 & 2.949 & 0.000 & 0.001 & -1.613 & 1.607 & 22.6 & 10.3 \\
\hline 10 & 227 & 1.743 & 0.250 & 8.443 & 3.476 & -0.001 & 0.001 & -2.273 & 1.878 & 24.3 & 12.2 \\
\hline
\end{tabular}


Table 6c (continued)

\begin{tabular}{|c|c|c|c|c|c|c|c|c|c|c|c|}
\hline \multirow{2}{*}{ Decile } & \multirow{2}{*}{$\begin{array}{c}\text { Sample } \\
\text { Size }\end{array}$} & \multicolumn{2}{|c|}{$\widehat{\beta}_{\tau}^{M}$} & \multicolumn{2}{|c|}{$t\left(\widehat{\beta}_{\tau}^{M}\right)$} & \multicolumn{2}{|c|}{$\widehat{\beta}_{\tau}^{H Q}$} & \multicolumn{2}{|c|}{$t\left(\widehat{\beta}_{\tau}^{H Q}\right)$} & \multicolumn{2}{|c|}{$\bar{R}^{2}(\%)$} \\
\hline & & Mean & S.D. & Mean & S.D. & Mean & S.D. & Mean & S.D. & Mean & S.D. \\
\hline \multicolumn{12}{|c|}{ January 1987 to December 1991 (261 Weeks) } \\
\hline 1 & 216 & 0.225 & 0.226 & 2.499 & 2.477 & -0.001 & 0.001 & -0.378 & 1.768 & 5.1 & 6.3 \\
\hline 2 & 217 & 0.501 & 0.053 & 4.629 & 2.998 & 0.000 & 0.001 & -0.013 & 2.282 & 11.0 & 9.7 \\
\hline 3 & 217 & 0.660 & 0.039 & 5.205 & 2.573 & 0.000 & 0.001 & -0.845 & 1.507 & 12.9 & 8.9 \\
\hline 4 & 217 & 0.794 & 0.039 & 6.035 & 3.358 & 0.000 & 0.001 & -0.718 & 1.985 & 16.5 & 12.2 \\
\hline 5 & 217 & 0.918 & 0.031 & 7.190 & 3.599 & 0.000 & 0.001 & -0.843 & 1.638 & 20.5 & 12.9 \\
\hline 6 & 217 & 1.017 & 0.028 & 7.886 & 3.813 & 0.000 & 0.001 & -0.909 & 1.458 & 23.3 & 13.4 \\
\hline 7 & 217 & 1.111 & 0.028 & 8.692 & 3.965 & 0.000 & 0.001 & -1.058 & 1.384 & 26.3 & 14.3 \\
\hline 8 & 217 & 1.222 & 0.034 & 9.086 & 4.338 & -0.001 & 0.001 & -1.153 & 1.438 & 27.9 & 15.8 \\
\hline 9 & 217 & 1.364 & 0.050 & 9.211 & 4.311 & -0.001 & 0.001 & -1.390 & 1.264 & 28.7 & 15.7 \\
\hline 10 & 217 & 1.701 & 0.233 & 8.494 & 3.768 & -0.001 & 0.001 & -1.302 & 1.310 & 28.0 & 14.5 \\
\hline \multicolumn{12}{|c|}{ January 1992 to December 1996 (261 Weeks) } \\
\hline 1 & 241 & -0.990 & 1.628 & -0.866 & 0.807 & 0.013 & 0.016 & 1.839 & 1.487 & 5.7 & 8.1 \\
\hline 2 & 241 & 0.169 & 0.122 & 0.378 & 0.368 & 0.003 & 0.003 & 0.871 & 0.855 & 6.2 & 7.5 \\
\hline 3 & 242 & 0.526 & 0.092 & 1.026 & 0.504 & 0.000 & 0.003 & 0.140 & 0.709 & 5.7 & 7.6 \\
\hline 4 & 241 & 0.846 & 0.099 & 1.609 & 0.750 & -0.001 & 0.003 & -0.212 & 0.641 & 7.7 & 8.2 \\
\hline 5 & 241 & 1.177 & 0.088 & 2.072 & 0.883 & -0.003 & 0.003 & -0.714 & 0.586 & 7.5 & 7.6 \\
\hline 6 & 242 & 1.509 & 0.100 & 2.499 & 1.100 & -0.005 & 0.003 & -1.118 & 0.619 & 8.5 & 8.3 \\
\hline 7 & 241 & 1.877 & 0.124 & 2.985 & 1.229 & -0.008 & 0.003 & -1.559 & 0.721 & 9.3 & 7.3 \\
\hline 8 & 242 & 2.365 & 0.160 & 3.276 & 1.458 & -0.011 & 0.004 & -1.815 & 0.828 & 10.8 & 9.3 \\
\hline 9 & 241 & 3.101 & 0.250 & 3.724 & 1.624 & -0.016 & 0.005 & -2.343 & 1.033 & 11.4 & 8.6 \\
\hline 10 & 241 & 5.284 & 2.356 & 3.925 & 1.876 & -0.036 & 0.026 & -2.855 & 1.246 & 11.1 & 8.8 \\
\hline
\end{tabular}




\section{Table 6d}

Summary statistics for market and SMB-portfolio return betas estimated with weekly returns data for NYSE and AMEX stocks from July 1962 to December 1996 in five-year subperiods. Returns of individual stocks are regressed on the returns of the CRSP value-weighted returns index and the return to a portfolio of small-minus-big capitalization stocks $R_{S M B t}$, yielding two beta coefficients $\widehat{\beta}_{j}^{M}$ and $\widehat{\beta}_{j}^{S M B}$. The pairs are sorted into deciles according to their market betas and means and standard deviations of the estimated coefficients are reported for each decile.

\begin{tabular}{|c|c|c|c|c|c|c|c|c|c|c|c|}
\hline \multirow{2}{*}{ Decile } & \multirow{2}{*}{$\begin{array}{c}\text { Sample } \\
\text { Size }\end{array}$} & \multicolumn{2}{|c|}{$\widehat{\beta}_{\tau}^{M}$} & \multicolumn{2}{|c|}{$t\left(\widehat{\beta}_{\tau}^{M}\right)$} & \multicolumn{2}{|c|}{$\widehat{\beta}_{\tau}^{S M B}$} & \multicolumn{2}{|c|}{$t\left(\widehat{\beta}_{\tau}^{S M B}\right)$} & \multicolumn{2}{|c|}{$\bar{R}^{2}(\%)$} \\
\hline & & Mean & S.D. & Mean & S.D. & Mean & S.D. & Mean & S.D. & Mean & S.D. \\
\hline \multicolumn{12}{|c|}{ January 1967 to December 1971 (261 Weeks) } \\
\hline 1 & 242 & 0.124 & 0.213 & 0.699 & 0.914 & 1.311 & 0.874 & 2.937 & 1.402 & 9.1 & 6.0 \\
\hline 2 & 243 & 0.423 & 0.049 & 2.398 & 1.224 & 0.927 & 0.802 & 2.339 & 1.689 & 12.4 & 5.5 \\
\hline 3 & 242 & 0.572 & 0.041 & 3.017 & 1.373 & 0.909 & 0.832 & 2.221 & 1.835 & 15.0 & 5.9 \\
\hline 4 & 243 & 0.708 & 0.037 & 3.715 & 1.560 & 0.871 & 0.862 & 2.075 & 1.829 & 17.7 & 6.2 \\
\hline 5 & 242 & 0.824 & 0.032 & 3.951 & 1.573 & 0.848 & 0.769 & 2.027 & 1.793 & 18.8 & 6.8 \\
\hline 6 & 243 & 0.926 & 0.028 & 4.498 & 1.834 & 0.860 & 0.768 & 2.030 & 1.711 & 21.3 & 6.7 \\
\hline 7 & 243 & 1.039 & 0.034 & 4.865 & 1.880 & 0.834 & 0.782 & 1.916 & 1.805 & 22.5 & 6.6 \\
\hline 8 & 242 & 1.178 & 0.046 & 5.444 & 2.198 & 0.881 & 0.785 & 1.981 & 1.789 & 26.1 & 7.0 \\
\hline 9 & 243 & 1.369 & 0.065 & 5.697 & 2.066 & 0.868 & 0.752 & 1.893 & 1.710 & 26.9 & 7.7 \\
\hline 10 & 242 & 1.717 & 0.207 & 6.248 & 1.855 & 0.952 & 0.704 & 2.038 & 1.474 & 31.4 & 8.0 \\
\hline \multicolumn{12}{|c|}{ January 1972 to December 1977 (261 Weeks) } \\
\hline 1 & 262 & 0.317 & 0.168 & 3.059 & 2.073 & 0.873 & 0.711 & 3.374 & 1.434 & 8.7 & 5.9 \\
\hline 2 & 263 & 0.564 & 0.048 & 4.884 & 2.163 & 0.889 & 0.557 & 3.563 & 1.426 & 13.2 & 6.6 \\
\hline 3 & 263 & 0.713 & 0.040 & 5.686 & 2.201 & 0.913 & 0.576 & 3.457 & 1.693 & 15.5 & 7.0 \\
\hline 4 & 263 & 0.830 & 0.030 & 6.254 & 2.429 & 0.970 & 0.630 & 3.439 & 1.933 & 17.6 & 7.8 \\
\hline 5 & 263 & 0.933 & 0.031 & 6.687 & 2.548 & 1.016 & 0.689 & 3.476 & 2.133 & 19.3 & 8.4 \\
\hline 6 & 263 & 1.040 & 0.034 & 7.548 & 2.847 & 0.929 & 0.741 & 3.056 & 2.209 & 21.9 & 9.2 \\
\hline 7 & 263 & 1.157 & 0.036 & 7.600 & 3.020 & 1.120 & 0.766 & 3.427 & 2.396 & 22.5 & 10.3 \\
\hline 8 & 263 & 1.287 & 0.043 & 8.095 & 2.965 & 1.138 & 0.836 & 3.316 & 2.536 & 24.3 & 10.0 \\
\hline 9 & 263 & 1.471 & 0.065 & 8.326 & 2.893 & 1.235 & 0.800 & 3.451 & 2.180 & 25.2 & 9.6 \\
\hline 10 & 262 & 1.857 & 0.221 & 9.475 & 2.904 & 1.364 & 0.947 & 3.533 & 1.946 & 29.5 & 9.3 \\
\hline \multicolumn{12}{|c|}{ January 1977 to December 1981 (261 Weeks) } \\
\hline 1 & 242 & 0.183 & 0.123 & 1.503 & 1.310 & 0.676 & 0.665 & 2.053 & 1.335 & 4.0 & 3.2 \\
\hline 2 & 243 & 0.411 & 0.046 & 3.313 & 1.603 & 0.636 & 0.549 & 2.159 & 1.533 & 8.2 & 4.6 \\
\hline 3 & 243 & 0.548 & 0.038 & 4.052 & 1.717 & 0.703 & 0.549 & 2.393 & 1.582 & 11.0 & 5.3 \\
\hline 4 & 243 & 0.661 & 0.032 & 4.529 & 1.767 & 0.779 & 0.534 & 2.588 & 1.422 & 12.9 & 5.8 \\
\hline 5 & 243 & 0.765 & 0.028 & 4.834 & 1.906 & 0.865 & 0.583 & 2.611 & 1.480 & 14.2 & 6.3 \\
\hline 6 & 243 & 0.871 & 0.031 & 5.958 & 2.352 & 0.792 & 0.652 & 2.456 & 1.822 & 18.1 & 7.6 \\
\hline 7 & 243 & 0.982 & 0.035 & 6.551 & 2.577 & 0.773 & 0.620 & 2.331 & 1.782 & 20.1 & 8.3 \\
\hline 8 & 243 & 1.108 & 0.039 & 7.148 & 2.594 & 0.844 & 0.622 & 2.548 & 1.910 & 22.9 & 8.7 \\
\hline 9 & 243 & 1.288 & 0.060 & 8.094 & 2.751 & 0.718 & 0.668 & 2.049 & 2.221 & 25.8 & 8.9 \\
\hline 10 & 242 & 1.638 & 0.219 & 8.809 & 2.915 & 0.785 & 0.641 & 2.089 & 1.790 & 30.2 & 9.6 \\
\hline \multicolumn{12}{|c|}{ January 1982 to December 1986 (261 Weeks) } \\
\hline 1 & 227 & 0.215 & 0.157 & 1.690 & 1.373 & 0.672 & 0.797 & 1.519 & 1.326 & 2.7 & 3.0 \\
\hline 2 & 228 & 0.463 & 0.045 & 3.872 & 1.687 & 0.510 & 0.557 & 1.389 & 1.612 & 7.4 & 4.5 \\
\hline 3 & 228 & 0.599 & 0.041 & 4.429 & 1.988 & 0.568 & 0.628 & 1.370 & 1.884 & 9.6 & 6.5 \\
\hline 4 & 227 & 0.727 & 0.032 & 4.952 & 1.881 & 0.765 & 0.677 & 1.905 & 1.508 & 11.5 & 6.3 \\
\hline 5 & 228 & 0.831 & 0.034 & 5.857 & 2.103 & 0.705 & 0.675 & 1.870 & 1.827 & 14.5 & 7.4 \\
\hline 6 & 228 & 0.938 & 0.027 & 6.513 & 2.604 & 0.796 & 0.726 & 1.964 & 1.881 & 16.9 & 8.6 \\
\hline 7 & 227 & 1.040 & 0.033 & 7.154 & 2.593 & 0.722 & 0.764 & 1.781 & 1.876 & 19.1 & 8.9 \\
\hline 8 & 228 & 1.150 & 0.035 & 7.769 & 2.697 & 0.662 & 0.700 & 1.747 & 1.822 & 21.3 & 9.7 \\
\hline 9 & 228 & 1.317 & 0.060 & 8.188 & 2.903 & 0.842 & 0.794 & 2.014 & 1.878 & 23.8 & 10.0 \\
\hline 10 & 227 & 1.681 & 0.226 & 8.286 & 3.262 & 1.117 & 0.872 & 2.302 & 1.690 & 24.4 & 11.5 \\
\hline
\end{tabular}


Table 6d (continued)

\begin{tabular}{|c|c|c|c|c|c|c|c|c|c|c|c|}
\hline \multirow{2}{*}{ Decile } & \multirow{2}{*}{$\begin{array}{c}\text { Sample } \\
\text { Size }\end{array}$} & \multicolumn{2}{|c|}{$\widehat{\beta}_{\tau}^{M}$} & \multicolumn{2}{|c|}{$t\left(\widehat{\beta}_{\tau}^{M}\right)$} & \multicolumn{2}{|c|}{$\widehat{\beta}_{\tau}^{S M B}$} & \multicolumn{2}{|c|}{$t\left(\widehat{\beta}_{\tau}^{S M B}\right)$} & \multicolumn{2}{|c|}{$\bar{R}^{2}(\%)$} \\
\hline & & Mean & S.D. & Mean & S.D. & Mean & S.D. & Mean & S.D. & Mean & S.D. \\
\hline \multicolumn{12}{|c|}{ January 1987 to December 1991 (261 Weeks) } \\
\hline 1 & 216 & 0.254 & 0.234 & 3.138 & 2.773 & 0.614 & 0.845 & 1.176 & 2.242 & 7.7 & 7.8 \\
\hline 2 & 217 & 0.522 & 0.056 & 4.668 & 2.949 & 0.658 & 0.711 & 1.474 & 2.816 & 12.8 & 10.2 \\
\hline 3 & 217 & 0.672 & 0.037 & 5.535 & 2.743 & 0.789 & 0.594 & 2.735 & 2.159 & 16.5 & 10.6 \\
\hline 4 & 217 & 0.808 & 0.037 & 6.285 & 3.354 & 0.910 & 0.672 & 2.632 & 2.306 & 19.0 & 12.0 \\
\hline 5 & 217 & 0.928 & 0.032 & 7.766 & 3.749 & 0.806 & 0.663 & 2.461 & 2.556 & 24.7 & 13.3 \\
\hline 6 & 217 & 1.025 & 0.027 & 8.062 & 3.971 & 0.841 & 0.733 & 2.353 & 2.326 & 25.1 & 13.6 \\
\hline 7 & 217 & 1.119 & 0.027 & 9.163 & 4.334 & 0.812 & 0.728 & 2.345 & 2.327 & 28.6 & 14.7 \\
\hline 8 & 217 & 1.228 & 0.036 & 9.188 & 4.240 & 0.855 & 0.666 & 2.490 & 2.026 & 29.6 & 15.0 \\
\hline 9 & 217 & 1.378 & 0.052 & 9.637 & 4.477 & 0.985 & 0.762 & 2.710 & 1.779 & 31.3 & 14.9 \\
\hline 10 & 217 & 1.726 & 0.258 & 9.021 & 4.098 & 1.102 & 0.765 & 2.504 & 1.678 & 30.3 & 15.0 \\
\hline \multicolumn{12}{|c|}{ January 1992 to December 1996 (261 Weeks) } \\
\hline 1 & 241 & -0.002 & 0.442 & 0.400 & 0.794 & 0.790 & 1.087 & 1.307 & 1.222 & 0.8 & 1.7 \\
\hline 2 & 241 & 0.368 & 0.049 & 2.310 & 1.338 & 0.445 & 0.657 & 0.934 & 1.902 & 3.7 & 3.7 \\
\hline 3 & 242 & 0.514 & 0.032 & 2.983 & 1.688 & 0.480 & 0.743 & 0.757 & 2.492 & 5.9 & 5.7 \\
\hline 4 & 241 & 0.634 & 0.036 & 3.432 & 1.692 & 0.547 & 0.674 & 1.273 & 2.213 & 7.0 & 5.7 \\
\hline 5 & 241 & 0.763 & 0.040 & 3.937 & 1.858 & 0.618 & 0.673 & 1.495 & 1.824 & 8.1 & 5.9 \\
\hline 6 & 242 & 0.881 & 0.030 & 4.761 & 2.149 & 0.597 & 0.615 & 1.560 & 1.975 & 11.0 & 6.6 \\
\hline 7 & 241 & 1.000 & 0.035 & 5.035 & 2.168 & 0.670 & 0.666 & 1.696 & 1.872 & 11.9 & 6.9 \\
\hline 8 & 242 & 1.139 & 0.046 & 5.704 & 2.653 & 0.634 & 0.685 & 1.522 & 2.029 & 14.3 & 9.0 \\
\hline 9 & 241 & 1.336 & 0.074 & 5.651 & 2.501 & 0.946 & 0.787 & 2.365 & 1.519 & 14.6 & 8.5 \\
\hline 10 & 241 & 1.820 & 0.343 & 5.955 & 2.850 & 1.462 & 1.490 & 2.671 & 1.667 & 17.1 & 9.9 \\
\hline
\end{tabular}




\section{Table 6e}

Summary statistics for market and optimal-forecast-portfolio return betas estimated with weekly returns data for NYSE and AMEX stocks from July 1962 to December 1996 in five-year subperiods. Returns of individual stocks are regressed on the returns of the CRSP value-weighted returns index and the return $R_{O F P t}$ of the optimal-forecast portfolio (OFP) for the set of 25 market-beta-sorted basis portfolios, yielding two beta coefficients $\widehat{\beta}_{j}^{M}$ and $\widehat{\beta}_{j}^{O F P}$. The pairs are sorted into deciles according to their market betas and means and standard deviations of the estimated coefficients are reported for each decile.

\begin{tabular}{|c|c|c|c|c|c|c|c|c|c|c|c|}
\hline \multirow{2}{*}{ Decile } & \multirow{2}{*}{$\begin{array}{c}\text { Sample } \\
\text { Size }\end{array}$} & \multicolumn{2}{|c|}{$\widehat{\beta}_{\tau}^{M}$} & \multicolumn{2}{|c|}{$t\left(\widehat{\beta}_{\tau}^{M}\right)$} & \multicolumn{2}{|c|}{$\widehat{\beta}_{\tau}^{O F P}$} & \multicolumn{2}{|c|}{$t\left(\widehat{\beta}_{\tau}^{O F P}\right)$} & \multicolumn{2}{|c|}{$\bar{R}^{2}(\%)$} \\
\hline & & Mean & S.D. & Mean & S.D. & Mean & S.D. & Mean & S.D. & Mean & S.D. \\
\hline \multicolumn{12}{|c|}{ January 1967 to December 1971 (261 Weeks) } \\
\hline 1 & 242 & 0.161 & 0.146 & 0.932 & 0.904 & -0.592 & 0.368 & -2.771 & 1.784 & 12.0 & 8.3 \\
\hline 2 & 243 & 0.551 & 0.081 & 2.543 & 0.975 & -0.361 & 0.378 & -1.126 & 0.941 & 11.6 & 7.3 \\
\hline 3 & 242 & 0.777 & 0.051 & 3.464 & 1.350 & -0.272 & 0.371 & -0.748 & 0.930 & 14.9 & 8.4 \\
\hline 4 & 243 & 0.945 & 0.050 & 3.968 & 1.409 & -0.176 & 0.344 & -0.434 & 0.923 & 16.3 & 8.0 \\
\hline 5 & 242 & 1.107 & 0.044 & 4.333 & 1.512 & -0.130 & 0.391 & -0.227 & 1.030 & 17.6 & 8.0 \\
\hline 6 & 243 & 1.261 & 0.046 & 4.668 & 1.711 & -0.065 & 0.464 & -0.041 & 1.141 & 18.9 & 8.8 \\
\hline 7 & 243 & 1.450 & 0.056 & 5.035 & 1.709 & 0.032 & 0.429 & 0.197 & 1.082 & 20.1 & 8.4 \\
\hline 8 & 242 & 1.649 & 0.071 & 5.241 & 1.841 & 0.029 & 0.422 & 0.219 & 1.139 & 21.4 & 8.4 \\
\hline 9 & 243 & 1.952 & 0.104 & 5.636 & 1.612 & 0.220 & 0.452 & 0.533 & 0.989 & 22.6 & 8.4 \\
\hline 10 & 242 & 2.629 & 0.414 & 6.970 & 1.899 & 0.777 & 0.625 & 1.570 & 1.258 & 28.0 & 8.4 \\
\hline \multicolumn{12}{|c|}{ January 1972 to December 1977 (261 Weeks) } \\
\hline 1 & 262 & 0.310 & 0.163 & 2.392 & 1.681 & -0.102 & 0.596 & -0.083 & 1.153 & 4.5 & 5.6 \\
\hline 2 & 263 & 0.572 & 0.044 & 3.795 & 1.657 & 0.014 & 0.512 & 0.156 & 1.054 & 8.5 & 6.1 \\
\hline 3 & 263 & 0.712 & 0.038 & 4.402 & 1.743 & 0.075 & 0.497 & 0.218 & 1.122 & 11.0 & 7.4 \\
\hline 4 & 263 & 0.840 & 0.036 & 4.968 & 1.900 & 0.107 & 0.517 & 0.273 & 1.130 & 13.1 & 8.6 \\
\hline 5 & 263 & 0.955 & 0.029 & 5.573 & 2.078 & 0.213 & 0.551 & 0.533 & 1.136 & 15.2 & 9.3 \\
\hline 6 & 263 & 1.067 & 0.038 & 6.260 & 2.496 & 0.182 & 0.582 & 0.446 & 1.275 & 18.6 & 11.4 \\
\hline 7 & 263 & 1.187 & 0.032 & 6.049 & 2.153 & 0.279 & 0.566 & 0.583 & 1.174 & 17.3 & 9.8 \\
\hline 8 & 263 & 1.317 & 0.045 & 6.317 & 2.415 & 0.374 & 0.651 & 0.673 & 1.131 & 18.7 & 11.0 \\
\hline 9 & 263 & 1.502 & 0.068 & 6.882 & 2.338 & 0.357 & 0.653 & 0.629 & 1.225 & 21.3 & 11.0 \\
\hline 10 & 262 & 1.910 & 0.301 & 7.252 & 2.322 & 0.595 & 0.923 & 0.844 & 1.262 & 23.4 & 10.7 \\
\hline \multicolumn{12}{|c|}{ January 1977 to December 1981 (261 Weeks) } \\
\hline 1 & 242 & 0.267 & 0.122 & 2.338 & 1.633 & 0.004 & 0.567 & -0.264 & 1.267 & 2.8 & 3.6 \\
\hline 2 & 243 & 0.504 & 0.045 & 4.172 & 1.865 & -0.125 & 0.471 & -0.531 & 1.344 & 7.4 & 5.3 \\
\hline 3 & 243 & 0.654 & 0.037 & 4.711 & 1.906 & -0.119 & 0.458 & -0.288 & 1.097 & 9.0 & 6.1 \\
\hline 4 & 243 & 0.771 & 0.032 & 5.299 & 2.060 & -0.095 & 0.533 & -0.233 & 1.224 & 11.3 & 6.9 \\
\hline 5 & 243 & 0.883 & 0.035 & 6.066 & 2.495 & -0.141 & 0.427 & -0.314 & 1.193 & 13.8 & 9.4 \\
\hline 6 & 243 & 0.994 & 0.029 & 6.702 & 2.464 & -0.180 & 0.480 & -0.425 & 1.172 & 16.2 & 9.1 \\
\hline 7 & 243 & 1.110 & 0.038 & 6.825 & 2.666 & -0.219 & 0.503 & -0.404 & 1.074 & 17.0 & 9.9 \\
\hline 8 & 243 & 1.249 & 0.043 & 7.680 & 2.723 & -0.262 & 0.491 & -0.582 & 1.214 & 19.9 & 10.5 \\
\hline 9 & 243 & 1.436 & 0.067 & 7.727 & 2.431 & -0.456 & 0.595 & -0.974 & 1.153 & 20.3 & 8.9 \\
\hline 10 & 242 & 1.805 & 0.223 & 9.143 & 2.722 & -0.540 & 0.596 & -1.194 & 1.184 & 27.3 & 9.7 \\
\hline \multicolumn{12}{|c|}{ January 1982 to December 1986 (261 Weeks) } \\
\hline 1 & 227 & 0.179 & 0.160 & 1.301 & 1.135 & -0.392 & 0.716 & -0.748 & 1.140 & 1.4 & 2.3 \\
\hline 2 & 228 & 0.436 & 0.050 & 3.347 & 1.602 & -0.287 & 0.524 & -0.488 & 1.135 & 5.4 & 4.1 \\
\hline 3 & 228 & 0.574 & 0.035 & 4.237 & 1.976 & -0.175 & 0.623 & -0.103 & 1.435 & 8.3 & 6.0 \\
\hline 4 & 227 & 0.695 & 0.033 & 4.886 & 1.780 & -0.267 & 0.504 & -0.546 & 1.188 & 10.7 & 6.3 \\
\hline 5 & 228 & 0.801 & 0.031 & 5.254 & 1.993 & -0.306 & 0.580 & -0.668 & 1.157 & 11.9 & 7.2 \\
\hline 6 & 228 & 0.905 & 0.030 & 6.063 & 2.337 & -0.228 & 0.657 & -0.450 & 1.228 & 14.9 & 8.2 \\
\hline 7 & 227 & 1.013 & 0.032 & 6.586 & 2.595 & -0.215 & 0.605 & -0.381 & 1.197 & 16.7 & 9.1 \\
\hline 8 & 228 & 1.119 & 0.032 & 7.549 & 2.587 & -0.199 & 0.513 & -0.384 & 1.128 & 20.5 & 9.5 \\
\hline 9 & 228 & 1.280 & 0.059 & 7.641 & 2.850 & -0.243 & 0.669 & -0.395 & 1.146 & 21.4 & 10.2 \\
\hline 10 & 227 & 1.645 & 0.240 & 8.210 & 3.135 & -0.173 & 0.751 & -0.223 & 1.137 & 23.9 & 11.2 \\
\hline
\end{tabular}


Table 6e (continued)

\begin{tabular}{|c|c|c|c|c|c|c|c|c|c|c|c|}
\hline \multirow{2}{*}{ Decile } & \multirow{2}{*}{$\begin{array}{c}\text { Sample } \\
\text { Size }\end{array}$} & \multicolumn{2}{|c|}{$\widehat{\beta}_{\tau}^{M}$} & \multicolumn{2}{|c|}{$t\left(\widehat{\beta}_{\tau}^{M}\right)$} & \multicolumn{2}{|c|}{$\widehat{\beta}_{\tau}^{O F P}$} & \multicolumn{2}{|c|}{$t\left(\widehat{\beta}_{\tau}^{O F P}\right)$} & \multicolumn{2}{|c|}{$\bar{R}^{2}(\%)$} \\
\hline & & Mean & S.D. & Mean & S.D. & Mean & S.D. & Mean & S.D. & Mean & S.D. \\
\hline \multicolumn{12}{|c|}{ January 1987 to December 1991 (261 Weeks) } \\
\hline 1 & 216 & 0.231 & 0.247 & 2.664 & 2.457 & 0.663 & 1.210 & 1.187 & 1.077 & 5.6 & 6.6 \\
\hline 2 & 217 & 0.500 & 0.060 & 4.482 & 2.731 & 0.588 & 0.746 & 1.261 & 1.194 & 10.9 & 8.7 \\
\hline 3 & 217 & 0.657 & 0.035 & 5.034 & 2.403 & 0.663 & 0.727 & 1.511 & 1.267 & 13.0 & 8.9 \\
\hline 4 & 217 & 0.793 & 0.041 & 6.255 & 3.263 & 0.627 & 0.707 & 1.299 & 1.478 & 17.2 & 11.5 \\
\hline 5 & 217 & 0.919 & 0.033 & 7.248 & 3.555 & 0.536 & 0.688 & 1.162 & 1.498 & 21.2 & 12.8 \\
\hline 6 & 217 & 1.018 & 0.028 & 7.919 & 3.734 & 0.591 & 0.679 & 1.189 & 1.511 & 23.4 & 13.0 \\
\hline 7 & 217 & 1.114 & 0.028 & 8.658 & 4.462 & 0.512 & 0.736 & 0.954 & 1.603 & 25.8 & 15.6 \\
\hline 8 & 217 & 1.218 & 0.034 & 9.028 & 4.089 & 0.539 & 0.643 & 1.169 & 1.353 & 27.9 & 14.7 \\
\hline 9 & 217 & 1.366 & 0.055 & 9.412 & 4.311 & 0.719 & 0.683 & 1.506 & 1.404 & 29.7 & 15.3 \\
\hline 10 & 217 & 1.694 & 0.220 & 8.709 & 4.024 & 0.541 & 0.838 & 0.987 & 1.228 & 28.5 & 15.0 \\
\hline \multicolumn{12}{|c|}{ January 1992 to December 1996 (261 Weeks) } \\
\hline 1 & 241 & 0.006 & 0.439 & 0.424 & 0.810 & 0.066 & 0.971 & 0.146 & 1.134 & -0.1 & 1.1 \\
\hline 2 & 241 & 0.384 & 0.052 & 2.278 & 1.372 & 0.135 & 0.517 & 0.708 & 1.769 & 2.9 & 4.5 \\
\hline 3 & 242 & 0.530 & 0.032 & 3.100 & 1.858 & 0.132 & 0.611 & 1.001 & 2.203 & 5.4 & 6.6 \\
\hline 4 & 241 & 0.648 & 0.037 & 3.542 & 1.780 & 0.165 & 0.483 & 0.800 & 1.874 & 6.0 & 6.0 \\
\hline 5 & 241 & 0.769 & 0.037 & 4.105 & 1.971 & 0.080 & 0.468 & 0.335 & 1.668 & 7.6 & 6.7 \\
\hline 6 & 242 & 0.883 & 0.031 & 4.629 & 2.057 & 0.052 & 0.446 & 0.090 & 1.323 & 9.0 & 6.4 \\
\hline 7 & 241 & 1.002 & 0.034 & 5.077 & 2.225 & -0.002 & 0.516 & -0.068 & 1.414 & 10.6 & 7.5 \\
\hline 8 & 242 & 1.141 & 0.045 & 5.363 & 2.594 & -0.005 & 0.671 & -0.017 & 1.437 & 12.2 & 9.0 \\
\hline 9 & 241 & 1.337 & 0.077 & 5.627 & 2.418 & 0.037 & 0.549 & 0.069 & 1.260 & 12.7 & 8.5 \\
\hline 10 & 241 & 1.823 & 0.341 & 5.754 & 2.820 & 0.079 & 0.795 & 0.228 & 1.058 & 13.8 & 9.5 \\
\hline
\end{tabular}




\section{Table 7}

Cross-sectional regression tests of various linear factor models along the lines of Fama and MacBeth (1973) using weekly returns for NYSE and AMEX stocks from 1962 to 1996 , five-year subperiods for the portfolio-formation, estimation, and testing periods, and 100 portfolios in the cross-sectional regressions each week. The five linear-factor models are: the standard CAPM $\left(\widehat{\beta}_{p}^{M}\right)$, and four two-factor models in which the first factor is the market beta and the second factors are, respectively, the hedging portfolio return beta $\left(\widehat{\beta}_{p}^{H R}\right)$, the hedging portfolio dollar-return beta $\left(\widehat{\beta}_{p}^{H Q}\right)$, the beta of a small-minus-big cap portfolio return $\left(\widehat{\beta}_{p}^{S M B}\right)$, and the beta of the optimal forecast portfolio based on a set of 25 market-beta-sorted basis portfolios $\left(\widehat{\beta}_{p}^{O F P}\right)$.

\begin{tabular}{|c|c|c|c|c|c|}
\hline Model & Statistic & $\hat{\gamma}_{0 t}$ & $\hat{\gamma}_{1 t}$ & $\hat{\gamma}_{2 t}$ & $\bar{R}^{2}(\%)$ \\
\hline \multicolumn{6}{|c|}{ January 1972 to December 1976 (261 Weeks) } \\
\hline$R_{p t}=\gamma_{0 t}+\gamma_{1 t} \widehat{\beta}_{p}^{M}+\epsilon_{p t}$ & $\begin{array}{l}\text { Mean: } \\
\text { S.D.: } \\
t \text {-Stat: }\end{array}$ & $\begin{array}{l}0.002 \\
0.015 \\
1.639\end{array}$ & $\begin{array}{l}0.000 \\
0.021 \\
0.348\end{array}$ & & $\begin{array}{l}10.0 \\
10.9\end{array}$ \\
\hline $\begin{array}{l}R_{p t}=\gamma_{0 t}+\gamma_{1 t} \widehat{\beta}_{p}^{M}+\gamma_{2 t} \widehat{\beta}_{p}^{H R}+\epsilon_{p t} \\
(\phi=1.25)\end{array}$ & $\begin{array}{l}\text { Mean: } \\
\text { S.D.: } \\
\text { t-Stat: }\end{array}$ & $\begin{array}{l}0.004 \\
0.035 \\
2.040\end{array}$ & $\begin{array}{r}-0.002 \\
0.035 \\
-1.047\end{array}$ & $\begin{array}{r}-0.002 \\
0.037 \\
-0.820\end{array}$ & $\begin{array}{l}14.3 \\
10.9\end{array}$ \\
\hline $\begin{array}{l}R_{p t}=\gamma_{0 t}+\gamma_{1 t} \widehat{\beta}_{p}^{M}+\gamma_{2 t} \widehat{\beta}_{p}^{H Q}+\epsilon_{p t} \\
(\phi=1.50)\end{array}$ & $\begin{array}{l}\text { Mean: } \\
\text { S.D.: } \\
\text { t-Stat: }\end{array}$ & $\begin{array}{l}0.004 \\
0.032 \\
2.162\end{array}$ & $\begin{array}{r}-0.002 \\
0.034 \\
-1.081\end{array}$ & $\begin{array}{r}-0.104 \\
3.797 \\
-0.442\end{array}$ & $\begin{array}{l}15.5 \\
10.9\end{array}$ \\
\hline$R_{p t}=\gamma_{0 t}+\gamma_{1 t} \widehat{\beta}_{p}^{M}+\gamma_{2 t} \widehat{\beta}_{p}^{S M B}+\epsilon_{p t}$ & $\begin{array}{l}\text { Mean: } \\
\text { S.D.: } \\
t \text {-Stat: }\end{array}$ & $\begin{array}{l}0.001 \\
0.014 \\
1.424\end{array}$ & $\begin{array}{l}0.000 \\
0.024 \\
0.217\end{array}$ & $\begin{array}{l}0.063 \\
1.142 \\
0.898\end{array}$ & $\begin{array}{l}12.1 \\
10.8\end{array}$ \\
\hline \multicolumn{6}{|c|}{ January 1977 to December 1981 (261 Weeks) } \\
\hline$R_{p t}=\gamma_{0 t}+\gamma_{1 t} \widehat{\beta}_{p}^{M}+\epsilon_{p t}$ & $\begin{array}{l}\text { Mean: } \\
\text { S.D.: } \\
t \text {-Stat: }\end{array}$ & $\begin{array}{l}0.001 \\
0.011 \\
1.166\end{array}$ & $\begin{array}{l}0.003 \\
0.022 \\
2.566\end{array}$ & & $\begin{array}{l}11.7 \\
12.8\end{array}$ \\
\hline $\begin{array}{l}R_{p t}=\gamma_{0 t}+\gamma_{1 t} \widehat{\beta}_{p}^{M}+\gamma_{2 t} \widehat{\beta}_{p}^{H R}+\epsilon_{p t} \\
(\phi=4.75)\end{array}$ & $\begin{array}{l}\text { Mean: } \\
\text { S.D.: } \\
\text { t-Stat: }\end{array}$ & $\begin{array}{l}0.003 \\
0.014 \\
3.748\end{array}$ & $\begin{array}{r}-0.001 \\
0.020 \\
-0.902\end{array}$ & $\begin{array}{r}-0.012 \\
0.051 \\
-3.712\end{array}$ & $\begin{array}{l}13.1 \\
12.4\end{array}$ \\
\hline $\begin{array}{l}R_{p t}=\gamma_{0 t}+\gamma_{1 t} \widehat{\beta}_{p}^{M}+\gamma_{2 t} \widehat{\beta}_{p}^{H Q}+\epsilon_{p t} \\
(\phi=4.25)\end{array}$ & $\begin{array}{l}\text { Mean: } \\
\text { S.D.: } \\
t \text {-Stat: }\end{array}$ & $\begin{array}{l}0.003 \\
0.013 \\
3.910\end{array}$ & $\begin{array}{r}-0.001 \\
0.020 \\
-0.754\end{array}$ & $\begin{array}{r}-1.564 \\
6.104 \\
-4.140\end{array}$ & $\begin{array}{l}12.5 \\
12.2\end{array}$ \\
\hline$R_{p t}=\gamma_{0 t}+\gamma_{1 t} \widehat{\beta}_{p}^{M}+\gamma_{2 t} \widehat{\beta}_{p}^{S M B}+\epsilon_{p t}$ & $\begin{array}{l}\text { Mean: } \\
\text { S.D.: } \\
\text { t-Stat: }\end{array}$ & $\begin{array}{l}0.001 \\
0.011 \\
2.251\end{array}$ & $\begin{array}{r}0.000 \\
0.017 \\
-0.164\end{array}$ & $\begin{array}{l}0.299 \\
1.088 \\
4.433\end{array}$ & $\begin{array}{l}14.9 \\
13.4\end{array}$ \\
\hline$R_{p t}=\gamma_{0 t}+\gamma_{1 t} \widehat{\beta}_{p}^{M}+\gamma_{2 t} \widehat{\beta}_{p}^{O F P}+\epsilon_{p t}$ & $\begin{array}{l}\text { Mean: } \\
\text { S.D.: } \\
\text { t-Stat: }\end{array}$ & $\begin{array}{l}0.003 \\
0.018 \\
2.735\end{array}$ & $\begin{array}{l}0.001 \\
0.023 \\
0.843\end{array}$ & $\begin{array}{l}0.001 \\
0.036 \\
0.632\end{array}$ & $\begin{array}{l}14.1 \\
11.6\end{array}$ \\
\hline
\end{tabular}


Table 7 (continued)

\begin{tabular}{|c|c|c|c|c|c|}
\hline Model & Statistic & $\hat{\gamma}_{0 t}$ & $\hat{\gamma}_{1 t}$ & $\hat{\gamma}_{2 t}$ & $\bar{R}^{2}(\%)$ \\
\hline \multicolumn{6}{|c|}{ January 1982 to December 1986 (261 Weeks) } \\
\hline$R_{p t}=\gamma_{0 t}+\gamma_{1 t} \widehat{\beta}_{p}^{M}+\epsilon_{p t}$ & $\begin{array}{l}\text { Mean: } \\
\text { S.D.: } \\
t \text {-Stat: }\end{array}$ & $\begin{array}{l}0.006 \\
0.011 \\
8.169\end{array}$ & $\begin{array}{r}-0.001 \\
0.019 \\
-1.044\end{array}$ & & $\begin{array}{r}9.4 \\
11.1\end{array}$ \\
\hline $\begin{array}{l}R_{p t}=\gamma_{0 t}+\gamma_{1 t} \widehat{\beta}_{p}^{M}+\gamma_{2 t} \widehat{\beta}_{p}^{H R}+\epsilon_{p t} \\
(\phi=1.75)\end{array}$ & $\begin{array}{l}\text { Mean: } \\
\text { S.D.: } \\
t \text {-Stat: }\end{array}$ & $\begin{array}{l}0.006 \\
0.011 \\
8.390\end{array}$ & $\begin{array}{r}-0.001 \\
0.020 \\
-0.780\end{array}$ & $\begin{array}{r}-0.006 \\
0.055 \\
-1.732\end{array}$ & $\begin{array}{l}9.6 \\
9.4\end{array}$ \\
\hline $\begin{array}{l}R_{p t}=\gamma_{0 t}+\gamma_{1 t} \widehat{\beta}_{p}^{M}+\gamma_{2 t} \widehat{\beta}_{p}^{H Q}+\epsilon_{p t} \\
(\phi=2.00)\end{array}$ & $\begin{array}{l}\text { Mean: } \\
\text { S.D.: } \\
\text { t-Stat: }\end{array}$ & $\begin{array}{l}0.006 \\
0.011 \\
8.360\end{array}$ & $\begin{array}{r}-0.002 \\
0.019 \\
-1.297\end{array}$ & $\begin{array}{r}-0.740 \\
19.874 \\
-0.602\end{array}$ & $\begin{array}{r}10.4 \\
9.5\end{array}$ \\
\hline$R_{p t}=\gamma_{0 t}+\gamma_{1 t} \widehat{\beta}_{p}^{M}+\gamma_{2 t} \widehat{\beta}_{p}^{S M B}+\epsilon_{p t}$ & $\begin{array}{l}\text { Mean: } \\
\text { S.D.: } \\
\text { t-Stat: }\end{array}$ & $\begin{array}{l}0.005 \\
0.012 \\
7.451\end{array}$ & $\begin{array}{r}-0.002 \\
0.019 \\
-1.264\end{array}$ & $\begin{array}{l}0.038 \\
1.154 \\
0.531\end{array}$ & $\begin{array}{r}10.0 \\
8.4\end{array}$ \\
\hline$R_{p t}=\gamma_{0 t}+\gamma_{1 t} \widehat{\beta}_{p}^{M}+\gamma_{2 t} \widehat{\beta}_{p}^{O F P}+\epsilon_{p t}$ & $\begin{array}{l}\text { Mean: } \\
\text { S.D.: } \\
t \text {-Stat: }\end{array}$ & $\begin{array}{l}0.005 \\
0.011 \\
7.545\end{array}$ & $\begin{array}{r}-0.001 \\
0.020 \\
-0.818\end{array}$ & $\begin{array}{l}0.000 \\
0.021 \\
0.199\end{array}$ & $\begin{array}{l}11.7 \\
10.8\end{array}$ \\
\hline \multicolumn{6}{|c|}{ January 1987 to December 1991 (261 Weeks) } \\
\hline$R_{p t}=\gamma_{0 t}+\gamma_{1 t} \widehat{\beta}_{p}^{M}+\epsilon_{p t}$ & $\begin{array}{l}\text { Mean: } \\
\text { S.D.: } \\
t \text {-Stat: }\end{array}$ & $\begin{array}{l}0.002 \\
0.013 \\
2.649\end{array}$ & $\begin{array}{l}0.000 \\
0.023 \\
0.204\end{array}$ & & $\begin{array}{l}5.9 \\
8.7\end{array}$ \\
\hline $\begin{array}{l}R_{p t}=\gamma_{0 t}+\gamma_{1 t} \widehat{\beta}_{p}^{M}+\gamma_{2 t} \widehat{\beta}_{p}^{H R}+\epsilon_{p t} \\
(\phi=47)\end{array}$ & $\begin{array}{l}\text { Mean: } \\
\text { S.D.: } \\
\text { t-Stat: }\end{array}$ & $\begin{array}{l}0.002 \\
0.016 \\
2.254\end{array}$ & $\begin{array}{l}0.000 \\
0.019 \\
0.105\end{array}$ & $\begin{array}{l}0.000 \\
0.060 \\
0.132\end{array}$ & $\begin{array}{l}5.4 \\
6.1\end{array}$ \\
\hline $\begin{array}{l}R_{p t}=\gamma_{0 t}+\gamma_{1 t} \widehat{\beta}_{p}^{M}+\gamma_{2 t} \widehat{\beta}_{p}^{H Q}+\epsilon_{p t} \\
(\phi=20)\end{array}$ & $\begin{array}{l}\text { Mean: } \\
\text { S.D.: } \\
t \text {-Stat: }\end{array}$ & $\begin{array}{l}0.002 \\
0.016 \\
2.434\end{array}$ & $\begin{array}{r}0.000 \\
0.019 \\
-0.147\end{array}$ & $\begin{array}{r}0.189 \\
18.194 \\
0.168\end{array}$ & $\begin{array}{l}6.0 \\
6.7\end{array}$ \\
\hline$R_{p t}=\gamma_{0 t}+\gamma_{1 t} \widehat{\beta}_{p}^{M}+\gamma_{2 t} \widehat{\beta}_{p}^{S M B}+\epsilon_{p t}$ & $\begin{array}{l}\text { Mean: } \\
\text { S.D.: } \\
\text { t-Stat: }\end{array}$ & $\begin{array}{l}0.003 \\
0.014 \\
3.101\end{array}$ & $\begin{array}{l}0.000 \\
0.020 \\
0.158\end{array}$ & $\begin{array}{r}-0.075 \\
1.235 \\
-0.979\end{array}$ & $\begin{array}{l}7.8 \\
8.2\end{array}$ \\
\hline$R_{p t}=\gamma_{0 t}+\gamma_{1 t} \widehat{\beta}_{p}^{M}+\gamma_{2 t} \widehat{\beta}_{p}^{O F P}+\epsilon_{p t}$ & $\begin{array}{l}\text { Mean: } \\
\text { S.D.: } \\
\text { t-Stat: }\end{array}$ & $\begin{array}{l}0.003 \\
0.015 \\
2.731\end{array}$ & $\begin{array}{r}-0.001 \\
0.021 \\
-0.385\end{array}$ & $\begin{array}{r}0.000 \\
0.021 \\
-0.234\end{array}$ & $\begin{array}{l}6.4 \\
7.3\end{array}$ \\
\hline
\end{tabular}


Table 7 (continued)

\begin{tabular}{|c|c|c|c|c|c|}
\hline Model & Statistic & $\hat{\gamma}_{0 t}$ & $\hat{\gamma}_{1 t}$ & $\hat{\gamma}_{2 t}$ & $\bar{R}^{2}(\%)$ \\
\hline \multicolumn{6}{|c|}{ January 1992 to December 1996 (261 Weeks) } \\
\hline$R_{p t}=\gamma_{0 t}+\gamma_{1 t} \widehat{\beta}_{p}^{M}+\epsilon_{p t}$ & $\begin{array}{l}\text { Mean: } \\
\text { S.D.: } \\
t \text {-Stat: }\end{array}$ & $\begin{array}{l}0.002 \\
0.013 \\
2.679\end{array}$ & $\begin{array}{l}0.001 \\
0.020 \\
1.178\end{array}$ & & $\begin{array}{l}5.7 \\
7.7\end{array}$ \\
\hline $\begin{array}{l}R_{p t}=\gamma_{0 t}+\gamma_{1 t} \widehat{\beta}_{p}^{M}+\gamma_{2 t} \widehat{\beta}_{p}^{H R}+\epsilon_{p t} \\
(\phi=38)\end{array}$ & $\begin{array}{l}\text { Mean: } \\
\text { S.D.: } \\
\text { t-Stat: }\end{array}$ & $\begin{array}{l}0.002 \\
0.013 \\
2.785\end{array}$ & $\begin{array}{l}0.001 \\
0.020 \\
1.164\end{array}$ & $\begin{array}{r}-0.004 \\
0.091 \\
-0.650\end{array}$ & $\begin{array}{l}6.9 \\
6.8\end{array}$ \\
\hline $\begin{array}{l}R_{p t}=\gamma_{0 t}+\gamma_{1 t} \widehat{\beta}_{p}^{M}+\gamma_{2 t} \widehat{\beta}_{p}^{H Q}+\epsilon_{p t} \\
(\phi=27)\end{array}$ & $\begin{array}{l}\text { Mean: } \\
\text { S.D.: } \\
t \text {-Stat: }\end{array}$ & $\begin{array}{l}0.003 \\
0.015 \\
3.279\end{array}$ & $\begin{array}{r}0.000 \\
0.022 \\
-0.178\end{array}$ & $\begin{array}{r}-1.584 \\
12.992 \\
-1.970\end{array}$ & $\begin{array}{l}6.2 \\
6.6\end{array}$ \\
\hline$R_{p t}=\gamma_{0 t}+\gamma_{1 t} \widehat{\beta}_{p}^{M}+\gamma_{2 t} \widehat{\beta}_{p}^{S M B}+\epsilon_{p t}$ & $\begin{array}{l}\text { Mean: } \\
\text { S.D.: } \\
\text { t-Stat: }\end{array}$ & $\begin{array}{l}0.002 \\
0.015 \\
1.653\end{array}$ & $\begin{array}{l}0.001 \\
0.019 \\
0.861\end{array}$ & $\begin{array}{l}0.154 \\
1.157 \\
2.147\end{array}$ & $\begin{array}{l}6.7 \\
7.0\end{array}$ \\
\hline$R_{p t}=\gamma_{0 t}+\gamma_{1 t} \widehat{\beta}_{p}^{M}+\gamma_{2 t} \widehat{\beta}_{p}^{O F P}+\epsilon_{p t}$ & $\begin{array}{l}\text { Mean: } \\
\text { S.D.: } \\
t \text {-Stat: }\end{array}$ & $\begin{array}{l}0.001 \\
0.016 \\
0.895\end{array}$ & $\begin{array}{l}0.002 \\
0.020 \\
1.236\end{array}$ & $\begin{array}{l}0.002 \\
0.015 \\
2.407\end{array}$ & $\begin{array}{l}7.9 \\
7.4\end{array}$ \\
\hline
\end{tabular}

